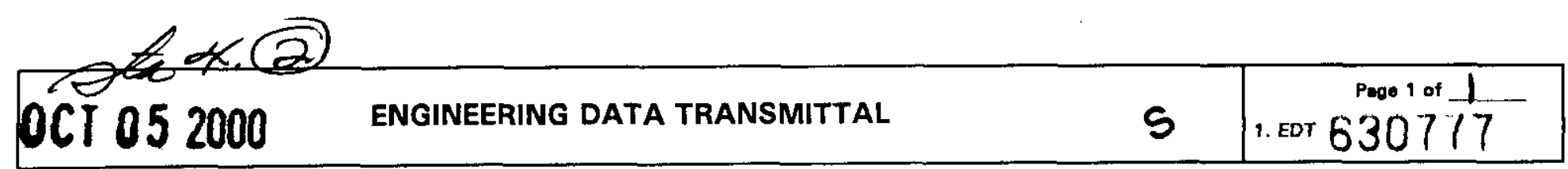

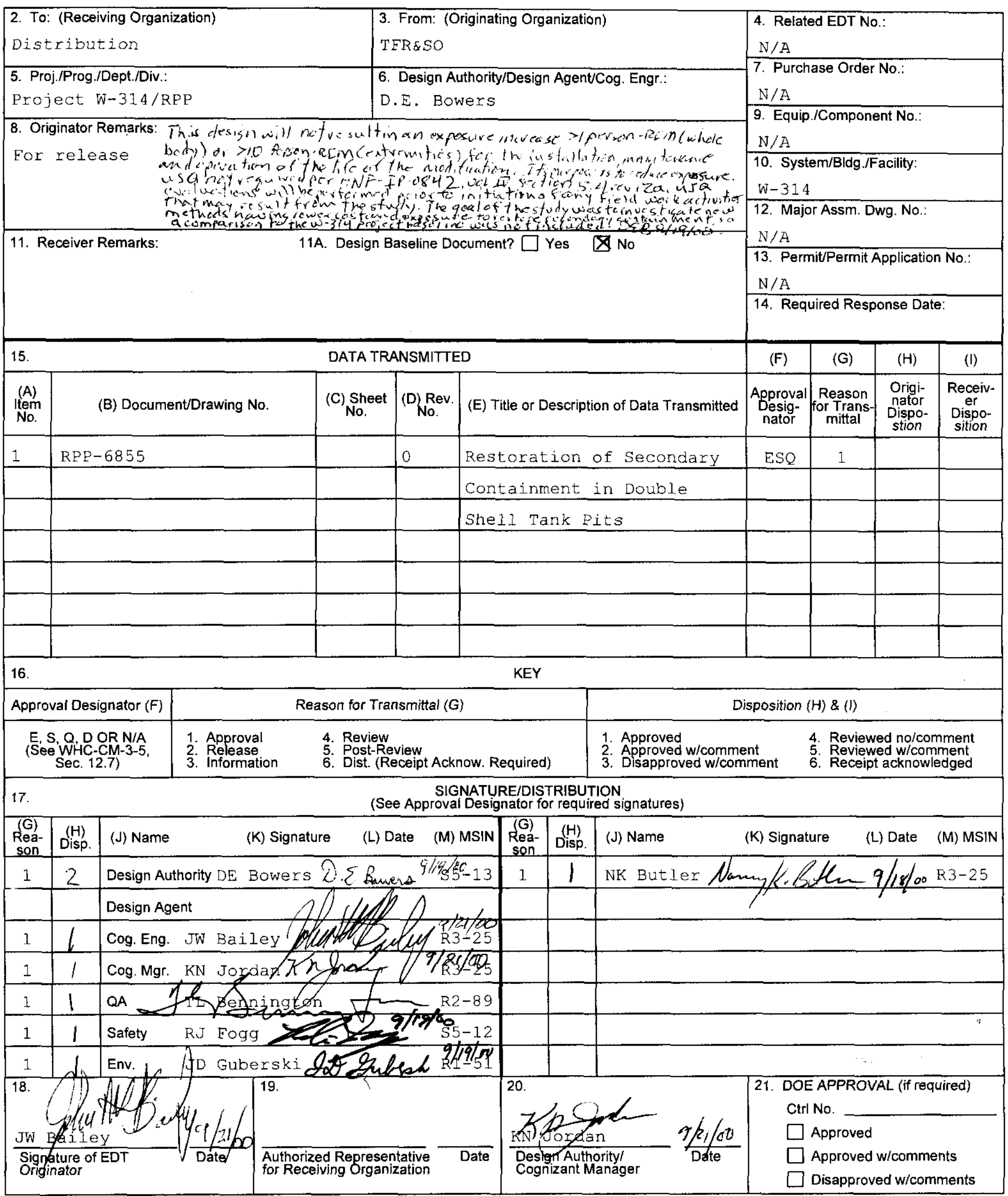




\title{
Restoration of Secondary Containment in Double Shell Tank Pits
}

\author{
EJ Shen \\ CHG \\ Richland, WA 99352 \\ U.S. Department of Energy Contract DE-AC06-99RL14047 \\ EDT/ECN: 630777 UC: \\ Cost Center: 7C900 Charge Code: 109749 \\ B\&R Code: \\ Total Pages: $10 /$. \\ Key Words: Project $\mathbf{W}-314$, Tank Farm Restoration and Safe Operations, \\ concrete, cracks, cracking, double shell tank pits, coating secondary \\ containment \\ Abstract: This study was commissioned to identify viable options for \\ maintain/restoring secondary contaminment capability in these pits.
}

TRADEMARK DISCLAIMER. Reference herein to any specific commercial product, process, or service by trade name, trademark, manufacturer, or otherwise, does not necessarily constitute or imply its endorsement, recommendation, or favoring by the United States Government or any agency thereof or its contractors or subcontractors.

Printed in the United States of America. To obtain copies of this document, contact: Document Control Services, P.O. Box 950, Mailstop H6-08, Richland WA 99352, Phone (509) 372-2420; Fax (509) 376-4989.
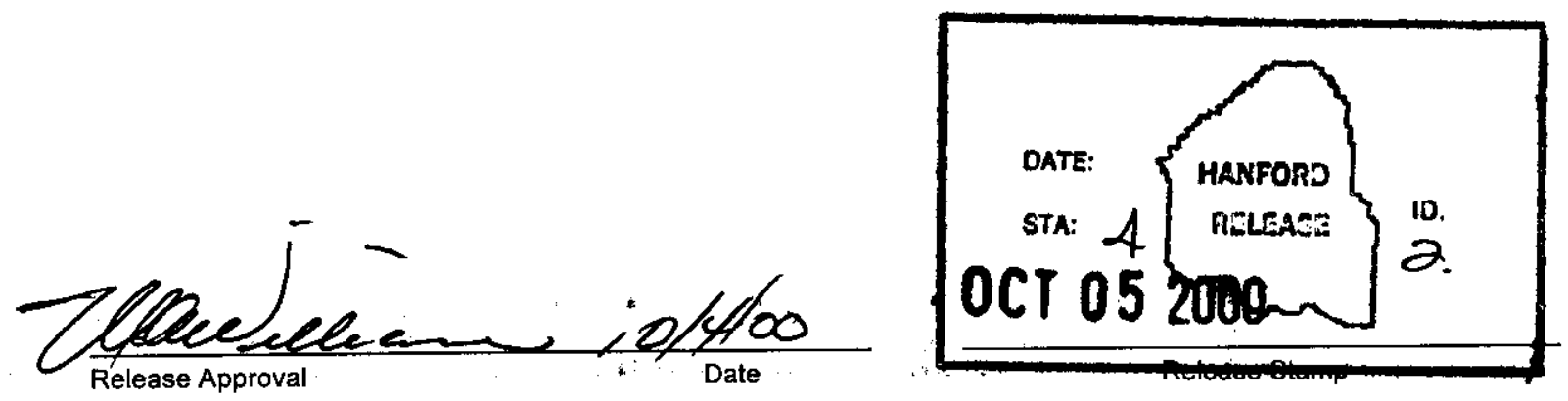

\section{Approved For Public Release}




\title{
RPP-6855 \\ Revision 0
}

\section{RESTORATION OF SECONDARY CONTAINMENT IN DOUBLE-SHELL TANK PITS}

\author{
prepared for
}

\section{CH2M HILL HANFORD GROUP, INC. \\ Contract No. 4412, Release 47 \\ Report No. 990922301-001 \\ Revision 0}

September 2000

prepared by 


\section{RESTORATION OF SECONDARY CONTAINMENT IN DOUBLE-SHELL TANK PITS}

prepared for

\section{CH2M HILL HANFORD GROUP, INC.}

\section{Contract No. 4412, Release 47}

Report No. 990922301-001

Revision 0

September 2000

Prepared by:

Eric J. Shen Anne Griggs Bruce Groth

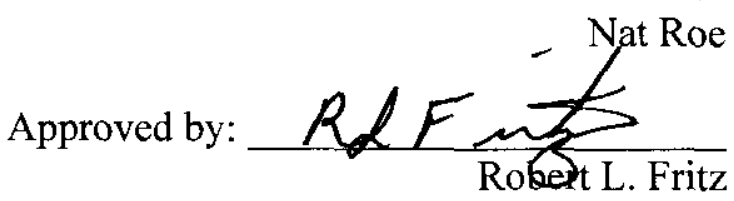

Date: $10-3-00$ 


\section{Table of Contents}

1.0 DECISION ANALYSIS SUMMARY 5

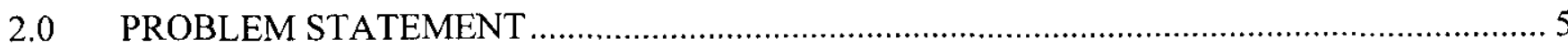

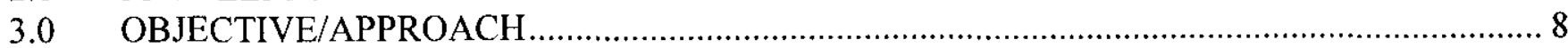

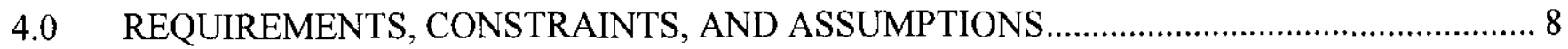

4.1 From Washington State Department of Ecology (Ecology), Guidance for Assessing Dangerous Waste Secondary Containment Systems, Pub \#95-420 ...................................8

4.2 Requirements from HNF-SD-W314-TI-013, Revision 1, Requirements Analysis Study for Special Protective Coating Project Development Specification....

4.3 Requirements From the July 24, 2000, Workshop and Other Sources ................................11

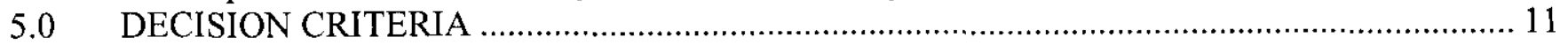

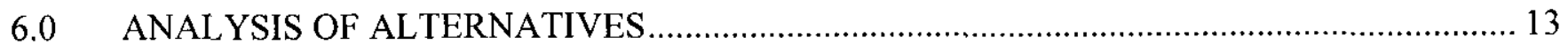

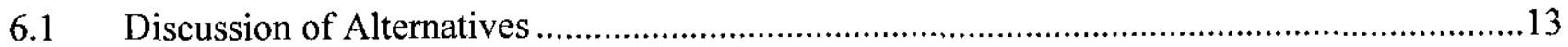

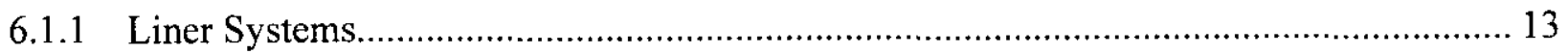

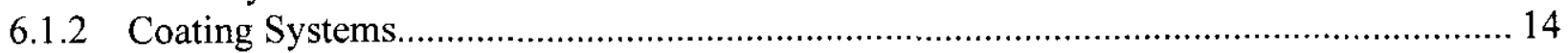

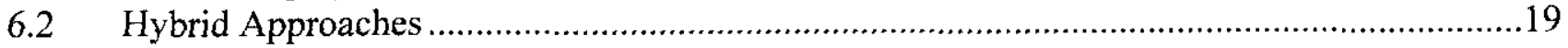

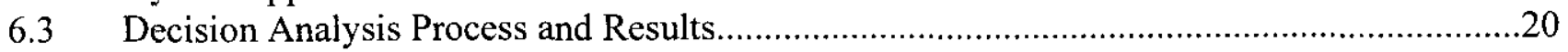

6.3.1 Secondary Containment Restoration Systems ................................................... 20

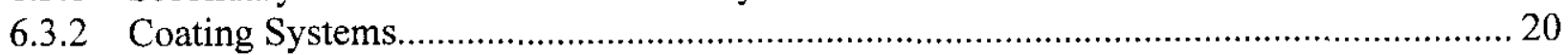

7.0 ANALYSIS OF LIFE-CYCLE COSTS FOR VIABLE ALTERNATIVES ............................22

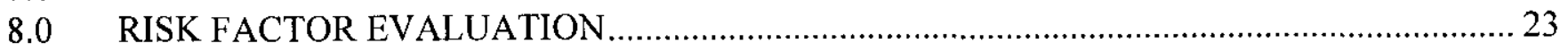

9.0 RECOMMENDATIONS AND ITEMS REQUIRING FURTHER RESOLUTION ..................2 24

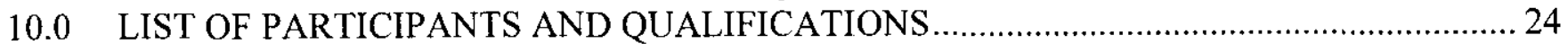

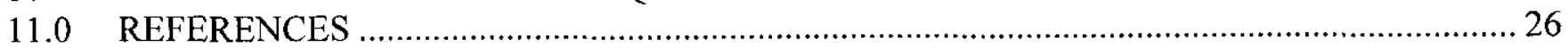

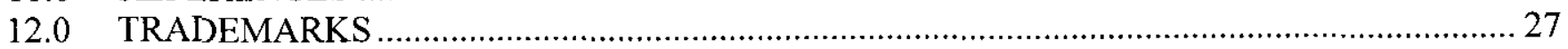

\section{APPENDICES}

Appendix A

Current Practices for Crack and Coating Repair

Appendix B

Properties Tables

Appendix C

Product Evaluations and Vendor Literature

Appendix D

Cost Estimates 


\section{Figures}

Figure 2-1. Crack Across Joint.

Figure 2-2. Cracks Around Embedment. .

Figure 6-1. Damage Caused By Coverblock.

\section{Tables}

Table 2.1. Examples of Types of Damage in Concrete. 6

Table 5-1. Decision Criteria

Table 6-1. Tank Pit Secondary Containment Decision Analysis

Table 7-1. Installation Costs 


\section{Acronyms}

ALARA as low as reasonably achievable

DF decontamination factor

DST

Double-shell tank

Ecology

Washington State Department of Ecology

$\mathrm{SPC}$ special protective coating

VOC

Volatile organic content

WVT

water vapor transmission 


\subsection{DECISION ANALYSIS SUMMARY}

Cracks found in many of the double-shell tank (DST) pump and valve pits bring into question the ability of the pits to provide secondary containment and remain in compliance with State and Federal regulations. This study was commissioned to identify viable options for maintain/restoring secondary containment capability in these pits.

The basis for this study is the decision analysis process which identifies the requirements to be met and the desired goals (decision criteria) that each option will be weighed against. A facilitated workshop was convened with individuals knowledgeable of Tank Farms Operations, engineering practices, and safety/environmental requirements. The outcome of this workshop was the validation or identification of the critical requirements, definition of the current problem, identification and weighting of the desired goals, baselining of the current repair methods, and identification of potential alternate solutions. The workshop was followed up with further investigations into the potential solutions that were identified in the workshop and through other efforts. These solutions are identified in the body of this report.

Each of the potential solutions were screened against the list of requirements and only those meeting the requirements were considered viable options. To expand the field of viable options, hybrid concepts that combine the strongest features of different individual approaches were also examined. Several were identified. The decision analysis process then ranked each of the viable options against the weighted decision criteria, which resulted in a recommended solution.

The recommended approach is based upon installing a sprayed on coating system.

Three coatings systems all preliminarily offer acceptable results:

- Polyurea Systems,

- CeRam-Kote $2000 \otimes^{1}$, and

- $\quad$ Sherwin Williams $\left(\operatorname{Kem}^{\circledR}\right.$ Cure $^{2}$ Tank Lining.

Overall, all are viable. However, more study and testing is recommended to validate vendor claims on physical and chemical compatibility and to provide a uniform basis for comparing the three systems.

\subsection{PROBLEM STATEMENT}

The principal access to the single and double shell underground storage tanks for waste transfers is through the pump and valve pits located on top or near the tanks. These concrete pits with barrier coatings provide a secondary containment function to prevent waste spills and leaks from reaching the environment. The past practice of no or minimal repairs is no longer acceptable. The degraded or cracked coatings do not provide an impervious waste barrier to the concrete (Washington Administrative

'CeRam-Kote $2000 \otimes$ is a registered trademark of Freecom, Inc, of Big Springs, Texas.

${ }^{2}$ Sherwin Williams $B$ and $\operatorname{Kem}(B)$ Cure are registered trademarks of the Sherwin Williams Company, Cleveland, Ohio. 
Code 303-173) and therefore a leakage pathway to the environment is possible. It has been determined that, over time, components of the waste may diffuse through the concrete and contaminate the adjacent soil. In addition to diffusion, cracks in the concrete and barrier coating create potential direct leak paths to the environment. Many of the cracks probably occurred early in the life of the structure because of normal curing and aging effects in the concrete. Figure 2-1 shows examples of these cracks. Other causes for cracking are impacts from heavy loads (cover block impact, equipment impacts), separation cracks located at embedment interfaces (thermal and mechanical) (see Figure 2-2), and thermal cycling during operations. Settling of the soil beneath the concrete is not suspected to be a source of cracking.

The current practices employed to repair pump and valve pit secondary containment defects (cracks in concrete and epoxy liner, paint spalling/peeling, etc.) is via manual entry into the pit to effect repairs. Aside from the dose to workers, the incremental costs to implement these repairs are approximately $\$ 500,000$ per pit based on the most recent work in ay pits by ongoing projects (actual cost accrual without site adders).

Examples of types of Damage in Concrete and their current condition are shown in Table 2.1:

Table 2.1. Examples of Types of Damage in Concrete.

\begin{tabular}{|c|c|c|}
\hline Damage & Current Condition & Description \\
\hline Curing induced & Stable & Hairline: $2 \mathrm{~mm}$ through wall and floor \\
\hline Cracks mechanical- pipe motion & Unstable & Cracks outline penetration - risers, pipes, and drains \\
\hline $\begin{array}{l}\text { Crack mechanical- impacts } \\
\text { (wrench) }\end{array}$ & Stable & Spalling, chips, grout seal damage, \\
\hline Cracks thermal- waste transfers & Unstable & $\begin{array}{l}\text { Tend to be radial around penetration with some long } \\
\text { linear cracks }\end{array}$ \\
\hline $\begin{array}{l}\text { Cracks from equipment installation- } \\
\text { jumpers/pumps }\end{array}$ & Unstable & Include with mechanical impacts \\
\hline Crushed concrete (protect rebar) & Unstable & \\
\hline Embedment interfaces & Unstable & Gouges, dents, holes, outline cracks \\
\hline Cracks from moisture/freezing & Unstable & May have cracks larger than $2 \mathrm{~mm}$ \\
\hline
\end{tabular}

Examples of Damage Found in the Coatings include:

- Cracks in the coating that do not go into the concrete - differential growth between coating and concrete,

- Scratches and chips,

- Peeling, spalling - attributed to aging of coating and deficiencies in surface preparation, 


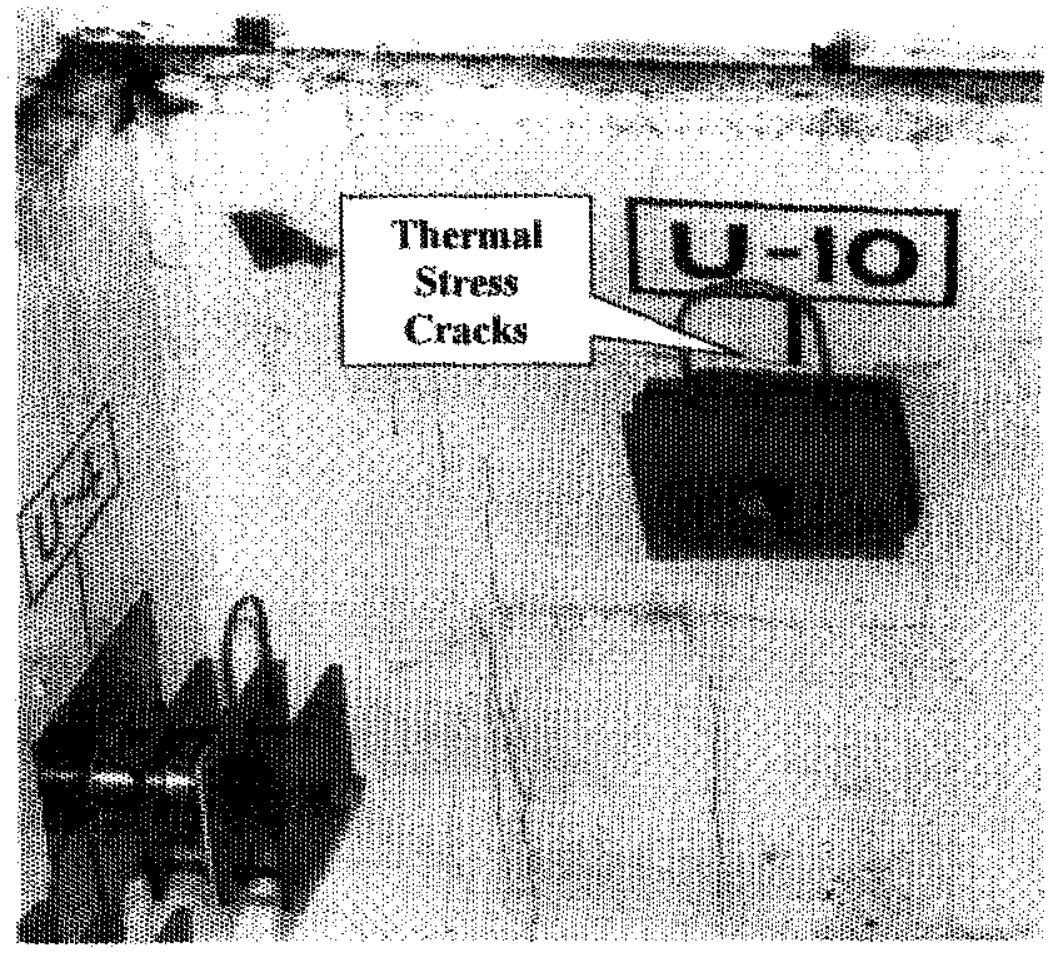

Figure 2-1. Crack Across Joint.

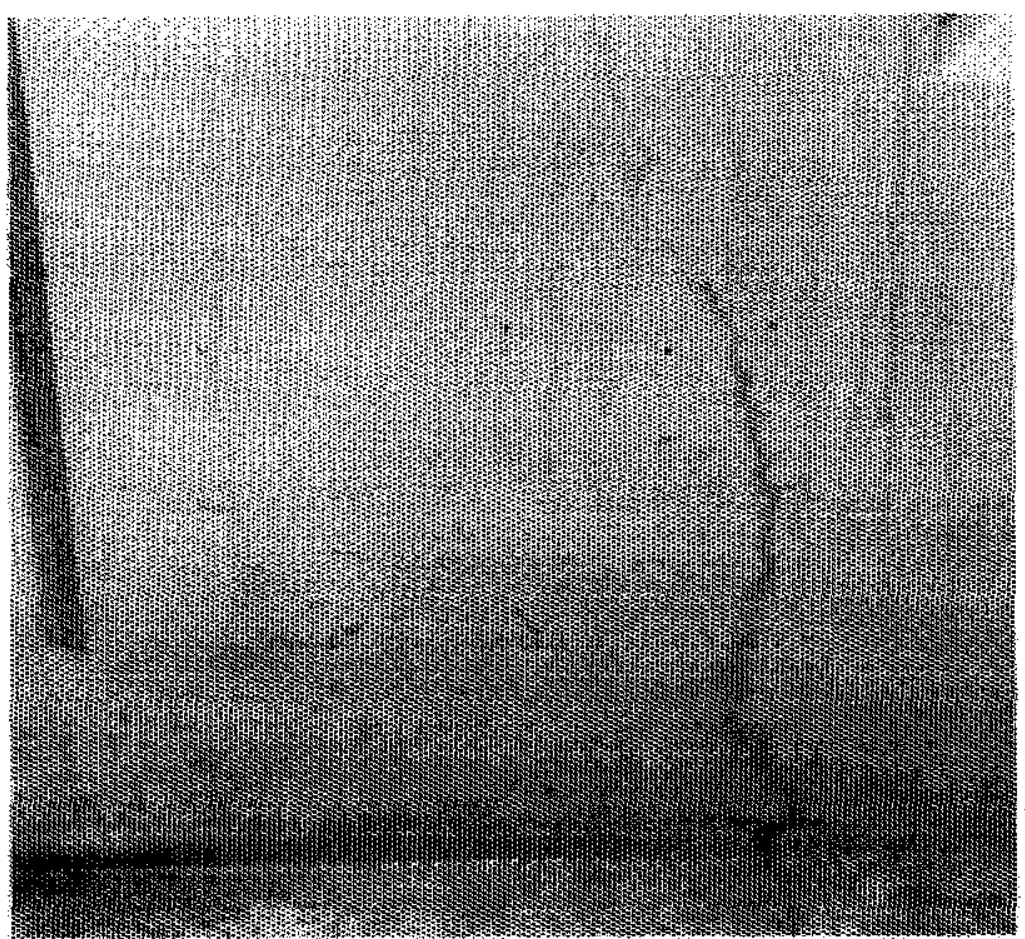

Figure 2-2, Craclis Around Lmbedment. 
- Oxidation - chalking paint,

- Abraded surface,

- $\quad$ Staining (rusty water trails),

- Oily films (oils and greases from equipment leaks), and

- Damage from decon solutions.

\subsection{OBJECTIVE/APPROACH}

The objective of this effort was to perform an analysis that identifies and evaluates potential coatings, sealants, and liners that might be suitable for maintaining and restoring secondary containment capabilities in the included pits. The analysis will address the benefits and drawbacks of each viable option regarding performance and cost the analysis will also consider issues of health, safety, environment, effects of radiation on the system, and other applicable issues. The report recommends the option(s) that represent the most significant improvements above the current practices employed to maintain/restore secondary containment from a system performance, cost, and schedule standpoint. The current methods to re-establish secondary containment are outlined in Appendix A.

The scope of this task will be to maintain/restore secondary containment within the pit structure. The pit structure is defined as including the floor and walls of the pit up to the front edge of the ledge that supports the cover blocks.

The analysis utilized the Alternative Generation and Analysis Process, HNF-IP-0842, Revision 3.3. The Alternative Generation and Analysis Process is a systematic approach to identify viable options and then use decision analysis techniques to select the preferred alternative that best satisfies the decision criteria.

\subsection{REQUIREMENTS, CONSTRAINTS, AND ASSUMPTIONS}

\subsection{From Washington State Department of Ecology (Ecology), Guidance for Assessing Dangerous Waste Secondary Containment Systems, Pub \#95-420}

The purpose of secondary containment is to capture and contain releases and spills from primary containment structures, facilitate timely cleanup of these releases and spills, and prevent releases of these wastes to the environment. Secondary containment is widely used for containers and tanks that store, accumulate, and treat dangerous waste.

Note: This document provides guidance for assuring compliance with WAC 173-303-GAC. 


\section{Requirements:}

1. The base of the secondary containment system must be free of cracks or gaps and be sufficiently impervious to contain leaks, spills, and accumulated rainfall until the collected material is detected and removed.

2. Unless the containers storing dangerous wastes are elevated or otherwise protected from contact with accumulated liquids, the base of the secondary containment system must be sloped or otherwise designed and operated to drain and remove liquids from leaks, spills, and accumulated rainfall.

3. The secondary containment system must prevent any migration of wastes or accumulated liquid out of the secondary containment system to the soil, groundwater, or surface water at any time during the use of the tank system.

4. The secondary confinement system must be constructed of materials that are compatible with the wastes to be placed in the tank system.

5. The secondary confinement system must have sufficient strength to withstand stresses due to static head during a release, pressure gradients, climatic conditions, nearby vehicle traffic, and other stresses resulting from daily operations must be provided.

6. The secondary confinement system must be provided with an impermeable interior coating or lining which is chemically compatible with the waste to be contained, that will prevent the stored waste from migrating into the concrete if a release occurs must be provided.

7. The secondary confinement system must be capable of preventing a release from the tank from migrating laterally or vertically into the surrounding soil.

8. The liner must be free of cracks or gaps.

Note: Ecology does not feel concrete will meet the requirements for secondary confinement without a barrier or liner.

\subsection{Requirements from HNF-SD-W314-TI-013, Revision 1, Requirements Analysis Study for Special Protective Coating Project Development Specification}

Requirements that are presented in the Ecology section will not be repeated in this section.

\section{Requirements:}

1. Stainless steel liners will not be coated with special protective coating (SPC).

2. The SPC system shall be compatible with the waste radionuclides listed under the W-314 column in Table B-2 (Appendix B). 
3. The top coating of the SPC system shall demonstrate relative ease of decontamination with a minimum Decontamination Factor (DF) of 100. The DF after initial water wash shall be a minimum of 20 .

4. The SPC system shall develop the ability to resist the development of "holidays" with time.

5. The SPC system shall successfully fill or bridge cracks of $1.0-1.5 \mathrm{~mm}(0.040$ to 0.060 inches $)$ caused by thermal movement and stresses within concrete.

6. The SPC system shall be volatile organic content (VOC) compliant with a maximum VOC of $2.9 \mathrm{lbs} /$ gallon (350 grams/liter).

7. The SPC system shall have minimum acceptable tensile properties as tabulated in Tables B-3, B-4, and B-5 (Appendix B).

8. The top coating shall demonstrate appropriate abrasion resistance properties. The acceptable abrasion resistance values of the installed coating are tabulated in Table B-6 (Appendix B). The weight loss values are for 1000 cycles when a CS-17 wheel is used with a $1000 \mathrm{~g}$ load in accordance with ASTM D 4060.

9. The SPC system shall be capable of resisting the migration of liquid waste/water into the pit wall. The permeability shall be measured as follows:

- $\quad$ The maximum water vapor transmission (WVT) rate for a top coating shall be 8 $\mathrm{gm} / \mathrm{m}^{2} / 24$ hours.

- $\quad$ The maximum water absorption rate for a top coating and joint sealant shall be $0.5 \%$ per 24 hours.

10. The SPC system shall display an adhesion property to the underlying concrete and previous coated surfaces. Minimum pull-off strength shall be $6,200 \mathrm{Kpa}(900 \mathrm{psi})$.

11. The color of the topcoat shall be white or near white such that nozzle labels and markers can be painted over the topcoat.

12. Paint (coating) used for identification marking on the SPC topcoat shall be compatible with the SPC system.

13. The SPC system shall have a design life of 12 years when installed per the manufacturer's recommendations.

14. The SPC system shall be repairable for cracks appearing through the applied coated surface to the substrate for chips and flaking due to mechanical damage.

15. The SPC System must be compatible with an ambient air temperature range of $48.90^{\circ} \mathrm{C}\left(120^{\circ} \mathrm{F}\right)$ to $-35.50^{\circ} \mathrm{C}\left(-32^{\circ} \mathrm{F}\right)$, with a maximum 24 -hour differential of $29.90^{\circ} \mathrm{C}\left(52^{\circ} \mathrm{F}\right)$. 
16. The SPC System must be compatible with a relative humidity range of 0 to 100 percent (the rate of change is negligible).

17. The SPC System must be able to withstand contact with the wastes [pH 7 to 14 , temperature $27^{\circ}$ to $93^{\circ} \mathrm{C}\left(50^{\circ}\right.$ to $\left.\left.200^{\circ} \mathrm{F}\right)\right]$.

18. The materials used in the pit shall be capable of operating in the following radiation environment:

Total accumulated dose: $\quad 6 \times 10^{7} \mathrm{rads}$

Dose rate: $\quad 1 \times 10^{1} \mathrm{r} / \mathrm{hr}$

19. Any materials with unusual fire characteristics, such as urethane foams, and any materials that develop significant quantities of toxic or other harmful products of combustion, shall not be used as interior finishes or other interior application without the approval of the cognizant U.S. Department of Energy fire protection authority. The use of foamed plastics in construction shall be prohibited unless it fully complies with Factory Mutual 1-57.

\subsection{Requirements From the July 24, 2000, Workshop and Other Sources}

1. The tank pit liners/coatings must meet flammable gas requirements during installation and after it is fully cured.

2. The SPC system must meet environmental requirements during and following installation.

\subsection{DECISION CRITERIA}

Decision criteria are desirable characteristics, that are "like to have" traits. Unlike requirements, if a product or system does not meet a decision criteria, that product or system is not disqualified from consideration. A product or system that falls short on a decision criteria will receive a lower score than one that performs better in this area.

The decision criteria identified in Table 5-1 resulted from discussions held during the July 24, 2000, workshop. These criteria were utilized in the analysis as the basis for identifying the superior candidate for recommendation. The list on Table 5-1 is a consolidation of 20 desired traits that were identified during the workshop. These 20 traits were then consolidated under 8 decision criteria to form a manageable evaluation matrix. Each of the decision criteria were ranked in importance by using a pairwise comparison technique. The final ranking established the weight each of the criteria. During the evaluation of the concept options, the decision criteria will be used to identify the superior option. 
Table 5-1. Decision Criteria.

\begin{tabular}{|c|c|}
\hline Decision Criteria & Weight \\
\hline $\begin{array}{l}\text { As Low As Reasonably Achievable (ALARA) Considerations } \\
\text { - } \quad \text { Dose to workers to implement the repair is minimized } \\
\text { - } \quad \text { Can be deconned to low levels } \\
\text { - } \quad \text { Does not require (or minimizes) pit entry }\end{array}$ & 8 \\
\hline - Cost $\quad$ Costs to implement the repair are minimized & 7 \\
\hline $\begin{array}{l}\text { - Good Installation Characteristics } \\
\text { - Installation of the repair minimizes the number of workers required and the time } \\
\text { necessary to complete repair } \\
\text { - } \quad \text { Minimizes interactions with waste during installation and during use } \\
\text { - Solution does not require removal of in-pit hardware }\end{array}$ & 6 \\
\hline $\begin{array}{l}\text { - Good lifetime } \\
\text { - The repair will have a long lifetime- retains adhesion to the concrete it is applied to, } \\
\text { tolerates additional concrete movement, maintains its integrity and physical } \\
\text { characteristics }\end{array}$ & 5 \\
\hline $\begin{array}{l}\text { - Good physical characteristics } \\
\text { - Good resistance to degradation when exposed to chemical wastes } \\
\text { - } \quad \text { Good elasticity to resist thermal effects and future cracks in concrete base } \\
\text { - } \quad \text { Ability to tolerate movement at joints } \\
\text { - Improved toughness characteristics }\end{array}$ & 4 \\
\hline $\begin{array}{l}\text { - Good operating characteristics } \\
\text { - } \quad \text { Fire resistant and does not generate toxic fumes in the event of a fire } \\
\text { - } \quad \text { Minimizes interactions with waste during operation } \\
\text { - } \quad \text { Minimizes residual odors/smell in the pit or the origin of the smell can credibly be } \\
\text { - } \quad \text { Satisfactorily deconned using water alone } \\
\text { - } \quad \text { Ease of inspection (defects in the coating easily show up) }\end{array}$ & 3 \\
\hline - Minimizes Schedule & 2 \\
\hline $\begin{array}{l}\text { Waste Generation } \\
\quad \text { Waste generated is minimized }\end{array}$ & 1 \\
\hline
\end{tabular}




\subsection{ANALYSIS OF ALTERNATIVES}

The options identified in this study were researched to understand the performance characteristics of the system along with an assessment of safety, health, environmental characteristics/impacts, and costs to implement. The decision analysis process is premised upon the basis that all viable options must meet the requirements that have been identified in Section 4.0. Those that do not are discarded from further consideration. In the remaining sections of this report, each option is described as to how this application would be used to maintain/restore secondary containment capability in the tank pits. If the option does not meet key criteria, a brief discussion will be presented on which criteria are not being met and why the requirement(s) are not met. In some cases, it may appear that requirements are being violated, however discussions found with the specific option will explain why this is not the case. A specific example can be found with the requirement:

"The SPC system shall display an adhesion property to the underlying concrete and previously coated surfaces. Minimum pull-off strength shall be 6,200 Kpa (900 psi)."

Coating systems probably do not require such high adhesion strengths, since the weak link in this system will be the concrete itself. The rule of thumb is that the tensile strength of concrete is 8 percent of the compressive strength. When typically using 3,000 lb. concrete, the tensile strength will be around $240 \mathrm{psi}$. Therefore, this study looked for material systems that could ensure that the concrete would fail before the coating could be pulled off the Amercoat $\mathbb{R}^{3}$ or concrete surface.

Following a screening for compliance to requirements, the viable options were examined from a strengths and weaknesses viewpoint. In other words, no repair system was found to be strong in all areas and perhaps a mix and match approach would identify a superior hybrid system. The combination of the original concepts found to be viable and the hybrid concepts formed the basis for conducting the decision analysis.

\subsection{Discussion of Alternatives}

The potential candidates fall into two classes: liners and coating systems. In each class, a number of different materials and configurations were examined.

\subsubsection{Liner Systems}

Stainless steel liners seem to be the most logical solution based upon their inherent durability, long lifetime, and ability to resist chemical attack. The approach for establishing secondary containment is to build a box made from stainless steel. The box would be built in sections that could be lowered into the pit and then assembled in place. The seams would be sealed by metal inert gas welding. Though this approach will meet the requirements spelled out for secondary containment, its downfall resides in the complexity of installation in existing structures and the difficulty in establishing a seal around existing

${ }^{3}$ Amercoat $($ is a registered trademark of Ameron Protective Coatings Division, Brea, California. 
penetrations. Entry into a pit would be unavoidable, which means that this concept will not score well in the decision criteria matrix.

The use of fiberglass as a liner system would have similar installation considerations that have been mentioned for stainless steel. However, fiberglass is not as durable, its lifetime is more limited than a metal liner, and its fire resistance is less. A particular concern associated with fiberglass would be its susceptibility to impact damage from dropped items and the difficulty in forming seals around existing penetrations. These limitations make fiberglass an inferior choice over metal liners. Fiberglass will not be considered further for secondary containment.

Thermal setting plastics were given cursory consideration as a liner material. Of the candidate materials examined, none were found that could resist sodium hydroxide in the concentrations expected to be present in the pits. Thermal setting plastics are discarded from further consideration.

\subsubsection{Coating Systems}

On a structurally sound base material, coating systems offer a good option for establishing a secondary containment. However, the pit structures contain numerous cracks and other defects, which may or may not be stable. All coating systems must be installed on a structurally stable base, however, some were able to tolerate small defects in the concrete.

Some types of coatings could also accommodate limited movement at crack interfaces, if bond breakers are applied at the crack. Bond breakers are tapes and/or sub-coatings that are applied over a crack that prevents the coating from adhering in the area immediately adjacent to the edge of a crack. The bond breaker allows the crack movement to be absorbed over a greater area of the coating. The more significant damage to the concrete structure was found in the region located above the cover block ledge (Figure 6-1). This damage tended to be crushing damage that had cracks extending from it. A number of repair methods were documented in American Concrete Institute reports on crack repair. The use of injectable polyurethanes and epoxies appear to be the superior choice for repair and have been used successfully to repair underground pit structures.

None of the coating systems that were identified were discounted because of toxic or hazardous components present during installation. It was assumed that special precautions would be taken through engineered and/or administrative controls in accordance with manufacturers' recommendations to mitigate any potential problems.

\subsubsection{Powder Coat Option}

Powder coating is often used to protect materials from heat and chemical attack because it forms a smooth, waterproof, and chemical resistant finish that is very durable. The process of powder coating involves spraying a mist of electrostatically charged resin and pigment particles that are then attracted to the base material to be coated. This process depends on the base material being electrostatically grounded so that the charged powder particles will stick to the base and can then be cured into the final 


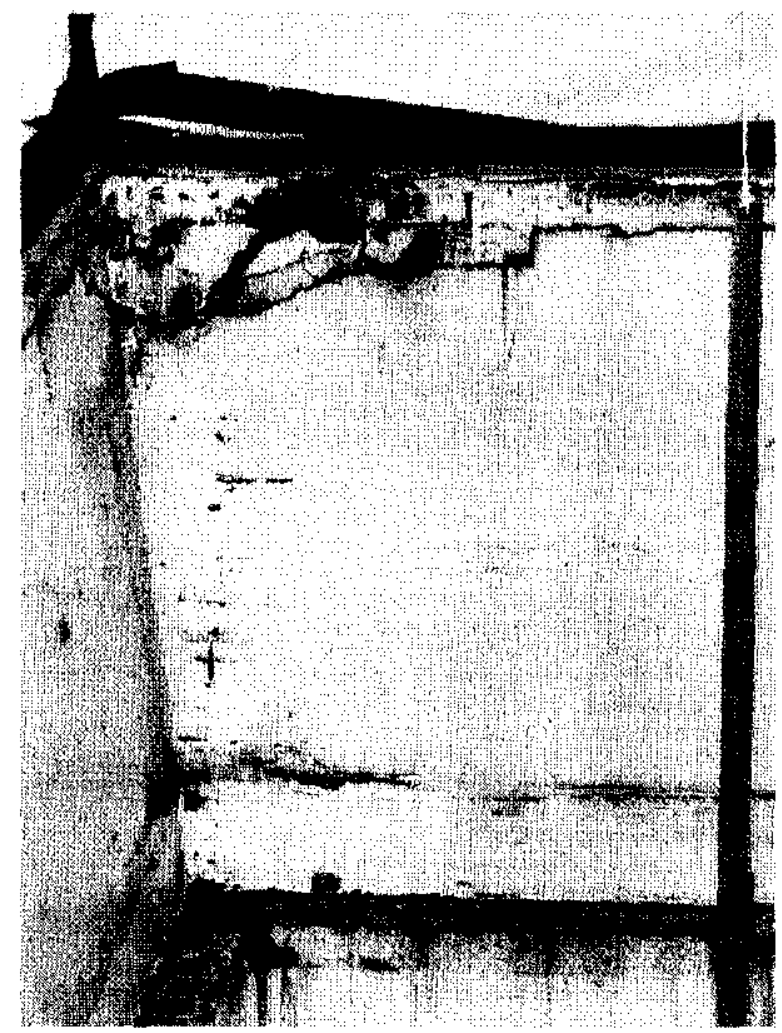

Figure 6-1. Damage Caused By Coverblock.

finish. Therefore, the base material must be metal, or have enough metal in it to attract the charged powder particles. Non-metallic base materials, such as concrete and old epoxy paint, would not be able to be grounded and would therefore not attract the charged powder being sprayed. After the spraying process, the curing process for the powder coat takes place. This requires that the surface to be coated be heated to a minimum of $325^{\circ} \mathrm{F}$, and in most cases the surface must be heated to temperatures exceeding $400^{\circ} \mathrm{F}$. Once applied, this coating would satisfy most of the requirements specified for this project, but since the application process cannot be performed with concrete, it is being rejected from consideration as a possible candidate.

\subsubsection{Ceramic Coatings}

Ceramic coatings are often used for temperature and wear protection in areas where normal coatings cannot be used. The most promising of these products found is CeRam-Kote 2000, a sprayed-on ceramic epoxy coating system that is meant for use in extremely harsh environments.

This product meets many, if not all, of the requirements for this project. It can be applied using either an airless or conventional spray system. Having an epoxy base, this coating will most likely cure and be smooth and easily decontaminated, and it will not develop "holidays" during the application or curing process. CeRam-Kote has acceptable elastic properties, which allow it to be stretched at least 30 percent longer than its original length. This indicates CeRam-Kote will be able to bridge existing cracks in the 
concrete base, it will also be able to stretch if more cracking should occur in the future. The WVT and water absorption values for CeRam-Kote are extremely low. The VOC of this product is $1.56 \mathrm{lb} . / \mathrm{gal}$. which is below the $2.9 \mathrm{lb}$./gal. requirement. The coating is extremely abrasion resistant and also has a very high tensile strength. The adhesion strength of this product is greater than any other that was found (it exceeded 4,000 psi in pull-off tests). The product is available in a range of colors that includes white, tan, and gray. If cracks should appear in the future, all that need be done is to sand the area surrounding the crack and apply another coat over the affected area. This product is able to withstand extremely high or low temperatures, whether wet or dry, and is compatible with a humidity range of $0-100$ percent. The coating is recommended for immersion service with a 70 percent $\mathrm{NaOH}$ solution.

This product has uncertainties that must also be mentioned. It is not known how the coating would react to radiation, as it has never been tested in a radioactive environment, however, epoxy compounds typically have excellent resistance to radiation exposure. A filler or backing material may be required to fill larger cracks in the pit walls and floors before the coating is applied. No product literature was provided to show CeRam-Kote will have a operating life of 12 years once installed the basic properties of epoxies, however, suggest that an operating life in excess of 12 years is a reasonable expectation. Also it is not known how much preparation would be needed to make the coating adhere well to a previous coating of Amercoat ${ }^{(}$epoxy paint. Most likely the surface would need to be thoroughly cleaned and then abraded in some fashion (such as sandblasting, sanding, or etching) before the product could be applied. Despite these uncertainties, this epoxy ceramic product seems to meet requirements and will be considered further.

Aside from this one product, which is an epoxy-ceramic mixture, there are many other types of ceramic coatings. Most are a ceramic enamel type of coating that, once applied, have outstanding heat resistant properties. Such coatings are used in high temperature conditions such as stove pipes, automotive engine and exhaust systems, and space shuttle exteriors. The heat handling capabilities of ceramic coatings of this type far exceed anything that would be encountered in the Hanford tank pits. Aside from this one attribute, these ceramic coatings fail to meet many of the project requirements. Ceramic coatings like this do not meet the water absorption or decontamination requirements, and require high temperatures to cure. Ceramic epoxy coatings are rejected from further consideration.

\subsubsection{Sherwin Williams Industrial and Marine Coatings}

Sherwin Williams offers an extensive line of products meant for coating both concrete and metal products. Most of their products offer protection from chemical attack, but one product appeared to fit the needs of this project better than all the others. Sherwin Williams® Kem ${ }^{\circledR}$ Cure Tank Lining is a two-component hybrid coating comprised of organic thermoset polymer and inorganic silicon oxide. It is meant for immersion and secondary containment use in situations that require resistance to alkalis, corrosion, flexing and stressing, impact, abrasion, and thermal shock.

This product meets or exceeds all the requirements of this project and in addition can be applied with a brush, roller, airless spray, or conventional spray methods. The coating has a gloss finish, which would most likely be easily decontaminated with water. If applied and allowed to cure properly, the product will be free of "holidays," cracks, and voids. The coating has a 8.2 percent elongation capability that 
meets requirements, but may be inadequate to accommodate future expansion and cracks. Further testing is needed. The VOC content is $0.9 \mathrm{lb} / \mathrm{gal}$, which is well below the $2.9 \mathrm{lb}$./gal. allowed for this project. The tensile strength of this product is $13,240 \mathrm{psi}$ and the flexural strength is $13,443 \mathrm{psi}$. Water absorption was $0.09 \%$ after 33 days at $88^{\circ} \mathrm{F}$. The adhesion strength of the product was 2,850 psi. The coating is easily repaired for cracks after it has been applied by sanding the cracked area and applying another coat over the sanded area. The product can also withstand conditions of $-40^{\circ} \mathrm{F}$ to $500^{\circ} \mathrm{F}$ and is compatible with highly alkaline environments.

This product has several drawbacks. It is only available in two colors, off-white or gray, and not pure white. It may be necessary to use a filler material or other method of covering the existing cracks before the product could be applied. Surface preparation before application would most likely involve some sort of abrading of the surface that the product is to be applied to. The fact that this is a thermoset polymer material means that in order to achieve the fastest curing times, the coating must be heated after application. Otherwise, even with proper ventilation, the coating could take up to 14 days to fully cure. The recommended method of allowing the coating to cure is to heat the applied coating to $180^{\circ} \mathrm{F}$ for a minimum of four hours. This could be achieved by placing a heat lamp or other heat source in the pit. After the coating has cured, it will meet or exceed the requirements for this project. This product meets all requirements and will be considered further.

\subsubsection{Polyurea}

Polyurea is a fast set, rapid curing, 100 percent solids, and flexible, two-component polyurea elastomer spray coating material. Polyurea is used by itself or in conjunction with other materials to produce coatings, liners, and resilient surfaces on concrete substrates. The material has an extremely fast gel time that makes it suitable for applications in cold or hot environments. The polyurea produces an extremely tough film at all thicknesses. Single or multiple pass applications produce films from 10 mils to 1,000 mils without appreciable sag or runs. Polyurea is inert, it will not hydrolyze, leach, or contaminate other materials and is relatively moisture and temperature insensitive, allowing application in the most problematic ambient conditions.

Polyurea is a coating material designed specifically for industrial applications receiving constant or intermittent attack from contained materials, subsurface hydrostatic pressure, most corrosive substances, and abrasive action. The material is flexible (200\% elongation), accommodating movement of the substrate, yet strong enough to remain intact under adverse conditions. Polyurea is recommended for liner/coating, repair of other films, damaged concrete, or new concrete construction.

Polyurea coatings do not meet the abrasion resistant properties identified in the subject requirements. The requirements are meant to ensure a protective coating that could withstand contact (scraping, etc.) with heavy equipment utilized during all types of operation in and around the pits. Further, it was found that the polyurea exhibits relatively weak resistance to tear/cutting damage when solid objects are dropped.

Polyurea coatings do not display the adhesion properties identified in the subject requirements. The requirements are meant to ensure the coating adheres to the existing epoxy and concrete so that the liner 
would not "pull-off" and leave the surface unprotected. However, the data suggests that the polyurea will bond to the existing epoxy at a higher value (approximately. $600 \mathrm{psi}$ ) than the strength the epoxy to concrete can produce.

The above information is a summary of the product evaluation found in Appendix C.

In addition to the information provided in the product literature, local vendors of polyurea coating products provided demonstrations of material application. The demonstrations simulated surface conditions and configurations that have been observed in the tank pits. Some of the more notable observations during the demonstration was the ability of polyurea to adhere to various surfaces with varying levels of contamination (coated with sugar/glycol solution) and the ability to bridge and/or fill racks up to $1 / 2$ " in cement blocks without surface preparation or prior crack filling. The vendor added that nails could be fastened to the wall prior to applying the coating to reduce the uncertainties associated with lack of adhesion due to poor surface preparation. This material will be considered further.

Note: A number of vendors were identified as potential suppliers of polyurea. It became apparent that all were using blends of the same basic materials and each could probably supply a product that addressed our needs. Therefore, it is probably appropriate to solicit the best price through the procurement process using a performance specification to ensure adequate performance.

\subsubsection{Epoxy Coatings}

Amercoat ${ }^{\circledR} 351$ is manufactured by Ameron, Inc., and is a solventless, high performance epoxy based coating that can be applied with standard airless equipment. It is suitable for use with highly caustic chemicals (such as the tank waste) for coating concrete. A glass flake additive can also be used with the coating to increase film buildup, further reinforce mechanical properties, and lower moisture permeability. Dry film thickness per coat is 8 to 12 mils and 12 to 25 mils with the glass flake additive. The coating is a two part epoxy system where the resin and the cure must be mixed immediately prior to application.

The Ameron epoxy will meet many but not all requirement that have been specified for secondary containment. The coating cures to a gloss finish that is decontaminable based upon prior demonstrations and on site usage of epoxy coatings. Amercoat ${ }^{\circledR} 351$ will meet abrasion specification (41mg. wt. Loss). The adhesion properties at 1,200 psi exceed the tensile strength of the base concrete. There are no VOCs per the vendor's literature. This type of epoxy is compatible with caustics up to 50 percent solutions at $160^{\circ} \mathrm{F}$.

On the negative side, the Amercoat ${ }^{\mathbb{B}} 351$ claims no elongation capability and typically hard finish epoxies do not exhibit elongation ability. Another shortcoming is that this coating may not be able to withstand contact with $200^{\circ} \mathrm{F}$ wastes.

Discussions with Ameron Inc. technical representatives indicated that the coating can be applied over Amercoat ${ }^{\circledR} 33$ if it is in good condition (i.e., not peeling), without acid etching or priming (Gilbert 1996). 
The surface would need to be cleaned and patched and then mechanically abraded before applying the first coat of Amercoat ${ }^{\mathbb{B}} 351$. A total of three coats, each 8 to 12 mils thick, would be used. If the existing coating is in good condition, another option would be to clean and patch the existing surface and apply one coat of Amerlock ${ }^{\circledR 4} 400$ ( 5 to 8 mils thick), which is a self- priming topcoat for use over existing coatings, and then apply two coats of Amercoat ${ }^{B} 351$. Amercoat ${ }^{(B)}$ is the baseline and considered representative of typical epoxies.

\subsection{Hybrid Approaches}

As mentioned earlier, no single concept possessed strengths in all categories covered by the decision criteria. However, some were strong in most areas with significant weaknesses in a few areas and, hence, it appeared reasonable to combine concepts that exploited the strengths of one concept to correct the weakness of another.

In this study, the most promising containment approaches were based upon using stainless steel to form a box within the pit and to use sprayed on coatings such as polyurea/epoxies that could be applied directly on the walls and floor. The use of stainless steel met all stated requirements, but falls short in the area of ease of installation, ALARA, and overall costs (due largely to the difficulty associated with fabricating a metal box within an existing structure in the presence of a radiation field). On the other hand, the sprayed on coating, such as the polyureas and epoxies also had deficiencies. As a class, they most likely require surface preparation (which may be difficult in radiation environment), long-term adhesion is a question, and they were weak in areas where an impact was possible. All other concepts failed to meet minimum requirements for reasons discussed in the previous section.

A range of hybrid options are possible using a combination of the strengths of stainless steel and sprayed on coatings. On one end of the range, a prefabricated stainless steel box is cut into modular sections designed to fit in a particular pit. The sections are lowered into place in sequential order such that the joints make a reasonably tight fit. The joints are then sealed using a polyurea.

Because close fitting joints are difficult to achieve in an existing structure without undue handling (and hence radiation exposure), a less demanding approach focusing upon using stainless steel "wall paper" to provide a prepared surface onto which a coating, such as polyurea, could be applied and considered. The stainless steel "wall paper" would be held in place by nails driven by a powder actuated gun and the floor would be allowed to float. The entire pit would then be sprayed with a coating system, such as polyurea. In this case, the "wall paper" stainless plates would be easily installed, loose fitting plates.

At the other end of the range, stainless steel would only be used for the floor and the floor and walls would be sprayed with a coating system. The metal floor would address the inherent weakness of coating systems to impact and cutting damage. If a nick or cut should occur, it would be unlikely to damage the stainless steel underneath and secondary containment integrity would be maintained. Since the floor receives the most exposure to dropped equipment or even heavy items being set down, a more durable floor system would be appropriate. Further, if the original floor could not be significantly

${ }^{4}$ Amerlock is a registered trademark of Ameron Protective Coatings Division, Brea, California. 
decontaminated, a thicker plate could set in place to help reduce the radiation source from the floor. In any event the floor plate would be prepared to optimize coating system adhesion.

\subsection{Decision Analysis Process and Results}

\subsubsection{Secondary Containment Restoration Systems}

A decision analysis employing weighted decision criteria was developed to identify the superior option for restoring secondary containment capability in the tank pits. The selected options will meet the requirements identified for this type of containment system. The superior option is that concept that is better than all the others in meeting or exceeding desired goals (called decision criteria) that are in many cases above and beyond the baseline requirements. The decision criteria and their relative weightings were developed during the facilitated workshop conducted July 24, 2000. The decision criteria are found in Table 5-1. The members selected to participate in that workshop provided a broad base of tank farm experience that span project management, tank farm engineering, safety, and environmental health.

Each concept is ranked relative to the other concepts to determine which is the best at meeting that particular criteria. The rankings are then multiplied by the weight for that criteria to obtain an overall score. Finally, all the scores for a candidate option are added together to obtain the total score. The highest scoring concept becomes the recommended option.

Based upon the analysis, see Table 6-1, the sprayed on coating system is the recommended system for restoring secondary containment in the tank pits. The use of a sprayed on coating is superior in the area of ALARA considerations because it minimizes the need for pit entry. It also scores well when considering installation characteristics, since the sprayed on coatings, such as polyurea, do not require prior crack repair prior to applying the coating.

The use of a steel plate on the floor is a close second in the scoring. The principle reason is the uncertainty associated with adhesion of sprayed on coatings to surfaces that have minimal preparation. The scoring process assumed that minimal surface preparation was required before the spray coating system was applied; however proper adhesion may be a concern over the design life. The use of a steel plate that has been pre-prepared on the floor will minimize this concern, but the increased effort to install a plate system caused this approach to fall behind a coating-only approach.

\subsubsection{Coating Systems}

The original intent of this study was to evaluate and select a superior coating system for this application. However, of the three leading candidates identified, none could clearly be identified as a recommended choice.

\section{- $\quad$ Polyurea Systems}

- CeRam-Kote 2000

- $\quad$ Sherwin Williams ${ }^{\circledR}$ Kem ${ }^{\circledR}$ Cure Tank Lining 
A decision analysis was unable to distinguish the properties of one system as being favored above the others. If there were differences between products, it was not clear that they had superior characteristics with the exception of polyurea's superior elongation properties and crack filling capabilities. Based upon product literature and vendor contacts alone, it was not clear that claims of chemical and physical properties could be substantiated or that a one-to-one correlation to our conditions was appropriate. However, CeRam-Kote and the polyureas appear to offer good crack filling capability along with good elongation properties (polyurea excels in this area). All three will likely provide adequate performance for our intended application. Should only a coating system be pursued, the Polyurea System (subject to cost confirmation) is the preferred option. However, testing to confirm performance charactertics of all three candidates is recommended (more to follow).

Table 6-1. Tank Pit Secondary Containment Decision Analysis.

\begin{tabular}{|c|c|c|c|c|c|}
\hline \multirow[b]{2}{*}{ DECISION CRITERIA } & \multirow[b]{2}{*}{ WEIGHT } & \multicolumn{4}{|c|}{ CANDIDATE OPTIONS } \\
\hline & & $\begin{array}{c}\text { SST Box Sealed at } \\
\text { Edges and } \\
\text { Penetration }\end{array}$ & $\begin{array}{c}\text { SST Panels on Walls } \\
\text { and Floor, Large } \\
\text { Gaps }\end{array}$ & $\begin{array}{c}\text { SST Plate on Floor } \\
\text { with Walls and } \\
\text { Floor Coated }\end{array}$ & Coating System \\
\hline $\begin{array}{l}\text { ALARA Considerations } \\
*\end{array}$ & 8 & 1 & 2 & 3 & 3 \\
\hline Overall Costs & 7 & 7 & 14 & 3 & 28 \\
\hline $\begin{array}{l}\text { Installation Characteristics } \\
*\end{array}$ & 6 & 6 & 12 & 3 & 24 \\
\hline Good Lifetime & 5 & 20 & 15 & 10 & 1 \\
\hline Physical Characteristics & 4 & 16 & 3 & 2 & 1 \\
\hline Operating Characteristics & 3 & 12 & 3 & 2 & 3 \\
\hline Minimizes Schedule & 2 & 2 & 2 & 3 & 8 \\
\hline $\begin{array}{l}\text { Waste Generation } \\
\qquad<\end{array}$ & 1 & 0 & 0 & 0 & 0 \\
\hline Score & & 71 & 82 & 93 & 96 \\
\hline
\end{tabular}

Notes:

Number in left corner is the relative rank and center number is score (rank x weighting) ( 1 = Lowest, $4=$ Highest)

* Uncertainty over floor surface preparation (lack of adhesion) caused polyurea to score slightly lower

- Stainless steel is the most durable of all materials found: better lifetime with more SST

$\diamond$ Waste generation was considered about equal for all concepts

$+\quad$ Both the SST plate on floor and coating system alone scored the same, since it was not clear one was a clearly superior option 


\subsection{ANALYSIS OF LIFE-CYCLE COSTS FOR VIABLE ALTERNATIVES}

The components considered in developing life-cycle costs for the recommended options are:

- Original Installation Costs,

- Maintenance Costs,

- Removal Costs (if required) and

- Re-installation Costs (if required).

The installation costs associated with the hybrid options evaluated by decision analysis in Table 6-1 are shown in summary on Table 7-1. The detailed cost makeup for each option can be found in Appendix D. The basis for these estimates is based upon vendor quotes for materials and fabrication and engineering experience associated with on site construction.

Table 7-1. Installation Costs

\begin{tabular}{|l|c|}
\hline \multicolumn{1}{|c|}{ Option } & Cost (/pit) \\
\hline 1. SST Box Sealed at Edges and Penetrations & $\$ 64,735^{*}$ \\
\hline $\begin{array}{l}\text { 2. SST Panels on Walls and Floor, Large Gaps (Wall Paper } \\
\text { Approach) }\end{array}$ & $\$ 50,600^{*}$ \\
\hline 3. SST Plate on Floor with Walls and Floor Coated & $\$ 42,400^{*}$ \\
\hline 4. Coating Systems & $\$ 28,700$ \\
\hline
\end{tabular}

* $\$ 2 \mathrm{~K}$ added for pit floor photogrametry

Maintenance costs for all the options is considered to be minimal to none for all the options. However, there is a risk associated of poor adhesion of the coating system over the 12-year life requirement that may lead to early failure. In that event, the damaged sections would have to be removed and reinstalled. This scenario is not anticipated for Options 1 and 2 where the coating will be applied to surfaces that have been prepared in accordance with vendor recommendations. It is options three and four where the coatings are to be applied over old epoxy surfaces that will receive minimal preparation that poses the concern.

Removal of any of the coating materials poses a unique challenge, because of the difficulty of accessing the pits and the potentially high radiation backgrounds. It is envisioned that a crew equipped with scraper knifes mounted on long poles would remove the defective coating in specific areas (especially around the top edge) and then re-apply a replacement coating. The effort required to accomplish such a task is estimated to require a crew similar in size to the original installation crew for a two-week period, which may represent a $\$ 65,000$ risk in the future if repair is required. Assuming that a coating failure does not occur during the life of the pit, then installation costs would constitute the entire life-cycle cost. In that case, a straight sprayed on coating would be the least expensive followed by a sprayed coating in combination with a floor plate. 


\subsection{RISK FACTOR EVALUATION}

There are a number of risks associated with the application of any new coating material in radioactive/contaminated pits. The hybrid solutions have these same issues where coating systems are used. In an effort to improve the coating performance from the existing practices, different materials were examined and compared to identify the best possible material for the required application. As the evaluation was performed, different concerns arose specific to the application/performance of polyurea and the other recommended sprayed on coatings in the 200 Area pits. Due to the relatively recent technology involved with these coatings, vendors do not have significant records identifying product performance in "like" applications. The lack of vendor data does not suggest that the material properties will not be satisfactory, it does, however, introduce a level of uncertainty. The material properties listed below are identified to have uncertainty associated with their performance. The material properties, the risk associated with those properties, and a possible path forward to mitigate the risks are shown below.

- A smooth/easily decontaminated surface: There is no objective evidence or data to ensure a field applied polyurea will produce a smooth, easily decontaminated surface. Small holes and other abrasions appear on the samples of polyurea obtained from the vendor (assumed to have been applied in optimal conditions). A sample of polyurea fixed to a cement block, applied in a similar manner as suggested for the pits, resulted in surface coating pits larger than the samples obtained from the vendor. The effectiveness of future decontamination efforts may be reduced with the presence of these pits.

Path Forward: Establish a test employing application methods and conditions like that planned for the pit to examine the effects of different cure times and component mixtures on surface conditions. The polyurea would be remotely sprayed to simulated pit walls.

- A long design life: There is no objective evidence of product lifetime for any of the coating products that were examined. The polyurea products had limited data (approximately eight years) on use of their product in a nuclear application.

Path Forward: Establish tests to expose the material to simulated environmental conditions to document how the material will respond. Of particular concern is exposure to strong caustic solutions and elevated temperatures for potentially prolonged periods.

- Good resistance to surface damage: There is concern that polyurea, and to a lesser extent the other coating systems, will not withstand the damage that may occur from operations and maintenance activities in the tank pits.

Path Forward: Conduct tests to evaluate the damage that could be expected from operations and maintenance activities. 


\subsection{RECOMMENDATIONS AND ITEMS REQUIRING FURTHER RESOLUTION}

- $\quad$ The recommended secondary containment system is a sprayed on coating system.

- $\quad$ Three coating systems appear to provide acceptable performance with polyurea systems being superior in the areas of elongation and crack filling capability. However, further testing is recommended to confirm vendor's performance claims.

- It is suggested that the tear-off strength requirement imposed upon coating systems be reduced to match the tensile strength of concrete.

- It is suggested that the compatibility of the three coating systems with pit environment, in particular chemical compatibility be verified through testing.

- It is suggested that the near-term and long-term adhesion ability of the three coating systems on minimally prepped epoxy, especially around floor penetrations and along top edge be verified.

- It is suggested that that the remote application techniques be reviewed to assure they will be successful.

\subsection{LIST OF PARTICIPANTS AND QUALIFICATIONS}

The following are a list of the participants of the facilitated workshop held July 24,2000 , along with their qualifications:

\section{John Bailey}

Mr. Bailey is currently the Lead Project Engineer for Project W-314 Phase 2. He has 25 years of nuclear facility process and project engineering and project management experience mainly in the area of nuclear waste management (waste storage tanks, pumping systems and transfer facilities). He maintains Hanford qualification cards as Facility Cognizant Engineer, Design Authority, and Project Engineer.

\section{Todd Blaak}

Mr. Blaak is currently a Cognizant Engineer for DST, Engineering, Tank Chemistry/Waste Compatibility and Transfer Systems. His background related to this effort includes the following: Member of Pit Decon team which evaluated decontaminating pits on-site and screened potential replacement coating for pits; evaluated decontamination chemicals and fixatives prior to use on-site; and knowledge of transfer systems including pit configuration. 


\section{Dave Bowers}

Mr. Bowers has over 26 years of operations and engineering experience with Hanford Tank Farms. He maintains qualification cards as Facility Cognizant Engineer and Design Authority for Project W-314. He has a B.S. degree in General Science (Radiation Science and Health Physics) from Oregon State University with extensive post-graduate classes in engineering.

\section{Nancy Butler}

Ms. Butler is currently the Construction Manager for Project W-314, Tank Farm Infrastructure Upgrades. She is a certified Industrial Hygienist in comprehensive practice per the American Board of Industrial Hygienists. She has a B.S. in Environmental Health, M.S. in Environmental Health/Industrial Hygiene, and eight years of U.S. Department of Energy working at the Hanford Site and at the Los Alamos National Laboratory. Ms. Butler also has 10 years of environmental protection and restoration experience.

\section{Robin Fogg}

Mr. Fogg's qualifications include an M.S. in Environmental Sciences at the Harvard School of Public Health, board certifications in Industrial Hygiene (CIH) and Safety Professional (CSP), and over 24 years of field experience in industrial hygiene and safety. In his current position as Industrial Hygienist for CH2M HILL Hanford Group, Tank Farm Projects, Mr. Fogg provides industrial hygiene oversight to tank farm upgrade construction projects, including reviewing/approving work documents, auditing work activities, conducting personnel monitoring, and reviewing sampling data to ensure compliance with standards.

\section{Bruce Groth}

Mr. Groth is a Senior Engineer with ARES Corporation responsible for conducting Engineering Studies, Conceptual Design Reports, preparation of specifications, estimating, detail design and performing design reviews, in addition to other engineering duties. As a Systems Engineer, he has extensive knowledge of design requirements contained in State and Federal regulations. He has over 15 years of experience in the design and operation of nuclear facilities. He has B.S. degrees in Chemistry and Mathematics from Willamette University.

\section{John Guberski}

Mr. Guberski has a B.S. degree in Nuclear Engineering and 20 years of experience in applying environmental, nuclear safety and industrial safety regulations to commercial power plants or industrial facilities. He has seven years of direct responsibility for environmental compliance at an electrical cable manufacturing plant and at a Resource Conservation and Recovery Act of 1976 treatment, storage, and disposal facility. He also has prepared environmental permit applications for National Pollution Discharge Elimination System and air emissions permits. 


\section{Mike Harty}

Mr. Harty has a B.S. degree in Environmental Engineering and Health Physics from Washington State University. He has 26 years of engineering/operations experience with the majority of the Hanford Site, primarily Plutonium Uranium Extraction Facility, Plutonium Finishing Plant, and Tank Farms.

\section{Paul Patterson}

Mr. Patterson has over 15 years as a consultant, facilitator, and writer supporting various Hanford Site and Idaho National Engineering Laboratory projects. He has facilitated and supported safety and regulatory identification processes, hazard analysis sessions, and alternatives generation studies; authored documents resulting from the facilitated processes, including hazard analysis reports and a Safety Requirements document analysis; participated in operational readiness reviews; designed and developed training and qualification programs; presented specialized training programs; designed and facilitated specialized group processes for conflict resolution, team building, communication, and interpersonal skills development.

\section{Eric Shen}

$\mathrm{Mr}$. Shen has over 26 years of experience leading and managing project teams to develop remote mechanical systems and facilities in support of the space reactor program, tank waste recovery, spent nuclear fuel recovery, and the next generation fusion test facilities. He has a BSME degree from Colorado State University and is a registered Professional Engineer in both Colorado and Washington.

\section{Dave Sparks}

Mr. Sparks has been a Field Crew Manager in Tank Farms for 10 years. He has been a member of many "Pit Decon" teams during the past seven years. He has a thorough knowledge of the tank farm "pits" and transfer systems. The Nuclear Chemical Operators that work in his group do all pit jumper changes and pit decon activities.

\subsection{REFERENCES}

ACI Report, 1994, Causes, Evaluation and Repair of Cracks in Concrete Structures, ACI 224.1R-93, ACI Committee 224, American Concrete Institute.

Baker, J.W., 1999, Paper, Vault Repair Provides Insight into effective Polyurethane Grouting, \#C99BO94, The Aberdeen Group.

Groth, B.D., 1996, Evaluation of Liner Requirements for Secondary Containment Pits for Ancillary Equipment, WHC-SD-W314-RPT-004, Rev. 0, ARES Corporation, Richland, Washington. 
July 24,2000 , Facilitated Workshop conducted to confirm scope, identify requirements, identify goals, weight those goals, and identify potential options.

McGrew, D.L., 1999, Requirement Analysis Study for Special Protective Coating Project: Development TI-013, Rev. 2, Numatec Hanford Corporation, Richland, Washington.

Summary Report, 1992, Repairing Cracks: A Summary of Repair Methods for Active and Dormant Cracks, \#R920160, The Aberdeen Group.

Washington State Department of Ecology, 1995, Guidance for Assessing Dangerous Waste Secondary Containment Systems, Publication \#95-420.

\subsection{TRADEMARKS}

Amercoat ${ }^{\circledR} 33$, Amercoat ${ }^{\circledR} 351$, Amerlock ${ }^{\circledR} 400$, and NuKlad 114 are registered trademarks of Ameron Protective Coatings Division, Brea, California.

CeRam-Kote 2000 is a registered trademark of Freecom, Inc., Big Springs, Texas.

Sherwin Williams ${ }^{\circledR}$ Kem Cure $($ Tank Lining is a registered trademark of the Sherwin Williams Company, Cleveland, Ohio. 


\section{Appendix A}

Current Practices for Crack and Coating Repair 


\section{Current Practices For Crack And Coating Repair}

For cracks (hairline or less in width), chips and spalling: local repair is the current approach. This includes:

- $\quad$ Preparation for coating repair: Wash, apply fixative, remove cover blocks, remove the jumpers and miscellaneous equipment, cover penetration openings, high pressure water wash (whole pit), install shielding (lead blankets), remove dirt and debris, inspect the pit for damage (photos), prep for Amerlock ${ }^{\mathbb{B}} 400$ (flush and rough up surface) and

- Apply two coats by roller: Poured in then spread around. (This approach poses a problem on future projects; no entry is possible in an pit and entry is discouraged in other pits.)

For cracks greater than hairline, the steps include:

- Determine if pit is structurally sound and agree upon repair process;

- $\quad$ Prep the structure and coating surfaces for repair (clear out the crack regions);

- Inspect the crack damage;

- Decide which cracks need to be cut out: Remove paint 2" on each side, clean crack out (water and vacuum), if the crack is less than $1 \mathrm{~mm}$, coat crack with Amercoat ${ }^{\mathbb{R}} 400$, and then fill with NuKlad 114, if the crack is greater than $1 \mathrm{~mm}$, use saw to create a .5-in. trapezoidal cut into crack for the entire length and then fill with a non-shrink grout);

- Allow the grout to cure to manufacturer's recommendations (Note: Additional costs incurred due to need to add water for curing and interim checks);

- Inspect the repairs;

- $\quad$ Prep for Amercoat ${ }^{\circledR}$ (see previous process steps for $<1 \mathrm{~mm}$ cracks);

- Apply four coats of Amerlock ${ }^{\circledR} 400$ on floors and two on the walls, minimum;

- Inspect each coat in pit; and

- $\quad$ Reinstall the jumpers and equipment.

Other Past Practices: Repoured the floor, reformed the damaged lips, 236-Z Canyon SS liner repair (puncture fixed with devcon), M Cell Purex (SS liner punctured repaired by welding a patch), poly bladders, pressure grouting at 225-B Cesium Cell. 
Appendix B

Properties Tables 
Table B-1. Chemical Composition Range (2 Sheets)

\begin{tabular}{|c|c|c|c|c|}
\hline \multicolumn{5}{|c|}{ RETRIEVED WASTE } \\
\hline \multirow{3}{*}{ SPECIES } & \multicolumn{2}{|c|}{ DST } & \multicolumn{2}{|c|}{ SST } \\
\hline & \multicolumn{2}{|c|}{ Anion/Cation } & \multicolumn{2}{|c|}{ Anion/Cation } \\
\hline & Min $\mathrm{mol} / \mathrm{L}$ & Max mol/L & $\mathrm{Min} \mathrm{mol} / \mathrm{L}$ & $\operatorname{Max} \mathrm{mol} / \mathrm{L}$ \\
\hline $\mathrm{Ag}$ & 0 & 0.0013 & - & - \\
\hline AI & 0.05 & 1.1 & 0.029 & 0.5 \\
\hline As & 0 & 0.0066 & - & - \\
\hline $\mathrm{B}$ & 0 & 0.013 & - & - \\
\hline $\mathrm{Ba}$ & 0 & 0.0004 & 0 & 0.0014 \\
\hline $\mathrm{Bi}$ & - & - & 0 & 0.076 \\
\hline $\mathrm{Ca}$ & 0.0014 & 0.1 & 0 & 0.17 \\
\hline $\mathrm{Cd}$ & 0 & 0.0074 & 0 & 0.0007 \\
\hline $\mathrm{Cr}$ & 0.0067 & 0.28 & 0.0001 & 0.091 \\
\hline $\mathrm{Cu}$ & 0 & 0.02 & - & - \\
\hline $\mathrm{Fe}$ & 0.0004 & 0.26 & 0.0057 & 0.89 \\
\hline $\mathrm{Hg}$ & 0 & $2.8 \mathrm{E}-05$ & 0 & 0.0001 \\
\hline $\mathrm{K}$ & 0.044 & 0.55 & 0.0002 & 0.0095 \\
\hline $\mathrm{La}, \mathrm{Nd}$ & 0 & 0.0066 & 0 & 0.001 \\
\hline $\mathrm{Mg}$ & 0.0004 & 0.046 & - & - \\
\hline $\mathrm{Mn}$ & 0.0003 & 0.16 & 0.0009 & 0.41 \\
\hline Mo & 0 & 0.0029 & - & - \\
\hline $\mathrm{Na}$ & 1.6 & 10.7 & 1.6 & 7.1 \\
\hline $\mathrm{Ni}$ & 0.0002 & 0.008 & 0 & 0.042 \\
\hline $\mathrm{Pb}$ & 0 & 0.004 & 0 & 0.12 \\
\hline $\mathrm{Pd}, \mathrm{Rh}$ & 0 & 0.0063 & 0 & 0 \\
\hline $\mathrm{Si}\left(\mathrm{SiO}_{2}\right)$ & 0.0024 & 0.028 & 0.0004 & 0.46 \\
\hline $\mathrm{Ti}$ & 0 & 0.002 & - & - \\
\hline $\mathrm{U}$ & 0 & 0.0092 & - & - \\
\hline $\mathrm{Zr}\left(\mathrm{ZrO}_{2}\right)$ & 0 & 0.3 & 0 & 0.065 \\
\hline Acetate & - & - & 0 & 0.0055 \\
\hline Citrate & 0 & 0.03 & 0.0042 & 0.06 \\
\hline EDTA & 0 & 0.016 & 0 & 0.011 \\
\hline
\end{tabular}


Table B-1. Chemical Composition Range (2 Sheets)

\begin{tabular}{|c|c|c|c|c|}
\hline \multicolumn{5}{|c|}{ RETRIEVED WASTE } \\
\hline \multirow{3}{*}{ SPECIES } & \multicolumn{2}{|c|}{ DST } & \multicolumn{2}{|c|}{ SST } \\
\hline & \multicolumn{2}{|c|}{ Anion/Cation } & \multicolumn{2}{|c|}{ Anion/Cation } \\
\hline & Min $\mathrm{mol} / \mathbf{L}$ & $\mathrm{Max} \mathrm{mol} / \mathrm{L}$ & Min $\mathrm{mol} / \mathrm{L}$ & Max mol/L \\
\hline HEDTA & 0 & 0.021 & - & - \\
\hline $\mathrm{Fe}(\mathrm{CN})_{6}$ & - & - & 0 & 0.025 \\
\hline $\mathrm{CI}$ & 0.003 & 0.17 & 0 & 0.022 \\
\hline $\mathrm{CO}_{3}$ & 0.03 & 0.69 & 0.014 & 0.38 \\
\hline $\mathrm{F}$ & 0.014 & 1 & 0.001 & 0.71 \\
\hline Fission Product & 0 & 0.0001 & - & - \\
\hline $\mathrm{NO}_{2}$ & 0.1 & 1.8 & 0.0086 & 0.83 \\
\hline $\mathrm{NO}_{\mathbf{x}}\left(\mathrm{NO}_{3}\right)$ & 0.15 & 3.6 & 0.64 & 5.1 \\
\hline $\mathrm{OH}$ & 0.24 & 4.4 & 0.25 & 6.9 \\
\hline $\mathrm{PO}_{4}$ & 0 & 0.4 & 0.0007 & 3.8 \\
\hline $\mathrm{SO}_{4}$ & 0.003 & 0.16 & 0.01 & 0.22 \\
\hline TOC & 0 & 2 & - & - \\
\hline
\end{tabular}

Notes:

DST $=$ Double-Shell Tank

EDTA = Ethylenediametetraacetic acid

HEDTA $=\mathrm{N}$-(hydroxyetheyl)-ethylenediaminetriacetic acid

SST $\quad=$ Single-Shell Tank

TOC $=$ Total Organic Carbon

Basis: $\quad$ This is the cross-site transfer system chemical composition from the "Recommended Waste Composition Changes to the MWTS FDC-Rev. I, " Waste Management Engineering internal memo 22170-93-012 to J. M. Light. June 23, 1993,

Westinghouse Hanford Company, Richland, Washington. The waste composition from the cross-site transfer system is the worst-case for the $W$-314 transfer piping. 
Table B-2. Radionuclide Concentrations

\begin{tabular}{|c|c|c|c|}
\hline \multirow{2}{*}{ NUCLIDE } & \multicolumn{3}{|c|}{ Nuclide concentrations $(\mathrm{Bq} / \mathrm{L})$} \\
\hline & All Liquids ${ }^{(a)}$ & All Solids ${ }^{(a)}$ & $W-314^{(b)}$ \\
\hline${ }^{14} \mathrm{C}$ & $2.3 \mathrm{E}+05$ & $1.6 \mathrm{E}+05$ & $2.3 \mathrm{E}+05$ \\
\hline${ }^{60} \mathrm{Co}$ & $9.5 E+06$ & $4.9 \mathrm{E}+08$ & $1.7 \mathrm{E}+08$ \\
\hline${ }^{79} \mathrm{Se}$ & (c) & $1.7 \mathrm{E}+04$ & $1.7 \mathrm{E}+04$ \\
\hline${ }^{90} \mathrm{Sr}$ & $1.1 \mathrm{E}+10$ & $2.9 \mathrm{E}+12$ & $9.6 \mathrm{E}+11$ \\
\hline${ }^{90} \mathrm{Y}$ & $1.1 \mathrm{E}+10$ & $2.9 \mathrm{E}+12$ & $9.6 \mathrm{E}+11$ \\
\hline${ }^{99} \mathrm{Tc}$ & $1.7 E+07$ & $1.2 \mathrm{E}+10$ & $4.0 \mathrm{E}+09$ \\
\hline${ }^{106} \mathrm{Ru}$ & $9.9 E+02$ & $7.2 E+04$ & $2.4 \mathrm{E}+04$ \\
\hline${ }^{126} \mathrm{Sb}$ & $3.4 \mathrm{E}+04$ & $1.8 \mathrm{E}+08$ & $5.9 \mathrm{E}+07$ \\
\hline${ }^{129} \mathrm{I}$ & $2.0 \mathrm{E}+04$ & $6.4 \mathrm{E}+06$ & $2.1 \mathrm{E}+06$ \\
\hline${ }^{134} \mathrm{Cs}$ & $6.1 E+06$ & $9.4 \mathrm{E}+06$ & $7.2 \mathrm{E}+06$ \\
\hline${ }^{137} \mathrm{Cs}$ & $8.8 \mathrm{E}+10$ & $1.0 \mathrm{E}+11$ & $9.2 E+10$ \\
\hline${ }^{144} \mathrm{Ce}$ & $9.1 \mathrm{E}+00$ & $3.4 \mathrm{E}+02$ & $1.2 \mathrm{E}+02$ \\
\hline${ }^{147} \mathrm{Pm}$ & $3.6 \mathrm{E}+07$ & (c) & $3.6 \mathrm{E}+07$ \\
\hline${ }^{154} \mathrm{Eu}$ & $2.4 \mathrm{E}+09$ & $1.1 E+10$ & $5.2 E+09$ \\
\hline${ }^{155} \mathrm{Eu}$ & $5.9 \mathrm{E}+07$ & $5.0 \mathrm{E}+06$ & $5.9 \mathrm{E}+07$ \\
\hline${ }^{237} \mathrm{~Np}$ & $2.3 \mathrm{E}+05$ & $9.9 E+08$ & $3.3 \mathrm{E}+08$ \\
\hline${ }^{238} \mathrm{Pu}$ & $1.8 E+06$ & $1.9 \mathrm{E}+08$ & $6.4 \mathrm{E}+07$ \\
\hline${ }^{239} \mathrm{Pu}^{(\mathrm{d})}$ & $3.6 \mathrm{E}+07$ & $1.6 \mathrm{E}+09$ & $5.5 E+08$ \\
\hline${ }^{241} \mathrm{Pu}$ & $2.6 \mathrm{E}+08$ & $3.8 E+09$ & $1.4 \mathrm{E}+09$ \\
\hline${ }^{241} \mathrm{AM}$ & $4.2 \mathrm{E}+07$ & $1.1 \mathrm{E}+10$ & $3.7 E+09$ \\
\hline${ }^{242} \mathrm{Cm}$ & $1.1 E+01$ & $2.0 \mathrm{E}+02$ & $7.3 E+01$ \\
\hline${ }^{244} \mathrm{Cm}$ & $4.2 \mathrm{E}+05$ & $6.1 \mathrm{E}+07$ & $2.0 \mathrm{E}+07$ \\
\hline
\end{tabular}

Notes: Analysis Consequence Assessments, WHC-SD-WM-SARR-016, Rev. 2, Westinghouse Hanford Company, Richland,

Washington.

(b) W-314 values represent a bounding mixture for design of $67 \%$ liquid and $33 \%$ solid, except for ${ }^{14} \mathrm{C}$ and ${ }^{155} \mathrm{Eu}$ where the maximum liquid value was used as it is higher than the mix and for ${ }^{79} \mathrm{Se}$ and ${ }^{147} \mathrm{Pm}$ where data is not available

(c) No available data.

(d) The ${ }^{239} \mathrm{Pu}$ activity concentration also includes ${ }^{240} \mathrm{Pu}$. 
Table B-3. Tensile Properties of Coatings

\begin{tabular}{|l|l|l|}
\hline \multicolumn{1}{|c|}{ Properties } & \multicolumn{1}{|c|}{ Rigid Coating (Epoxy) } & \multicolumn{1}{c|}{$\begin{array}{c}\text { Flexible Coating } \\
\text { (Elastomeric) }\end{array}$} \\
\hline Tensile Strength & N/A & Maximum $20,700 \mathrm{KPa}$ \\
\hline $\begin{array}{l}\text { Elongation at break at } 24^{\circ} \mathrm{C} \\
\left(75^{\circ} \mathrm{F}\right)\end{array}$ & Minimum 5 percent & $\begin{array}{l}\text { Minimum } 400 \text { percent at } 30 \\
\text { days }\end{array}$ \\
\hline
\end{tabular}

Table B-4. Tensile Properties of Joint Sealants

\begin{tabular}{|l|l|l|}
\hline \multicolumn{1}{|c|}{ Properties } & \multicolumn{1}{|c|}{ Flexibilized Epoxy } & \multicolumn{1}{|c|}{$\begin{array}{c}\text { Fluoroelastomer, } \\
\text { Polysulfide, Polyurethane }\end{array}$} \\
\hline Tensile Strength & $\begin{array}{l}\text { Minimum } 3,500 \mathrm{KPa} \\
(500 \mathrm{psi})\end{array}$ & $\begin{array}{l}\text { Minimum } 10,400 \mathrm{KPa} \\
(1,500 \mathrm{psi})\end{array}$ \\
\hline $\begin{array}{l}\text { Elongation at break at } 24^{\circ} \mathrm{C} \\
\left(75^{\circ} \mathrm{F}\right)\end{array}$ & Minimum 100 Percent & Minimum 100 Percent \\
\hline
\end{tabular}

Table B-5. Tensile Properties of Fillers

\begin{tabular}{|l|l|}
\hline \multicolumn{1}{|c|}{ Properties } & \multicolumn{1}{c|}{ Solid Epoxy Mastic } \\
\hline Tensile Strength & Minimum 3,500 KPa $(500 \mathrm{psi})$ \\
\hline Elongation at break at $24^{\circ} \mathrm{C}\left(75^{\circ} \mathrm{F}\right)$ & Minimum 20 Percent \\
\hline
\end{tabular}

Basis: $\quad$ The tensile strength and percent elongation at break are measures of the tensile properties of coating and sealant materials. The acceptable values are in accordance with the requirements outlined in Chemical Resistant Decontaminable Coating Guide Specification GSO9855.SP. The requirements are based on available data from manufacturers of the type of coatings currently used at the Hanford Site.

Table B-6. Abrasion Resistance Properties of Coatings

\begin{tabular}{|c|c|c|}
\hline Properties & Rigid Coating (Epoxy) & $\begin{array}{c}\text { Flexible Coating } \\
\text { (Elastomeric) }\end{array}$ \\
\hline Abrasion Resistance & Weight loss less than $100 \mathrm{mg}$ & Weight loss less than $10 \mathrm{mg}$ \\
\hline
\end{tabular}


Appendix C

Product Evaluations and Vendor Literature 


\section{C1.0 POLYUREA PRODUCT EVALUATION}

The objective of this product evaluation was to assess the characteristics associated with polyurea to determine its feasibility for use on 200 Area pits, supporting the Waste Feed Delivery System. The material was evaluated specifically for use as a secondary confinement barrier for pump pits and valve pits throughout the 200 Area Tank Farms.

Polyurea is a fast set, rapid curing, 100 percent solids, and flexible, two-component polyurea elastomer spray coating material. Polyurea is used by itself or in conjunction with other materials to produce coatings, liners, and resilient surfaces on concrete substrates. The material has an extremely fast gel time that makes it suitable for applications in cold or hot environments. The polyurea produces an extremely tough film at all thicknesses. Single or multiple pass applications produce films from 10 mils to 1000 mils without appreciable sag or runs. Polyurea is inert, it will not hydrolyze, leach, or contaminate other materials and is relatively moisture and temperature insensitive, allowing application in the most problematic ambient conditions.

Polyurea is a coating material designed specifically for industrial applications receiving constant or intermittent attack from contained materials, subsurface hydrostatic pressure, most corrosive substances, and abrasive action. The material is flexible, accommodating movement of the substrate, yet strong enough to remain intact under adverse conditions.

Polyurea is recommended for liner/coating, repair of other films, damaged concrete, or new concrete construction. The following are a sample of simple profiles regarding use of the polyurea material in chemical and nuclear applications:

- Great Western Chemical Tank Farm - Two 30,000-gallon tanks were sprayed at 40 mils thick to provide a chemical resistant protective coating/secondary containment. The polyurea material was chosen because it is fast setting, abrasion resistant, bird proof, seamless, and creates a onepiece, well-adhered liner.

- $\quad$ SRS Savanna River Site Nuclear Waste Processing Plant - Three square miles of low level contaminated concrete were sprayed (encapsulation of existing coating) to protect the surface from spreading contamination.

- Waste Isolation Pilot Plant (WIPP) - Polyurea was used on wash pads (concrete slabs) with heavy traffic to provide a radiological safe environment.

To evaluate the applicability/feasibility of the product for the application required, a detailed assessment was performed using requirements derived from WSDOE, Guidance for Assessing Dangerous Waste Secondary Containment Systems, Pub \#95-420 and HNF-SD-W314, Rev 1, Requirements Analysis Study for Special Protective Coating Project Development Specification. The following data is developed from a direct correlation between the material and the requirements and specification information contained in the aforementioned documents. 
Based on material information supplied by a number of vendors (documentation attached, phone conversations referenced), the following properties of polyurea satisfy requirements contained in WSDOE, Guidance for Assessing Dangerous Waste Secondary Containment Systems, Pub \#95-420 and HNF-SD-W314, Rev 1, Requirements Analysis Study for Special Protective Coating Project Development Specification.

1. The polyurea coating system shall develop the ability to resist the development of "holidays" in time.

2. The polyurea coating system has successfully bridged cracks up to $1.2 \mathrm{~mm}$ : These cracks did not propagate through the polyurea coating.

3. The polyurea coating system provides a tensile strength of 2,500 psi and an elongation of 265 percent. Although these values do not completely meet the requirements referenced, types of polyurea can be mixed with additives to enhance its performance in this area. Based on conversation with NUCOTE vendor - John Meyer, dated July 27, 2000.

4. The polyurea coating system is hydrophobic and therefore absorbs far less water than $.05 \%$ per $24 \mathrm{hrs}$. The highest WVT rate tested for polyurea was $0.934 \mathrm{gm} / \mathrm{m}^{2} / 24 \mathrm{hr}$. This coating is compatible with a relative humidity range of 0 to 100 percent

5. The polyurea coating system has high temperate stability with a service temperature of $-60^{\circ} \mathrm{F}$ to $300^{\circ} \mathrm{F}$.

6. The polyurea coating system is generally suitable for continuous contact with substances with $\mathrm{PH}$ ranging from 4 to 11 . The use at the 200 Area pits will not consist of continuous contact. The polyurea is suitable for application concerning the NAOH environment and the corresponding PH range. Based on conversation with NUCOTE vendor - John Meyer, dated July 27, 2000.

7. Polyurea is 100 percent solids and contains no solvents or VOCs. It has a flame spread rating of "10," a smoke density rating of " 5 ," and a National Fire Protection Agency classification of "A." The polyurea exhibits no unusual fire characteristics. Based on conversation with NUCOTE vendor - John Meyer, dated July 27, 2000.

8. Polyurea can be applied in numerous colors, a number of which suitable for painting over.

9. Documented evidence exists to show the durability of polyurea is good in applications from 3 to 8 years old. Vendor claims that Polyurea has a design life of about 30 years. Based on conversation with NUCOTE vendor - John Meyer, dated July 27, 2000.

10. Polyurea can be applied over itself to repair damage to the coating. Although this satisfies the requirements, the logistics of using polyurea repeatedly could prove to be difficult.

11. Polyurea is based on the use of aromatic isocyranate component, and other aromatic species are polymerized into the B component. Aromatics resonate in energized environments including 
radionuclides in levels listed in the provided specification. Aromatics have been used in gamma as well as slow and fast neutron environments - polyurea should provide an adequate level of containment with respect to the radionuclides associated with the pump pits and valve pits.

12. The polyurea coating material was tested concerning the ease of decontamination. The coating material was decontaminated to a maximum DF of 40 ( 97.5 percent removal) with ambient water. Further washes with ambient and hot decontamination solution increased the maximum DF to 43 (97.7 percent). Note: These values include contamination removal from previous steps.

13. Polyurea is capable of operating in radiation environments consistent with those found at the Waste Feed Delivery System valve pits and pump pits at the 200 Area. Tests conducted on specific types of polyurea showed the physical properties, when exposed to radiation levels comparable to those in the 200 Area pits, remained suitable for application.

The following polyurea characteristics identified below were determined not to meet the requirements identified in WSDOE, Guidance for Assessing Dangerous Waste Secondary Containment Systems, Pub \#95-420 and HNF-SD-W314, Rev 1, Requirements Analysis Study for Special Protective Coating Project Development Specification. These characteristics, although outside the "envelope" of compliance, do not necessarily disqualify the coating from consideration. The coating could be used with other methods to mitigate the deficiencies and provide an adequate pit surface liner. The following unsatisfied requirements and corresponding potential mitigation for each, may result in a combination of coating techniques that provide the desired protective liner for the 200 Area valve/pump pits:

1. Polyurea coatings do not meet the abrasion resistant properties identified in subject requirements. The requirements are meant to ensure a protective coating that could withstand contact (scraping, tool dropping, etc.,) with heavy equipment utilized during all types of operation in and around the pits. The potential for contact with the liner would be greatest at the floor (or other horizontal surfaces) as other areas would deflect or resist the force generated by lowered or fallen objects. To mitigate the deficiency, a protective barrier (plate) could be placed on the floor underneath the polyurea coating, therefore minimizing the potential for abrasion in areas most susceptible to damage.

2. Polyurea coating do not display the adhesion properties identified in subject requirements. The requirements are meant to ensure the coating adheres to the existing epoxy and concrete so that the liner would not "pull-off" and leave the surface unprotected. Vendor data suggests the polyurea would bond to the existing epoxy at a higher value (approx. 600 psi) than the weathered epoxy would adhere to the concrete. Based on conversation with NUCOTE vendor - John Meyer, dated July 27, 2000. Therefore, the polyurea coating would provide an adequate liner as all the epoxy is not anticipated to fail. Furthermore, areas of the concrete without the existing epoxy would be exposed and provide "anchors" for the polyurea, subsequently enhancing the adhesion properties of the liner.

To provide a more conservative design with respect to polyurea adhesion, individual pieces of steel could be prepared, lowered, and attached to the pit to maximize the surface to polyurea bond. 


\section{C1.1 Surface Preparation}

Polyurea general application surface preparations include: cleaning, washing (power wash), application of a primer, and finally a surface coat. These are the recommended preparations with regards to a favorable environment. These processes can be modified, both for coating properties and differing surface configurations. Vendor literature, as well as phone conversation confirmation, exists which documents situations where no priming in necessary, "substrate priming is not required on all substrates." Based on discussions with an approved/certified polyurea applicator (Cascade Industries), the application strategy for the 200 Area pits is suggested to be as follows: 1) Power wash at highest pressure allowable, apply a light coat of primer, then apply the polyurea coating.

\section{C1.2 Removal}

Polyurea removal is performed by physically cutting (hydraulic cutter, mechanical knife, etc.) the coating from the substrate. Discussions with an approved applicator resulted in data suggesting that an entire surface coating could not be removed without significant effort and time. However, removal of small isolated pieces of the coating, already free from the substrate, could be accomplished remotely (knife on a pole) and in a timely fashion. Regardless of the data received from the vendor, there is some uncertainty associated with removal of the polyurea coating with respect to radioactive/contaminated pits.

\section{C1.3 Vendor References}

1. VERSEFLEX Incorporated, Kansas City, KS 66101, (800) 321-0906

2. SPECIALTY PRODUCTS Inc., Lakewood, WA 98499, (800) 627-0773

3. NUKOTE THERMAL SYSTEMS, Renton, WA 98057, (425) 204-5607 
Manufacturer:

EnviroChem Technologies

P.O. Box 6499

Fort Worth, Texas 76115-0499

(817) 923-6466 - Fax (817) 923-6470

E-Mail: info@envirolastic.com

\section{Product Description:}

EnviroLastic ${ }^{\circledR}$ AR $200 \mathrm{HD}$ is a heavy duty version of EnviroChem's polyurea systems. It is designed to be used where a more dense, hard, and abrasion resistant system is required. Because of its physical properties, AR 200 HD is slightly more chemical resistant than the standard systems. Ultra fast set times (6 seconds) also allow for a "stipple" finish to be achieved, if desired.

Like all of EnviroChem's polyurea line, AR $200 \mathrm{HD}$ is a $100 \%$ solids, ultra fast cure, spray applied, seamless, waterproof, elastomeric coating and lining system, which exhibits extraordinary performance characteristics for a wide range of applications. It can be applied at thicknesses of $10 \mathrm{mil}$ to $250 \mathrm{mil}$, or greater, in a single application.

EnviroLastic ${ }^{\circledR}$ AR $200 \mathrm{HD}$ is the optimum choice where a tough, flexible, impact / abrasion resistant, waterproof surfacing system is required in extremely short down times with no VOCs and no odor.

\section{Limitations:}

- AR $200 \mathrm{HD}$ is an aromatic. Physical properties will not change, but light colors will change in UV light.

- Consult EnviroChem for corrosive environment applications.

- Do not install in moisture / vapor conditions > $>3$ lbs. MVT, $>5 \%$ moisture content.

\section{Advantages:}

- Fast Cure. Short down time.

- No VOCs and no odor.

- High strength.

- Seamless and flexible.

- Bridges moving cracks to $1 / 16$ ".

- Waterproofs.

- Accepts vehicular traffic.

- Added color stability.

- Enhanced adhesion properties.

- Application at $-20^{\circ} \mathrm{F}$ to $350^{\circ} \mathrm{F}$.

- Resists thermal shock.

- Resistant to many chemicals.

- Can be topcoated for added chemical resistance.

- USDA approved.

\section{Typical Uses:}

- Floor and Wall Systems

- Tank Linings

- Containment Areas

- Loading Docks / High Traffic Areas

- Digesters

- Food \& Beverage Processing Areas

- Cold Storage Areas

- Mechanical Rooms

- Chemical Plants

- Fertilizer Plants

- Pulp and Paper Mills

- Petrochemical Facilities

\begin{tabular}{|c|c|c|}
\hline PHYSICAL PROPERTIES & TEST METHOD & VALUE \\
\hline Elongation & D-638 & $200 \%$ \\
\hline Tensite Strength & $\mathrm{D}-638$ & $3,000 \mathrm{psi}$ \\
\hline Shore Hardness & D-2240 & D-55 \\
\hline Tear Strength (pli) & D-624 & $480 \mathrm{pli}$ \\
\hline Moisture Vapor Transmission & E-96 & 0.02 perm \\
\hline $\begin{array}{l}\text { Abrasion Resistance (wt. loss mg.) } \\
1000 \text { g., } 1000 \text { rev. H- } 18 \\
1000 \text { g., } 1000 \text { rev. CS } 17\end{array}$ & $\begin{array}{l}D-4060 \\
D-4060\end{array}$ & $\begin{array}{c}170 \mathrm{mg} . \\
4 \mathrm{mg} .\end{array}$ \\
\hline 100 Modulus (psi) & $1-038$ & . $\quad i, \overline{y 0} 05 \mathrm{psi}$ \\
\hline Coefficient of Thermal Expansion & C-531 & $4 \times 10^{-3}\left(\mathrm{in} / \mathrm{in} /{ }^{\circ} \mathrm{C}\right)$ \\
\hline Flash Point, components & & $>200^{\circ} \mathrm{F}$ \\
\hline Flame Spread & E-108 & $\begin{array}{c}\text { Class A (Comparabie } \\
\text { to UL 790) }\end{array}$ \\
\hline Gel Time / Tack Free & & $6 / 12$ seconds \\
\hline $\begin{array}{l}\text { Flexibility Testing: } \\
\text { Gardner Impact, in.-lbs. (on } 1 / 32 \text { " steel paneis) } \\
\text { Direct and Indirect }\end{array}$ & D-2794 & $>160$ in. - lbs. \\
\hline $\begin{array}{l}\text { Mandrel Bend: } \\
\text { Conical Bend (on } 1 / 32^{\prime \prime} \text { steel panels) } \\
1 / 4^{\prime \prime} \text { Mandrel, } 25^{\circ} \mathrm{C} \text { (free film, } 35-50 \text { mils) } \\
\text { I/4" Mandrel, }-20^{\circ} \mathrm{C} \text { (free film, } 35-50 \text { mils) }\end{array}$ & $\begin{array}{l}\text { D- } 522 \\
\text { D-1737 } \\
\text { D-1737 }\end{array}$ & $\begin{array}{l}\text { Pass } \\
\text { Pass } \\
\text { Pass }\end{array}$ \\
\hline
\end{tabular}


Installation:

The following is meant as a guide. Consult EnviroChem or an EnviroChem Certified Applicator for job specific specifications.

Project Conditions: Surface must be structurally sound, $d r y$, and uncontaminated. Concrete must be minimum 3,500 psi and free of voids, bugholes, honeycombs, and delaminations. Always perform Calcium Chloride test as per ASTM E-1907 (do not proceed with MVT $>3$ lbs. or moisture content $>5 \%$ ). Do not apply over light weight concrete, metal pan decks, or sandwich slab membranes. Honor all expansion joints. For steel, all welds must be continuous and ground smooth or filled. Weld splatters, burrs, etc. must be removed. Consult EnviroChem before coating over existing coatings.

Substrate Repairs:

Concrete: Route and seal all cracks > 1/16" with EnviroChem JS or approved urethane sealant. Pre-fill all bugholes with epoxy and aggregate or polymer modified-cement approved by EnviroChem. Repair concrete as per ICRI Technical Guidelines 03730 and 03731.

Steel: Adhere to NACE Standard RP 0178 latest revision.

Surface Preparation: Remove all dirt, grease, oil, contamination, etc. by high pressure waterblast (preferably hot) with appropriate degreaser or detergents. Monitor for "bleed back". For surface profile, mechanical methods such as sandblasting or shotblasting are preferred.

Concrete: Sandblast or shotblast to remove all laitance and achieve a profile equal to $80-100$ grit sandpaper. Refer to ICRI Guide 03732 or NACE No. 6 / SSPC-SP13.

Steel: Provide a "Near White Metal" blast to SSPC-SP-10 / NACE 2, with a 3 mil profile for immersion service, 2 mil for less severe conditions.

Mixing:

Agitate resin blend (B) component THOROUGHLY with a drum mixer before use to disperse pigment and assure homogeneity. Do not thin. Do not mix " $A$ " and " $B$ " resins together. (CAUTION - doe not agitate in air and moisture.)

\section{Application:}

Correct equipment is critical to installation. Use only heated, piural component equipment capable of producing 3,000 psi at $160^{\circ} \mathrm{F}$ and 2 gpm consistently, such as Gusmer H. 3500 .

Prime with EnviroPrime WB or as recommended by EnviroChem. All cracks must receive a $5^{n} \times 30$ mil detail coat. Continue spraying to achieve the required mil thickness with $50 \%$ overlaps. Blower apply approved aggregate, if required. Top coat if specified.

\section{Repairs and Maintenance:}

Small repairs and modifications can be made using EnviroLastic JS $\mathbf{8 0}$ or Hand Mix material. For traffic areas, keeping EnviroLastic ${ }^{\circ}$ clean will increase life.

\section{Bond Strength: \\ (primed substrate) \\ Concrete ASTM D.4541 $550 \mathrm{psi}$ (concrete failure) \\ Steel ASTM D.4541 1750 psi}

\section{Other Test Data Available:}

- Salt Spray Corrosion

- QUV Weatherometer

\section{Colors:}

Black, White, Light Grey, Medium Grey, Charcoal Grey, Tan, and Tile Red. See standard color chart. Custom colors available at additional charge. See limitations on color retention.
Clean Up and Disposal

RPP-6855, Rev. 0

Clean up "B" side with soap $=$ water, EnviroChem Tack Coat or EnviroChem Citriklean. Mix "A" side with water. Dispose of in accordance with local and federal disposal regulations.

\section{Safety:}

Read and understand the MSDS provided with all shipments. Always use products with adequate ventilation and use required PPE. For confined space use fresh air supply. For open air, use half face, twin cartridge respirators approved for MDI. Always protect eyes and skin. Strictly adhere to Society of Plastics Industry Safety Standards.

\section{Shelf Life and Storage:}

Twelve months in sealed unopened containers. Keep away from extreme heat, freezing, and moisture.

\section{Availability:}

Because of the technical nature of the material and equipment required that will assure you of a professional installation, EnviroLas. tic $^{\star}$ is only available through an international network of trained applicators on a limited basis. For an approved applicator near you, contact EnviroChem Technologies.

\section{Warranty Reference:}

The technical data and other printed information furnished is true and correct to the best of our knowledge. If a product fails to meet this warranty, Envirochem Technologies, at its option, will replace the product or refund the purchase price of the material.

Your Approved EnviroChem Contractor is: 
Eric Shen

From:

Sent:

To:

Subject:
John F. Unsworth [john@envirolastic.com]

Monday, September 25, 2000 2:48 PM

eshen@arescorporation.com

Fw: Undeliverable Mail

----Original Message-----

Erom: Postmaster <postmasterenvirolastic.com>

To: johneenvirolastic.com <johneenvirolastic.com>

Date: Monday, September 25, 2000 4:26 PM

Subject: Undeliverable Mail

>Unknown host: eshendariescorp.com

$>$

>original message follows.

$>$

>Received: from host [209.166.9.161] by envirolastic.com

$>$ (SMTPD32-6.00) id A2E92040282; Mon, 25 Sep 2000 16:26:01 -0500

$>$ Message-ID: <005f01C02737\$1206e460\$0900000alhost>

>Reply-To: "John F. Unsworth" <johndenvirolastic.com>

$>$ Erom: "John E. Unsworth" <johneenvirolastic.com>

$>$ To: <esheneariescorp. com>

$>$ Subject: Consent letter

>Date: Mon, 25 Sep 2000 16:24:59-0500

>MIME-Version: 1.0

>Content-Type: multipart/alternative;

$>$ boundary $="----=$ NextPart_000_005A_01C0270D.26684680"

>X-Priority: 3

>X-MSMail-Priority: Normal

>X-Mailer: Microsoft Outlook Express 4.72.3110.1

$>$ X-MimeoLE: Produced By Microsoft MimeoLE V4.72.3110.3

$>$

$>$ This is a multi-part message in MIME format.

$>$

$>----=$ NextPart 000 005A 01C0270D.26684680

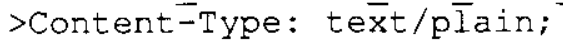

$>$ charset $="$ iso-8859-1"

>Content-Transfer-Encoding: quoted-printable

$>$

$>$ Hello Eric-

$>$ Please let this serve as my permission to use any and all information = $>$ that I have provided you to use in any papers or reports that you are = >doing. This includes spec data, specifications, test results, etc. $>$ If you have any questions please do not hesitate to call me at = $>800-734-0222$

$>$

$>$ Sincerely,

$>$ John F. Unsworth

$>$ Partner

$>$

$>$ For Aberdine, try 630-543-0870 or 630-705-2504

$>$ For ACI, try 248-848-3700

$>$ Eric, I'm sure they will give permission. I hope to have the up-dated $\Rightarrow$ sspec data on the AR 425 in the morning.

$>$

$>----=$ NextPart_000_005A_01C0270D.26684680

>Content-Type: text/hEml;

$>$ charset $="$ iso-8859-1"

>Content-Transfer-Encoding: quoted-printable $>$

$><$ ! DOCTYPE HTML PUBLIC "-//W3C//DTD W3 HTML//EN"> 


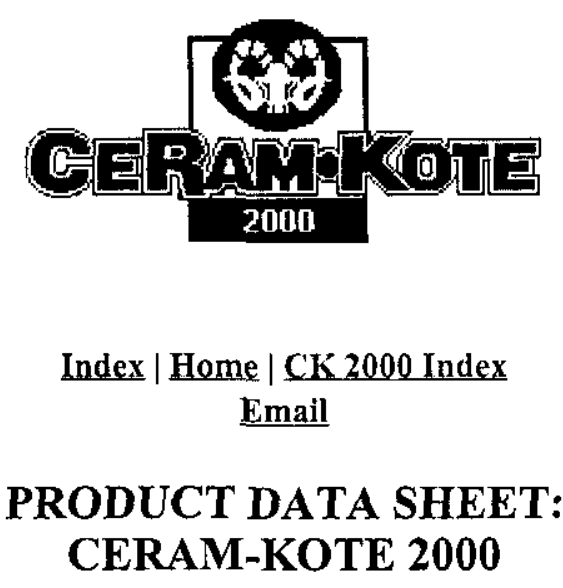

\section{Description:}

CeRam-Kote 2000 is a thin-film, spray-applied and air-dried ceramic epoxy coating system engineered to provide excellent chemical immersion service protection to all metals, fiberglass reinforced plastics, concrete and plastic substrata. CeRamKote 2000 is highly cross-linked to provide superior chemical resistance. The product may be force-cured with heat for enhanced performance in extremely harsh environments. CeRam-Kote 2000 is available in three colors: white, grey and tan.

\section{Suggested Uses:}

Secondary Containment
Harsh Chemical Environments
Hydrocarbon Service
Clarifiers
Internals in Vessels and Piping
Fuel Tanks
Wastewater Treatment Clarifiers
Brine Tanks

Internals in Tanks

Non-UV Areas

Blow Out Preventers

Petrochemical Environments

Internals in Valves

Hydrocarbon Service

Wastewater Treatment Pumps

Wastewater Treatment Lift Stations

\section{TECHNICAL DATA}

Volume Solids:

Weight Solids:

VOC:

Number of Coats:
$80 \%+/-2 \%$

$90 \%+/-2 \%$

\section{$1.56 \mathrm{lb} / \mathrm{gal}(187 \mathrm{~g} / \mathrm{l})$}

One coat, two passes, with each pass 5-6 mils (125-150 microns)

\section{Dry Film Thickness:}

CeRam.Kote 2000 should be applied holiday free at a minimum of 8 mils (200 microns) DFT with a preferred thickness of 10 mils (250 microns) DFT.

\section{Cure Time:}

A two-pass film of 8-10 mils DFT (200-250 microns) air dries to a dry touch finish within five (5) hours at $72^{\circ} \mathrm{F}\left(22.2^{\circ} \mathrm{C}\right)$ and dries to a $70 \%$ cure in fourteen (14) hours. Cure times lengthen at lower temperatures and shorten at higher temperatures. The coating should be fully cured before placing into service.

\section{Surface Preparation:}

Bonding strength depends on proper preparation of the surface to be protected for long-term performance of the product. The substrate should be free of oil, grease and salt/chloride contamination. Specifications call for a white metal (NACE 1, SSPCSP5, Swedish Standards SA-3) finish with a 1-2.5 mil (25 - 62.5 microns) anchor profile. Surface preparation should be no 
less than a near white metal (NACE 2, SSPC-SP10, Swedish Standards SA $21 / 2$ ) finish. Cleanliness is the most important step to produce a coated surface that will perform and last. Call Freecom, Inc. for surface preparation recommendations of materials such as aluminum, brass, plastic, fiberglass and/or concrete.

\section{Mixing Ratio:}

Four (4) parts of Part A to one (1) part of Part B by volume.

Seven (7) parts of Part A to one (1) part of Part B ratio by weight.

\section{Mixing:}

CeRam-Kote 2000 contains a high loading of ceramic particles which must be placed into full suspension with the epoxy resin prior to application. CeRam-Kote 2000 is packaged in two cans, Part A (base) and Part B (curing agent). Shake Part A (base) with a Cyclone air-powered shaker or mix Part A with an Edsan's Jiffler Mixer until all ceramic powders are suspended in the resin. Time required to place ceramics into suspension varies according to temperature and length of material storage time. At $72^{\circ} \mathrm{F}\left(22.2^{\circ} \mathrm{C}\right)$, generally a four (4) to six (6) minute shake will place the ceramic powders into suspension. Regardless of time needed, shake all ceramic material into suspension prior to proceeding. Failure to properly mix will keep CeRam-Kote 2000 from performing or curing properly. Check the can to assure all solids are in suspension prior to proceeding to the mixing step.

Combine Part A (base) and Part B (curing agent) and shake again until both parts are thoroughly mixed. Shaking time is temperature dependent, but a two (2) to four (4) minute shake at $72^{\circ} \mathrm{F}\left(22.2^{\circ} \mathrm{C}\right)$ should thoroughly mix the components. However, caution must be used to prevent heat buildup. No induction time is needed before application.

\section{Pot Life \& Shelf Life:}

Pot life for CeRam-Kote 2000 at $72^{\circ} \mathrm{F}\left(22.2^{\circ} \mathrm{C}\right)$ is approximately six (6) to eight (8) hours. Colder temperatures will increase the pot life and warmer temperatures will decrease the pot life. Keep cans out of direct sunlight to prevent heat buildup. CeRam-Kote 2000 has an indefinite shelf life. Preferred storage/usage is a dry enclosed area under $85^{\circ} \mathrm{F}\left(29^{\circ} \mathrm{C}\right) /$ used within two (2) years. However, if stored more than two years above $85^{\circ} \mathrm{F}\left(29^{\circ} \mathrm{C}\right)$, call Freecom Technical Support prior to use.

\section{Thinning:}

Use MEK, Isopropanol (99\%), or Acetone for any viscosity. Never thin CeRam-Kote 2000 more than $5 \%$ by volume. Thinning dilutes the high solids of CeRam-Kote 2000, creates excessive overspray and may affect the performance of the coating.

\section{Application:}

Spray apply for best results using conventional, airless, HVLP or cup gun. The air source must be dry. The compressed air source should be outfitted with air dryers as needed to supply moisture-free air. Use pressure feed equipment such as high volume, low pressure equipment or Binks 2001 spray equipment with a 563CVT needle, 63CVT fluid nozzle and 63PB air nozzle. Airless: use reversible carbide tip with orifice size of 0.019-0.021 inches. If applying with roller, use short nap, such as $1 / 4 "(.244 \mathrm{~mm})$.

After thoroughly shaking CeRam-Kote 2000, strain it with a standard paint strainer and pour CeRam-Kote 2000 into the spray equipment.

Apply a first pass of five (5) to six (6) mils (125-150 microns) WFT and allow sufficient time for solvent to flash off. At $72^{\circ} \mathrm{F}$ $\left(22.2^{\circ} \mathrm{C}\right), 30-40$ minutes is sufficient. Apply a second pass of five (5) to six (6) mils (100-125 microns) for a total DFT of eight (8) to ten (10) mils (200-250 microns). Cure time is temperature dependent.

Apply additional mils without incurring runs or sags if the finished product requires thicker coverage. Whenever possible, apply second coat in a cross-coat method.

\section{Climate:}

Use CeRam-Kote 2000 only if the substrate temperature and ambient air temperature is above $40^{\circ} \mathrm{F}\left(4.4^{\circ} \mathrm{C}\right)$. No coating should be permitted when substrate is wet from rain or dew, when surfaces are less than $5^{\circ} \mathrm{F}\left(3^{\circ} \mathrm{C}\right)$ above the dew point and holding or when relative humidity is greater than $85 \%$. Moisture will inhibit the catalyst reaction and CeRam-Kote 2000 will not cure or perform properly.

\section{Holiday Detection:}

CeRam-Kote 2000 is classified as a thin-film coating and should be tested for defects and holidays using a $671 / 2$ volt, wet sponge spark detector set at $80,000 \mathrm{ohms}$ resistance, such as a Tinker and Rasor model M-1. 
Repairs:

If application of the coating is less than seventy-two (72) hours old and has not been exposed to contamination, repair by wiping with MEK and then re-apply CeRam-Kote 2000. If contaminated or more than 72 hours old, first sand with appropriate grit sandpaper, then repeat repair process.

\section{Cleanup:}

Purge and clean spray equipment within thirty (30) minutes of the final spray. Flush equipment with MEK until solvent sprays clear. Disassemble and clean equipment to manufacturer's recommendations. Material left in spray equipment could solidify and damage equipment. Use precautionary measure applicable to any catalyzed material.

\section{Safety:}

See individual product label for safety and health data. A Material Safety Data Sheet is available upon request.

\section{Top of Page}




\section{Performance Profiles}

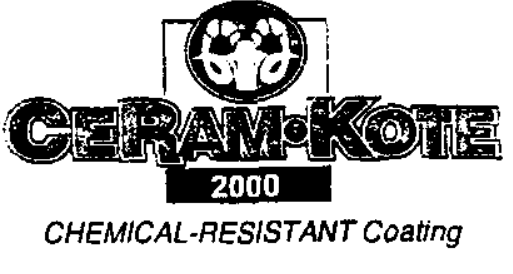

Distributor: D\&E Distributing

Customer: Chemical plant in Gainesville. Florida. USA

Applicator: Tri-State Contractors of Florida

- Several years of spills of hydrochloric acid and related wastewater had deteriorated secondary containment concrete

- Company needed protection of concrete from corrosion and erosion

- No previous coatings were able to withstand the environment

- CeRam-Kote 2000 was selected for its corrosion resistance and ceramic content

- Concrete was repaired before CeRam-Kote 2000 was applied by roller. There were no application problems

- A spill soon after application had no apparent effect to CeRam-Kote 2000 or the concrete it was protecting

Customer: City of Big Spring. Texas. USA

Applicator: Freecom. Inc.

- Corrosive waste matter and severe abrasion of $60 \mathrm{mph}$ suction intake velocity caused standard factory finish on interior of debris tank to break down. Original coating became difficult to clean and the tank began to corrode

- CeRam-Kote was requested for the tank due to previous success on wastewater applications with the city

- CeRam-Kote 2000 was recommended for the application due to. its high performance. chemical resistance and cleanability

- Recent inspection by City personnel reported the coating "looked like the day it was applied and was very easy to clean"
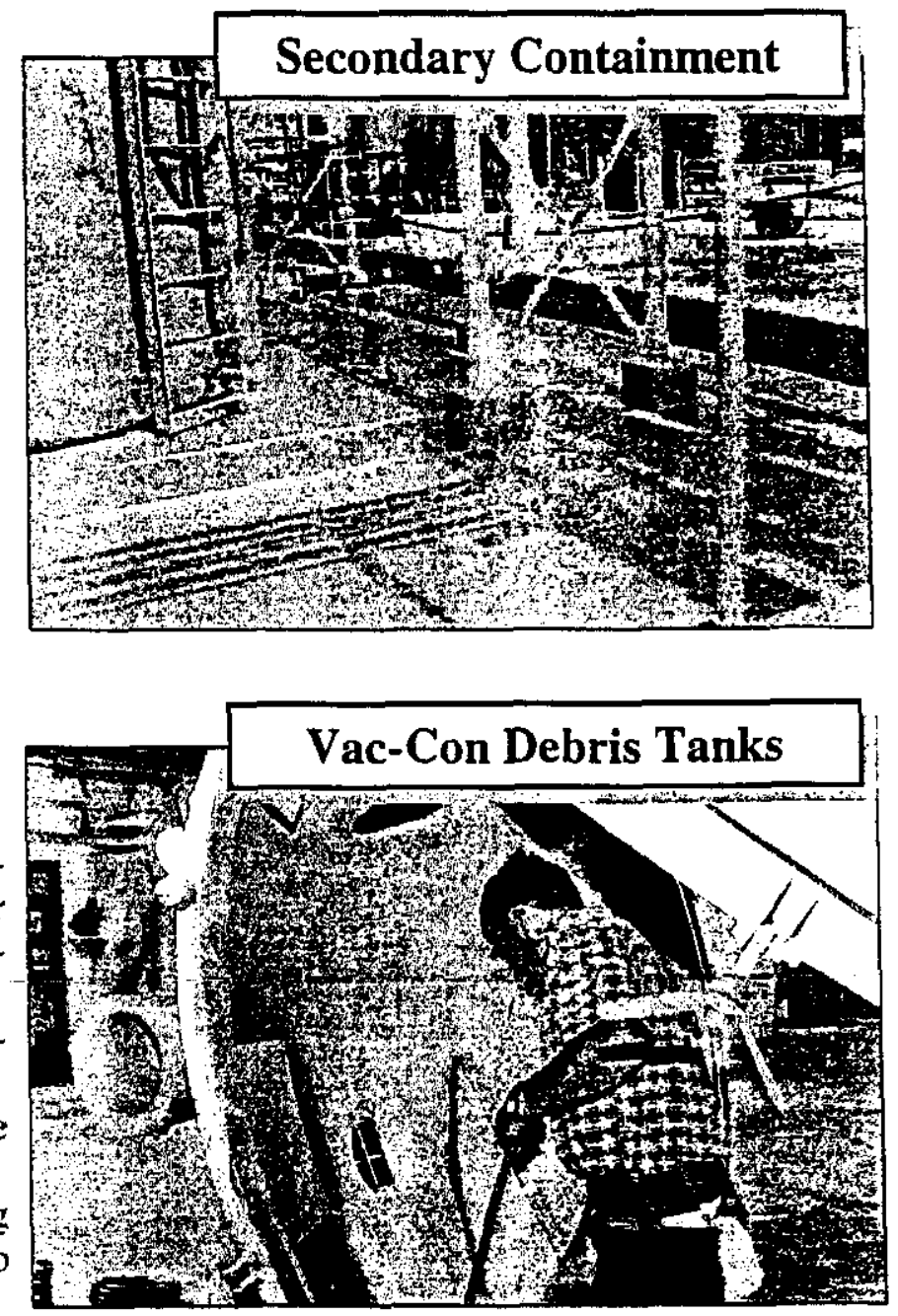

Customer: Fina Refinery. Big Spring. Texas. USA

Applicator: Spencer's Coating Specialist Co.

- Tank was internally coated six years earlier with CeRamKote $54(8$ to prolong the life of the tank. Tanks store a mixture of toluene/kerosene and/or water at $150-180^{\circ} \mathrm{F}$.

- Due to satisfaction of CeRam-Kote 54 (B) in many applications at the refinery. CeRam-Kote was again requested

- CeRam-Grout GC was applied to the properly prepared bottom third of the tank to protect against corrosion pitting

- Then CeRam-Kote 2000 was applied to the entire I.D. of the tank

- Satisfaction with the application has resulted in two more tanks coated internally with CeRam-Grout GC and CeRamKote 2000

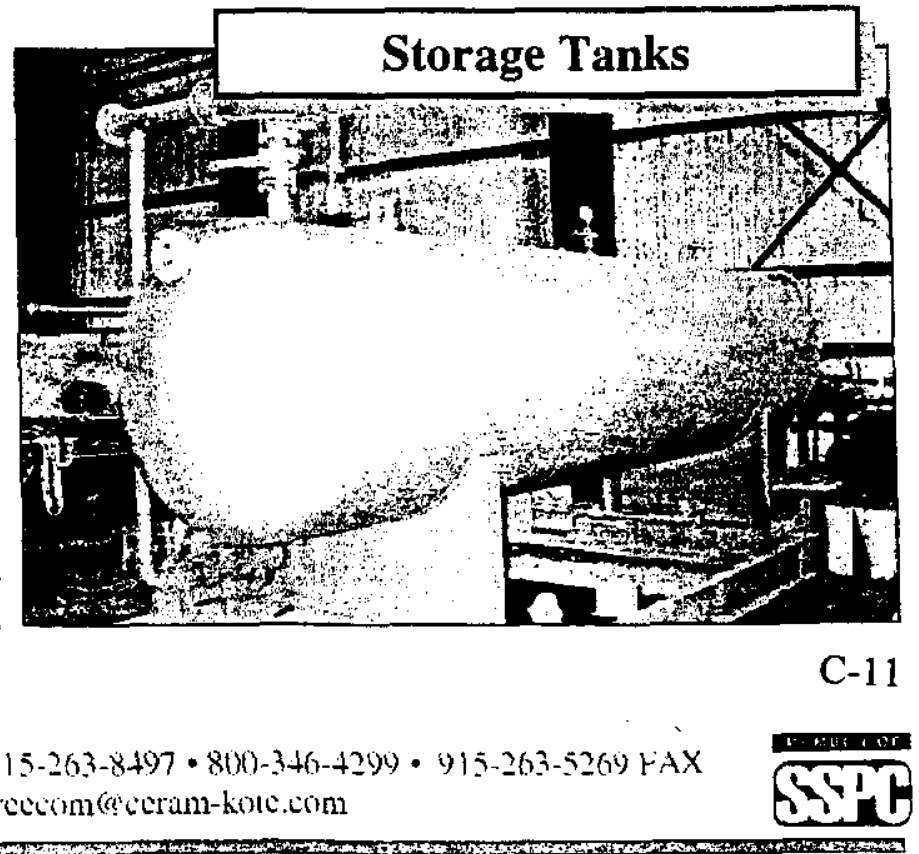

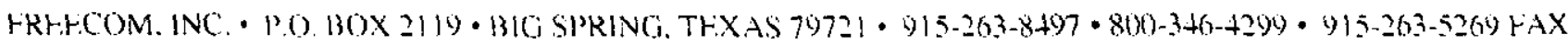

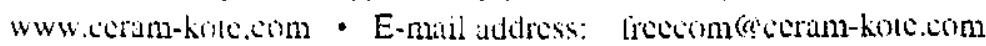




\section{CeRam-Kote 2000}

\section{Chemical Resistance Chart for Immersion Service at $72^{\circ} \mathrm{F}\left(22^{\circ} \mathrm{C}\right)$}

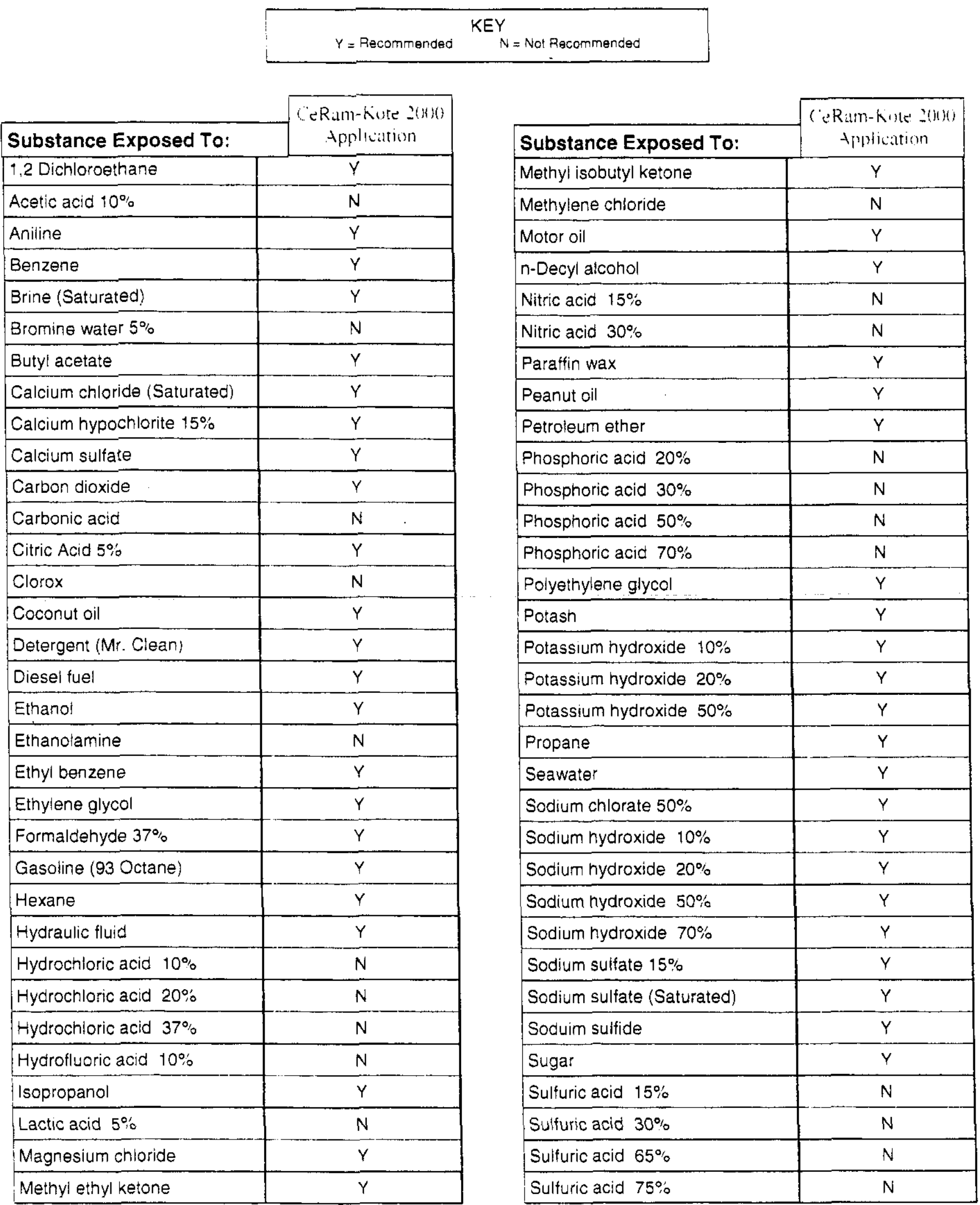




\begin{tabular}{|c|c|c|c|}
\hline & \multicolumn{2}{|c|}{$y=$ Becommended $K E Y$ N $=$ Not Pecommended } & \multirow{3}{*}{$\begin{array}{c}\text { CeRam-Kote zono } \\
\text { Application }\end{array}$} \\
\hline & \multirow{2}{*}{$\begin{array}{c}\text { CeRim-Kore } 2000 \\
\text { Applicition }\end{array}$} & \multirow[b]{2}{*}{ Substance Exposed To: } & \\
\hline Substance Exposed To: & & & \\
\hline Sweet crude & $\mathrm{Y}$ & Urea & Y \\
\hline Tall oil & Y & Vegetable oil & $Y$ \\
\hline Tetrachloroethylene & $Y$ & Vinegar & $\mathrm{N}$ \\
\hline Triethanolamine & $Y$ & Water (Distilled) & $Y$ \\
\hline Turpentine & Y & Xylene & Y \\
\hline
\end{tabular}

These tests have been conducted on cold rolled steel 1"x 6"x $1 / 4$ " panels that have been surface prepared to SSPC-SP5 (NACE 1) white metal blast and spray coated with 8-10 mil DFT (200250 microns) of CeRam-Kote 2000 . The coated panels were post-cured at $200^{\circ} \mathrm{F}\left(93.3^{\circ} \mathrm{C}\right)$ for 2 hours. All testing was done at ambient temperatures $\left[72^{\circ} \mathrm{F}\left(22^{\circ} \mathrm{C}\right)\right]$.

Under certain corrosive conditions, pigment might change color without affecting physical properties of the coating.

This information is provided to assist the specifier in the selection of an appropriate coating for an end use situation. No warranty is expressed or implied since the surface proparation, thickness of application and environmental conditions at the time of coating are beyond Freecom, Inc.'s control. The onus is on the user to determine if the product is fit for purpose. Should more information be required please contact Freecom, Inc. 


\section{CeRam-Kote 2000 \\ Chemical Resistance Chart for Secondary Containment \& Splash and Spill at $72^{\circ} \mathrm{F}\left(22^{\circ} \mathrm{C}\right)$}

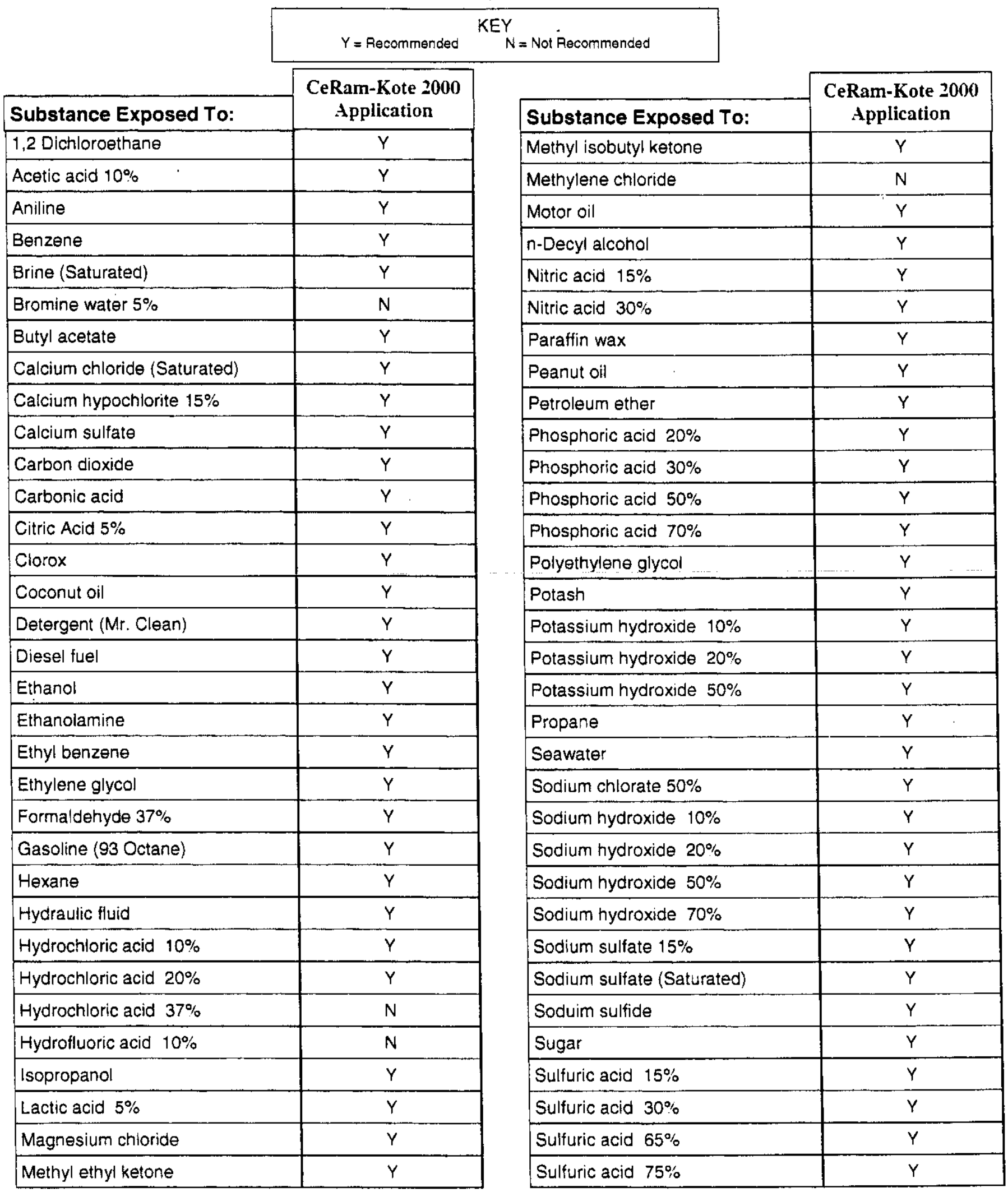




\begin{tabular}{|c|c|c|c|}
\hline & \multirow{2}{*}{\multicolumn{2}{|c|}{$\mathrm{KEY}$}} & \multirow{4}{*}{$\begin{array}{c}\text { CeRam-Kote } 2000 \\
\text { Application }\end{array}$} \\
\hline & & & \\
\hline & \multirow{2}{*}{$\begin{array}{c}\text { CeRam-Kote 2000 } \\
\text { Application }\end{array}$} & \multirow[b]{2}{*}{ Substance Exposed To: } & \\
\hline Substance Exposed To: & & & \\
\hline Sweet crude & Y & Urea & Y \\
\hline Tall oil & $Y$ & Vegetable oil & Y \\
\hline Tetrachloroethylene & $Y$ & Vinegar & Y \\
\hline Triethanolamine & $\mathrm{Y}$ & Water (Distilled) & $Y$ \\
\hline Turpentine & $Y$ & Xylene & Y \\
\hline
\end{tabular}

These tests have been conducted on cold rolled steel 1 "x6" $6^{1 / 4}$ " panels that have been surface prepared to SSPC-SP5 (NACE i) white metal blast and spray coated with 8-10 mil DFT (200 250 microns) of CeRam-Kote 2000 . The coated panels were post-cured at $200^{\circ} \mathrm{F}\left(93.3^{\circ} \mathrm{C}\right)$ for 2 hours. All testing was done at ambient temperatures $\left[72^{\circ} \mathrm{F}\left(22^{\circ} \mathrm{C}\right)\right]$.

Under certain corrosive conditions. pigment might change color without affecting physical properties of the coating.

This information is provided to assist the specifier in the selection of an appropriate coating for an end use situation. No warranty is expressed or implied since the surface proparation, thickness of application and environmental conditions at the time of coating are beyond Freecom, Inc.'s control. The onus is on the user to determine if the product is fit for purpose. Should more information be required please contact Freecom, Inc. 


\section{MATERIAL SAFETY DATA SHEET}

Section 1. Product and Company Information

MANUFACTURER: Freecom. Inc.

P.O. Box 2119

Big Spring, Texas 79721-2119

TELEPHONE: $\quad$ For information purposes 8:00 a.m. to 5:00 p.m. CDT $\begin{array}{ll}\text { (915) } 263-8497 & \text { (800) } 346-4299\end{array}$

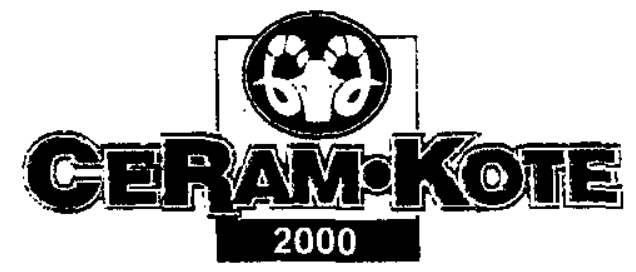

EMERGENCY: $\quad(915) 263-8497 \quad(800) 346-4299$

DATE OF PREPARATION: July 9, 1999

SUPERCEDES MSDS DATED: January 13, 1999

PRODUCT NAME: $\quad$ Cefam-Kote 2000

Section 2. Composition and Ingredient Information

\begin{tabular}{|c|c|c|c|}
\hline Common Name & Chemical Name & CAS Number & Weight \% \\
\hline \multicolumn{4}{|l|}{ PART-A CeRam-Kote 2000 (Base) } \\
\hline Ceramic Filler & Ceramic Filler & $67762-90-7$ & 43 to 78 \\
\hline & & $1344-28-1$ & \\
\hline$\cdots$ & 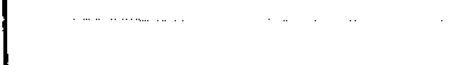 & $14807-96-6$ & \\
\hline Proprietary \#1 * \& \#2* & Epoxy Resin & $28064-14-4$ & 8 to 32 \\
\hline Isopropanol & 2-propanol & $67-63-0$ & 4 to 10 \\
\hline Methyl Ethyl Ketone & 2-butanone & $78-93-3$ & 4 to 7 \\
\hline \multicolumn{4}{|l|}{$\begin{array}{l}\text { PART-B CeRam-Kote } 2000 \\
\text { (Curing Agent) }\end{array}$} \\
\hline Benzyl Alcohol & & $100-51-6$ & $>45$ \\
\hline 4,4'--Methylenebicyclohexamine & & $1761-71-3$ & $<2$ \\
\hline Benzene-1,3-Dimethaneamine & & $1477-55-0$ & $<40$ \\
\hline
\end{tabular}

*The specific chemical identity of this ingredient is declared proprietary information under 29 CFR 1910.1200. section (i) Trade Secret. Hazard information is provided in this MSDS for this ingredient. 
Section 3. Physical Data

RPP-6855, Rev. 0

\begin{tabular}{|c|c|c|c|}
\hline Description & $\begin{array}{l}\text { CeRam-Kote } 2000 \\
\text { (catalyzed) }\end{array}$ & $\begin{array}{c}\text { PART-A: CeRam-Kote } 2000 \\
\text { (Base) }\end{array}$ & $\begin{array}{c}\text { PART-B: CeRam-Kote } 2000 \\
\text { (Curing Agent) }\end{array}$ \\
\hline Specific Gravity (kg/l) & 1.78 & 1.8369 & 1.07 \\
\hline Boiling Point & $>250^{\circ} \mathrm{F}$ & $241^{\circ} \mathrm{F}$ & $>200^{\circ} \mathrm{C}\left(392^{\circ} \mathrm{F}\right)$ \\
\hline Vapor Density $($ Air $=1)$ & $>$ Air & 3.2 & $>$ Air \\
\hline Solubility in Water & $\mathrm{N} / \mathrm{A}$ & Insoluble & Miscible \\
\hline Viscosity (centapoise) & 700 to 1,500 & 800 to 1,200 & 300 to 450 \\
\hline $\mathbf{p H}$ & Slightly Alkaline & Slightly Acidic & Alkaline \\
\hline Appearance and odor & aromatic odor & aromatic odor & Translucent, ammonical odor \\
\hline $\begin{array}{l}\text { Density - packaged } \\
\text { (on average) }\end{array}$ & $14.13 \mathrm{lb} / \mathrm{gal}(6.42 \mathrm{~kg})$ & $12.5 \mathrm{lb} / \mathrm{gal}(5.68 \mathrm{~kg})$ & $1.63 \mathrm{lbs} /$ quart $(0.74 \mathrm{~kg})$ \\
\hline Total Volatiles & 9 to 11 & 10 to 12 & Nil \\
\hline Non-Volatiles & 89 to 91 & 88 to 90 & $100 \%$ \\
\hline VOC content & $\begin{array}{l}1.56 \mathrm{lbs} / \mathrm{gal}(187 \mathrm{~g} / \mathrm{l}) \text { less } \\
\text { water }\end{array}$ & $1.8 \mathrm{lb} / \mathrm{gal}(215.7 \mathrm{~g} / \mathrm{l})$ less water & $0 \mathrm{lbs} / \mathrm{gal}(0 \mathrm{~g} / \mathrm{l})$ \\
\hline
\end{tabular}

Section 4. Fire Fighting Measures

\begin{tabular}{|c|c|c|}
\hline Description & PART A: CeRam-Kote 2000 (Base) & $\begin{array}{l}\text { PART-B: CeRam-Kote } 2000 \\
\text { (Curing Agent) }\end{array}$ \\
\hline Flashpoint & $<70^{\circ} \mathrm{F}\left(21.1^{\circ} \mathrm{C}\right)$ & $>200^{\circ} \mathrm{F}\left(93.3^{\circ} \mathrm{C}\right)$ \\
\hline Flammable Limits & $\begin{array}{l}\text { LFL: } 1.0 \% \\
\text { UFL: } 7.0 \%\end{array}$ & $\begin{array}{lll}\ldots & \ldots & \cdots\end{array}$ \\
\hline Auto Ignition Temperature & $750^{\circ} \mathrm{F}\left(399^{\circ} \mathrm{C}\right)-$ IPA & N/A \\
\hline Extinguishing Media & Foam, $\mathrm{CO}_{2}$, dry chemical, water fog & $\begin{array}{l}\text { Foam, } \mathrm{CO}_{2} \text {, or dry chemical. A water } \\
\text { spray can also be used. }\end{array}$ \\
\hline $\begin{array}{l}\text { Unusual Fire and Explosion } \\
\text { Hazards }\end{array}$ & $\begin{array}{l}\text { Do not apply to hot surfaces. Keep away } \\
\text { from heat, sparks or open flame. Keep con- } \\
\text { tainers tightly closed. Closed containers may } \\
\text { explode when exposed to extreme heat. Do } \\
\text { not store or mix with strong oxidants. }\end{array}$ & $\begin{array}{l}\text { Decomposition and combustion prod- } \\
\text { ucts may be toxic. }\end{array}$ \\
\hline Fire Fighting Instructions & $\begin{array}{l}\text { Use air-supplied rescue equipment for en- } \\
\text { closed areas. Full stream water may be un- } \\
\text { suitable as extinguishing method, but is help- } \\
\text { ful in keeping nearby containers cool. Avoid } \\
\text { spreading burning liquid with water used for } \\
\text { cooling. }\end{array}$ & Use self contained breathing apparatus. \\
\hline $\begin{array}{l}\text { Hazardous Combustion } \\
\text { Products }\end{array}$ & $\begin{array}{l}\text { Primary combustion products are carbon } \\
\text { monoxide, carbon dioxide and low molecular } \\
\text { weight hydrocarbons. Other undetermined } \\
\text { compounds could be released in small quan- } \\
\text { tities. }\end{array}$ & $\begin{array}{l}\text { Carbon monoxide, carbon dioxide, alde- } \\
\text { hydes and nitrogen oxides. }\end{array}$ \\
\hline
\end{tabular}




\section{Section 5. Reactivity Data}

\begin{tabular}{|c|c|c|}
\hline Description & PART-A: CeRam-Kote 2000 (Base) & PART-B: CeRam-Kote 2000 \\
\hline Stability & Avoid high heat. & Stable. \\
\hline Incompatibility & Avoid organic peroxides and oxidizers. & $\begin{array}{l}\text { Avoid strong oxidizing agents, acids, } \\
\text { copper and its alloys. }\end{array}$ \\
\hline $\begin{array}{l}\text { Hazardous Decomposition } \\
\text { Products }\end{array}$ & $\begin{array}{l}\text { Various hydrocarbon fragments. See section } \\
4 \text { of MSDS for combustion products state- } \\
\text { ment. }\end{array}$ & $\begin{array}{l}\text { Carbon monoxide, carbon dioxide, al- } \\
\text { dehydes, and nitrogen oxides. }\end{array}$ \\
\hline Hazardous Polymerization & $\begin{array}{l}\text { May occur. Avoid excessive heat, contami- } \\
\text { nation and prolonged storage above } 70^{\circ} \mathrm{F}\end{array}$ & Will not occur. \\
\hline
\end{tabular}

Section 6. Health and Safety

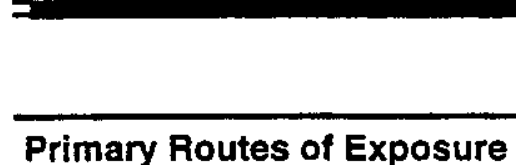

Potential Health Effects
Medical Conditions Aggravated by Exposure

\section{PART-A: CeRam-Kote 2000 (Base)}

Inhalation, skin, eye

Acute (short term): This product if inhaled may cause nose, throat, and mucous membrane irritation and possible central nervous system effects including headaches, nausea, vomiting, dizziness, drowsiness, loss of coordination, impaired judgment and general weakness. It may cause moderate irritation to the skin with dryness, cracking and possible dermatitis with prolonged or repeated contact. Direct eye contact with this product may cause immediate irritation to the eyes with redness, burning, tearing and blurred vision. It may cause mouth, throat and gastrointestinal irritation, nausea, vomiting and diarrhea if ingested. Aspiration of material into the lungs can cause chemical pneumonitis which can be fatal.

Chronic (long term): Prolonged or repeated skin contact may result in irritation, dermatitis marked by rough, dry, cracking skin. Contact with the epoxy resin may cause sensitization. In lab animals, overexposure by inhalation to MIBK has been reported to cause liver and kidney abnormalities, and lung and brain damage. Kidney disorders have been reported from human ingestion of isopropanol.

Persons with a history of chronic respiratory disease, skin disease or central nervous system disorders may be at increased risk for worsening their conditions from exposure to this product.
PART-B: CeRam-Kote 2000 (Curing Agent)

Dermal

Overexposure effects: Direct or prolonged skin or eye contact can cause skin and eye burns. Swallowing liquid can burn mouth and cause nausea, vomiting, diarrhea, abdominal pain and collapse. Can cause allergic skin and respiratory reactions after repetitive exposure. Animal studies on component (s) have shown effects on liver and fetus.

Persons with a history of allergic conditions may be at increased risk for wors. ening their conditions from exposure to this product. 


\begin{tabular}{|c|c|c|}
\hline Description & $\begin{array}{l}\text { CeRam-Kote } 2000 \text { (Mixed) and/or } \\
\text { PART-A: CeRam-Kote } 2000 \text { (Base) }\end{array}$ & $\begin{array}{l}\text { PART-B: CeRam-Kote } 2000 \\
\text { (Curing Agent) }\end{array}$ \\
\hline Inhalation & $\begin{array}{l}\text { Remove individual to fresh air. If breathing is } \\
\text { difficult, administer oxygen and obtain medi- } \\
\text { cal aid. }\end{array}$ & $\begin{array}{l}\text { Remove to fresh air. Give oxygen if } \\
\text { breathing is difficult. }\end{array}$ \\
\hline Eyes & $\begin{array}{l}\text { Flush with running water for at least } 15 \mathrm{~min} \text { - } \\
\text { utes. Seek medical attention. }\end{array}$ & $\begin{array}{l}\text { Immediately flush eyes with water for at } \\
\text { least } 15 \text { minutes. Get immediate medi- } \\
\text { cal assistance. }\end{array}$ \\
\hline Skin & $\begin{array}{l}\text { Wash with flowing water. Rernove contami- } \\
\text { nated clothing and launder before re-wearing. } \\
\text { If irritation persists, seek medical attention. }\end{array}$ & $\begin{array}{l}\text { Promptly wash thoroughly with mild } \\
\text { soap and water. }\end{array}$ \\
\hline Ingestion & $\begin{array}{l}\text { DO NOT induce vomiting. Seek medical at- } \\
\text { tention. }\end{array}$ & $\begin{array}{l}\text { DO NOT induce vomiting. Seek medi- } \\
\text { cal attention. }\end{array}$ \\
\hline
\end{tabular}

Section 8. Exposure Controls and Personal Protection

\section{Exposure controls}

\begin{tabular}{l|l|l}
\hline \multicolumn{1}{c|}{ INGREDIENT } & \multicolumn{1}{|c}{ OSHA PEL (8-HR TWA) } & \multicolumn{1}{c}{ ACGIH TLV (8-HR TWA) } \\
\hline *Proprietary \#1, \#2 & $\begin{array}{l}5 \mathrm{mg} / \mathrm{m}^{3} \text { (respirable fraction) } \\
15 \mathrm{mg} / \mathrm{m}^{3} \text { (total fraction) } \\
\text { Methyl Ethyl Ketone }\end{array}$ & $10 \mathrm{mg} / \mathrm{m}^{3}$ \\
Isopropanol & $400 \mathrm{PPM}$, STEL 300 PPM & $200 \mathrm{PPM}$, STEL 300 PPM \\
Ceramic Filler & $2 \mathrm{mg} / \mathrm{m}^{3}$ & $400 \mathrm{PPM}$, STEL 500 PPM \\
Benzyl Alcohol & $\mathrm{N} / \mathrm{E}$ & $2 \mathrm{mg} / \mathrm{m}^{3}$ \\
4,4-Methylenebicyclohexamine & $\mathrm{N} / \mathrm{E}$ & $\mathrm{N} / \mathrm{E}$ \\
Benzene-1,3-Dimethaneamine & $\mathrm{N} / \mathrm{E}$ & $\mathrm{N} / \mathrm{E}$ \\
& & $\mathrm{N} / \mathrm{E}$
\end{tabular}

\section{Personal Protection}

\begin{tabular}{|c|c|c|}
\hline Description & $\begin{array}{l}\text { CeRam-Kote 2000(Mixed) and/or } \\
\text { PART-A: CeRam-Kote } 2000 \text { (Base) }\end{array}$ & $\begin{array}{l}\text { PART-B: CeRam-Kote } 2000 \\
\text { (Curing Agent) }\end{array}$ \\
\hline Engineering controls & $\begin{array}{l}\text { General dilution ventilation and/or exhaust } \\
\text { ventilation should be provided as necessary } \\
\text { to maintain exposures below regulatory limits. }\end{array}$ & $\begin{array}{l}\text { Good general mechanical ventilation is } \\
\text { recommended. Local exhaust recom- } \\
\text { mended. }\end{array}$ \\
\hline Respiratory Protection & $\begin{array}{l}\text { If irritation occurs, or if the TLV or PEL is ex- } \\
\text { ceeded, use a NIOSH/OSHA approved air } \\
\text { purifying respirator with organic vapor car- } \\
\text { tridges or canisters, or supplied air respira- } \\
\text { tors. Use respiratory protection in accor- } \\
\text { dance with your company's respiratory pro- } \\
\text { gram, local regulations or OSHA regulations } \\
\text { under } 29 \text { CFR } 1910.134 \text {. }\end{array}$ & $\begin{array}{l}\text { Organic chemical cartridge respirator, if } \\
\text { needed. }\end{array}$ \\
\hline Dermal Protection & $\begin{array}{l}\text { Loose fitting long sleeved shirt, long pants } \\
\text { and chemical resistant gloves such as neo- } \\
\text { prene or natural rubber gloves. }\end{array}$ & Wear impervious rubber gloves. \\
\hline Eye Protection & Chemical protective goggles. & Splash-proof chemical goggles. \\
\hline
\end{tabular}


Section 9. Spills, Leaks, and Disposal

\begin{tabular}{|c|c|c|}
\hline Description & $\begin{array}{c}\text { CeRam-Kote } 2000 \text { (Mixed) andior PART-A: } \\
\text { Cefam-Kote } 2000 \text { (Base) }\end{array}$ & $\begin{array}{l}\text { PART-B: Cefam-Kote } 2000 \\
\text { (Curing Agent) }\end{array}$ \\
\hline Land Spill & $\begin{array}{l}\text { Prevent material from entering sewers or wa- } \\
\text { terways. Remove all sources of ignition } \\
\text { (flames. hot surfaces, and electrical static or } \\
\text { frictional sparks). Ventilate area. Absorb } \\
\text { with inert materials (vermiculite or sand) and } \\
\text { place in a closed container for disposal as } \\
\text { solid waste. Wash area well with trisodium } \\
\text { phosphate and water. }\end{array}$ & $\begin{array}{l}\text { Avoid all personal contact. Take up with ab- } \\
\text { sorbent material. Shovel into closeable con- } \\
\text { tainers. Fush contaminated area with water. } \\
\text {. }\end{array}$ \\
\hline Water Spill & $\begin{array}{l}\text { Material is mostly insoluble. The material will } \\
\text { sink. Notify local environmental, health and } \\
\text { wildlife authorities, and water intake opera- } \\
\text { tors. Contain with booms and minimize } \\
\text { spread on water. Disperse any remaining } \\
\text { residue to reduce aquatic harm. }\end{array}$ & $\begin{array}{l}\text { This product is miscible in water. That } \\
\text { means it is totally dissolved when mixed with } \\
\text { water. Due to this property, this is consid- } \\
\text { ered a marine pollutant; however, when } \\
\text { mixed with Part A, and after the product } \\
\text { cures, it is totally inert. }\end{array}$ \\
\hline Air Release & $\begin{array}{l}\text { Spills of this material may release volatile or- } \\
\text { ganic compounds into the air. Spills should } \\
\text { be cleaned or covered to prevent volatiliza- } \\
\text { tion. }\end{array}$ & $\begin{array}{l}\text { This product reacts with air by absorbing the } \\
\text { moisture out of the air. Take up with absorb- } \\
\text { ent material. Shovel into closeable contain- } \\
\text { ers. Flush contaminated area with water. }\end{array}$ \\
\hline $\begin{array}{l}\text { Disposal } \\
\text { Considerations }\end{array}$ & $\begin{array}{l}\text { Characteristic hazardous waste (D001) due } \\
\text { to ignitability. }\end{array}$ & $\begin{array}{l}\text { Not a hazardous waste under RCRA ( } 40 \\
\text { CFR 261). }\end{array}$ \\
\hline
\end{tabular}
Section 10. Transport Information

\begin{tabular}{|c|c|c|}
\hline Description & $\begin{array}{c}\text { PART-A: CeRam-Kote } 2000 \\
\text { (Base) }\end{array}$ & $\begin{array}{l}\text { PART-B: CeRam-Kote } 2000 \\
\text { (Curing Agent) }\end{array}$ \\
\hline DOT//ATA/MDG Shipping Names & Resin Solution & $\begin{array}{l}\text { Amines, liquid, corrosive, n.o.s. } \\
\text { [Benzene-1,3-diamethaneamine (MXDA)] }\end{array}$ \\
\hline Hazard Class or Division & 3.2 & 8 \\
\hline Secoṇdary & None & None \\
\hline UN Identification Number & UN 1866 & UN 2735 \\
\hline Packing Group & III & III \\
\hline Label(s) required & Flammable (3) & Corrosive (8) \\
\hline \multicolumn{3}{|l|}{ Quantity Limitations (Air only) } \\
\hline Passenger Aircraft & 60 liters (15 gallons) & 5 liters ( 1.25 gallons) \\
\hline Cargo Aircraft & 220 liters (58 gallons) & 60 liters ( 15 gallons) \\
\hline \multicolumn{3}{|l|}{ Packing instructions } \\
\hline Passenger Aircraft & 309 & 818 \\
\hline Cargo Aircraft & 310 & 820 \\
\hline \multicolumn{3}{|c|}{ Section 11. Regulatory Information } \\
\hline Description & $\begin{array}{c}\text { PART-A: CeRam-Kote } 2000 \\
\text { (Base) }\end{array}$ & $\begin{array}{l}\text { PART-B: CeRam-Kote } 2000 \\
\text { (Curing Agent) }\end{array}$ \\
\hline ERG Number & & $\mathrm{N} / \mathrm{A}$ \\
\hline TSCA Status & ach ingredient is on the inventory & Chemical components listed on inventory \\
\hline SARA Title III & $\begin{array}{l}\text { ec 304: N/A } \\
\text { ec 313: N/A }\end{array}$ & Sec 313: none \\
\hline Clean Air Act & A & Lana \\
\hline
\end{tabular}


PART A

Part A

PART B
CURE TANK LINING

B69WQ2101

B69AQ2102

B60VQ2100
OfF White

GraY

HARdener

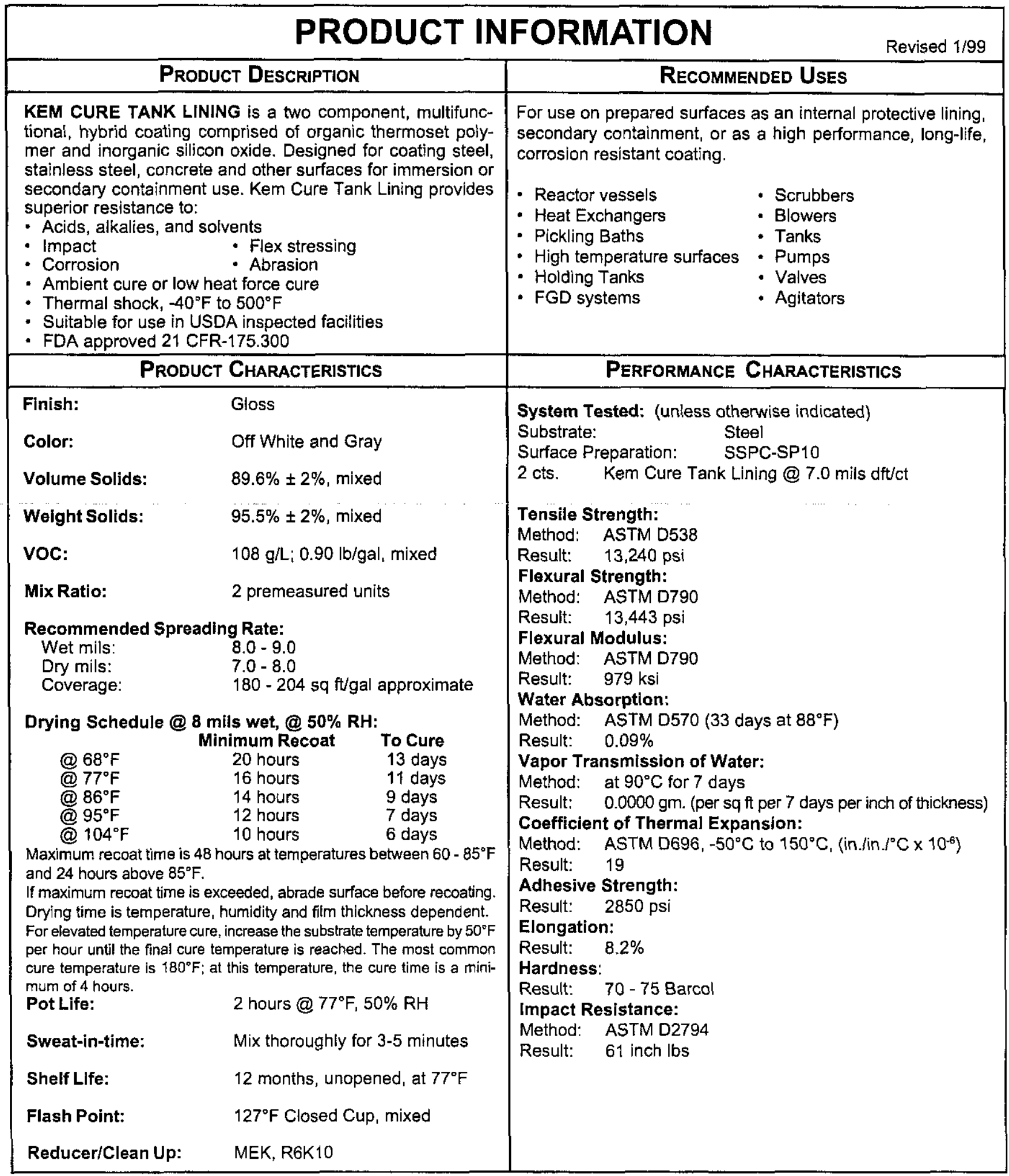


Part A

PART A

PART B .

\section{Con}

\section{PRODUCT INFORMATION}

\begin{tabular}{|c|c|}
\hline & Recommended Systems \\
\hline $\begin{array}{l}\text { Steel: } \\
2 \text { cts. }\end{array}$ & Kem Cure Tank Lining @ $7.0-8.0$ mils dft/ct \\
\hline $\begin{array}{l}\text { Stainles } \\
2 \text { cts. }\end{array}$ & $\begin{array}{l}\text { ss Steel: } \\
\text { Kem Cure Tank Lining @ } 7.0-8.0 \text { mils dft/ct }\end{array}$ \\
\hline $\begin{array}{l}\text { Concre } \\
1 \mathrm{ct} . \\
1-2 \mathrm{cts} . \\
2 \mathrm{cts} \text {. }\end{array}$ & $\begin{array}{l}\text { te \& Masonry: } \\
\text { Corobond 100 Epoxy Primer/Sealer } \\
\text { @ 4.0 - 6.0 mils dft } \\
\text { Kem Cati-Coat Epoxy Filler/Sealer @ } 10.0-30.0 \\
\text { mils dft/ct, as required to fill voids and bugholes to } \\
\text { provide a continuous substrate. } \\
\text { Kem Cure Tank Lining @ } 7.0-8.0 \text { mils dft/ct }\end{array}$ \\
\hline
\end{tabular}

Surface must be clean, dry, and in sound condition. Remove all oil, dust, grease, dirt, loose rust, and other foreign material to ensure good adhesion.

Refer to product Application Bulletin for detailed surface preparation information.

Minimum recommended surface preparation:

Iron \& Steel, immersion: $\quad$ SSPC-SP5, 3-4 mil profile

Stainless Steel, immersion: $\quad$ SSPC-SP5, 3-4 mil profile

Concrete \& Masonry:

Cures, clean, dry, sound, brush blasted

\section{Color Avallability/Tinting}

Do not tint.

Color: Off White and Gray

\begin{tabular}{|c|c|}
\hline \multicolumn{2}{|c|}{ APPLICATION CONDITIONS } \\
\hline $\begin{array}{l}\text { Temperature: } \\
\text { Relative humidity: } \\
\text { Refer to product } A \\
\text { information. }\end{array}$ & $\begin{array}{l}60^{\circ} \mathrm{F} \text { minimum, } 110^{\circ} \mathrm{F} \text { maximum } \\
\text { (air, surface, and materiai) } \\
\text { At least } 5^{\circ} \mathrm{F} \text { above dew point } \\
70 \% \text { maximum }\end{array}$ \\
\hline \multicolumn{2}{|c|}{ ORDERING INFORMATION } \\
\hline Packaging: & 1 gallon and 5 gallon kits \\
\hline \multicolumn{2}{|c|}{ SAFETy Precautions } \\
\hline $\begin{array}{l}\text { Refer to the MSDS } \\
\text { Published technical } \\
\text { without notice. Cor } \\
\text { for additional techr }\end{array}$ & $\begin{array}{l}\text { heet before use. } \\
\text { ata and instructions are subject to change } \\
\text { act your Sherwin-Williams representative } \\
\text { al data and instructions. }\end{array}$ \\
\hline
\end{tabular}

The systems listed above are representative of the product's use. Other systems may be appropriate. 


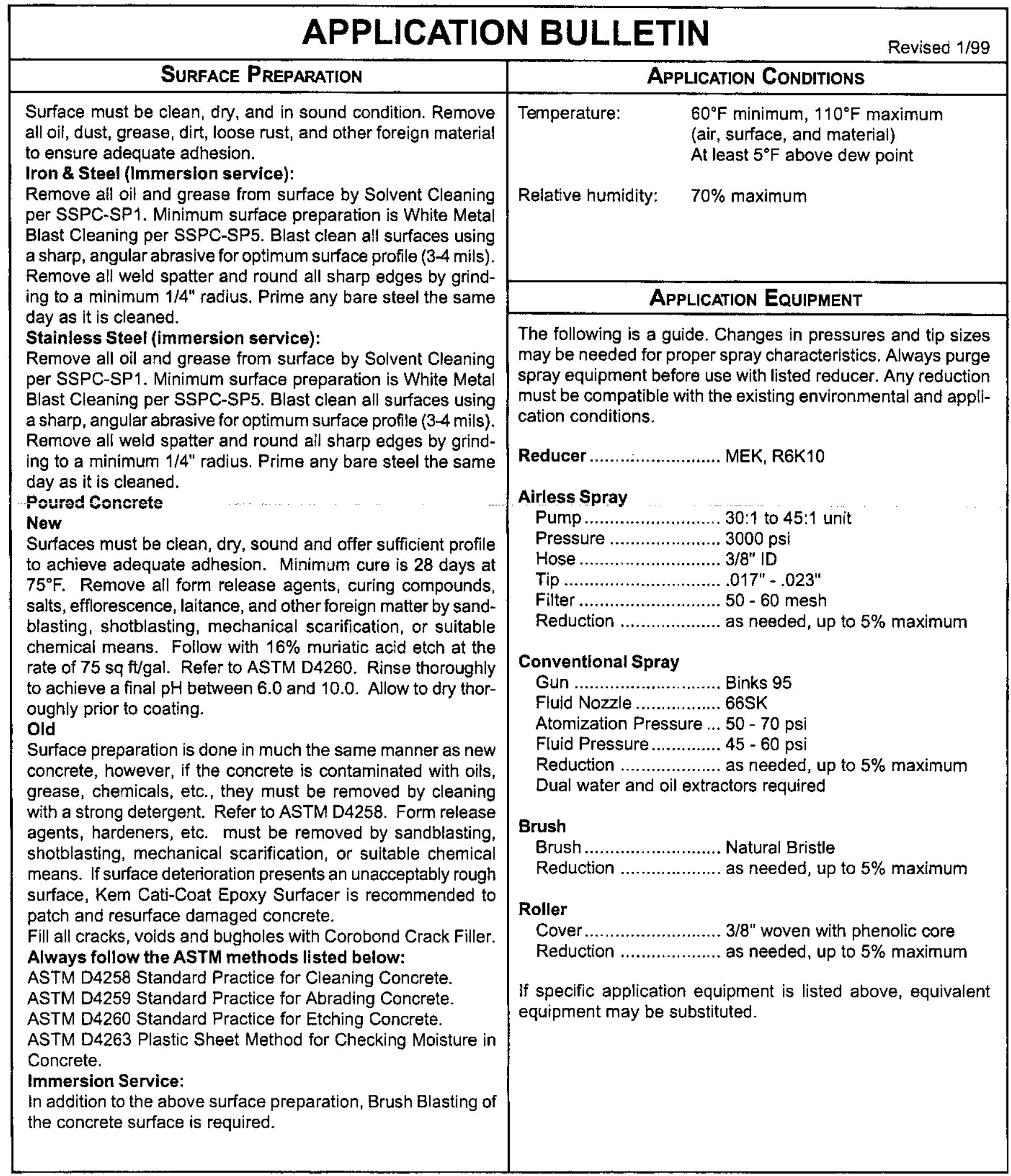


RPP-6855, Rev. 0

\section{SHERUI

\section{KEM $^{\circledR}$ CURE TANK LINING \\ PART A B69WQ2101 \\ PART A B69AQ2102 \\ PART B B60VQ2100 \\ OfF White \\ GRAY \\ HARDENER}

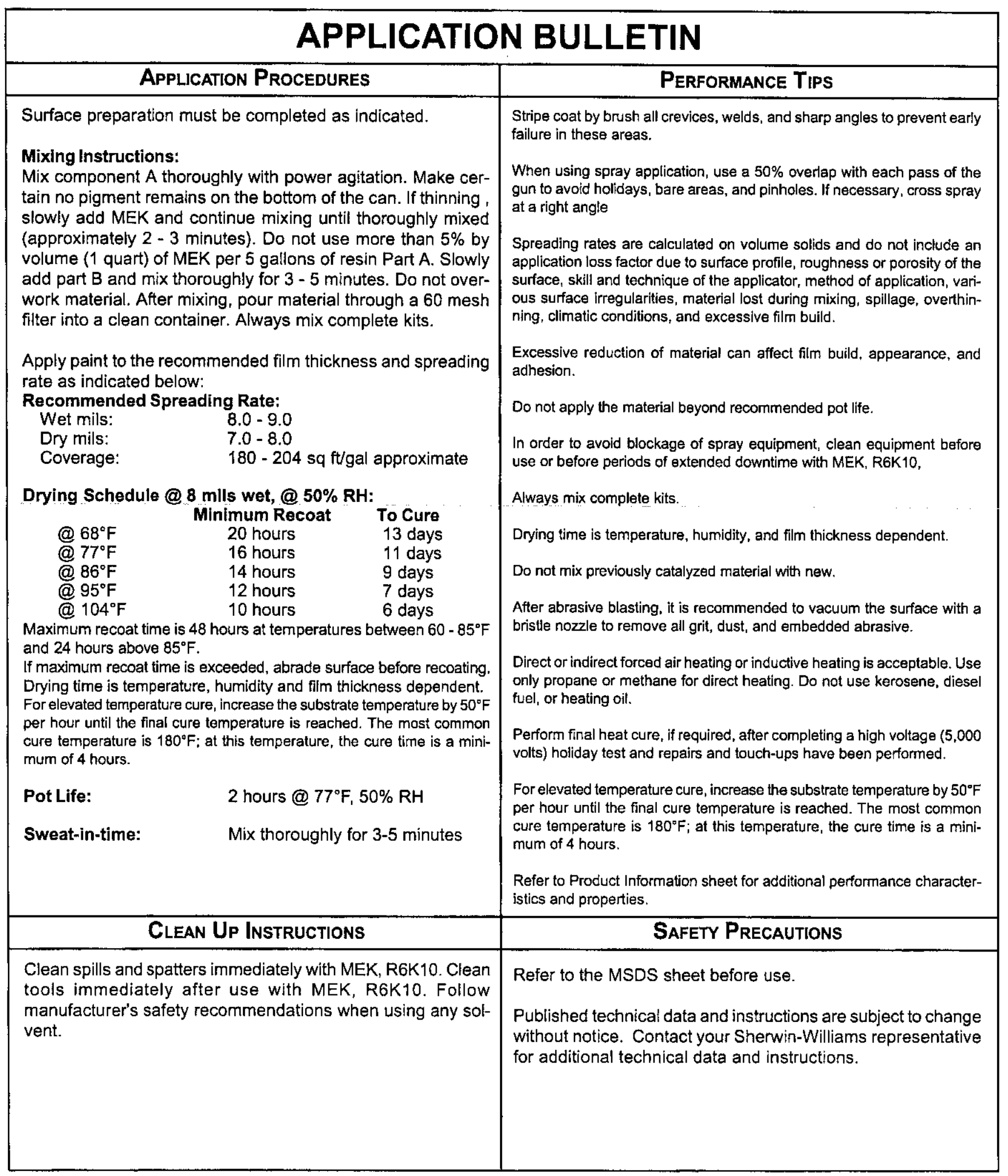


ัํํํำ

○े

on

혼

[I]

文资要

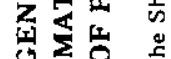

[1.

(T)

c)

|

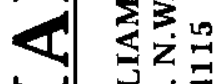

걸

Q1)

安

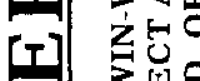

5

उํำ

学安

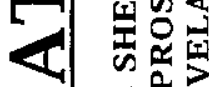

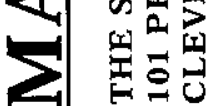

|

à

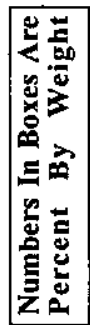

i

$\overbrace{\substack{0 \\ 0}}^{5}$

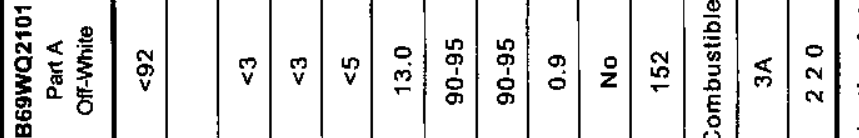

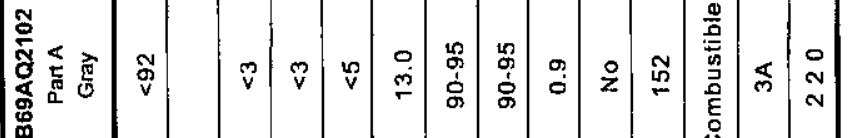

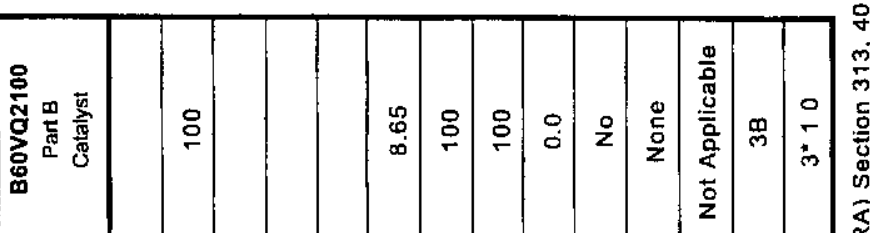

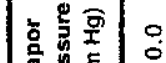

只 $\begin{aligned} & 0 \\ & 0\end{aligned}$

\begin{tabular}{lllllll}
\hline & & & & & & \\
\hline
\end{tabular}

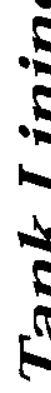

这

.

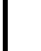

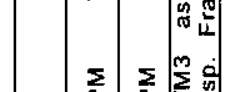

.

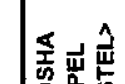

:

a $\frac{a}{2} \frac{\text { के }}{2}$

v

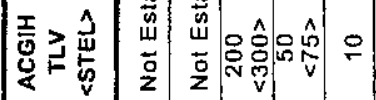

E

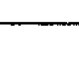

Er 1

$S \mid z \frac{z}{z}$

$0 \mid \begin{array}{lll}2 \\ 0\end{array}$

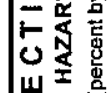

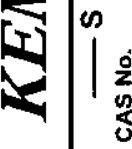

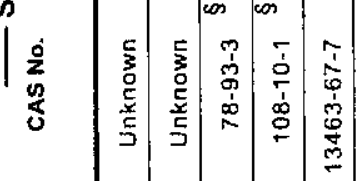



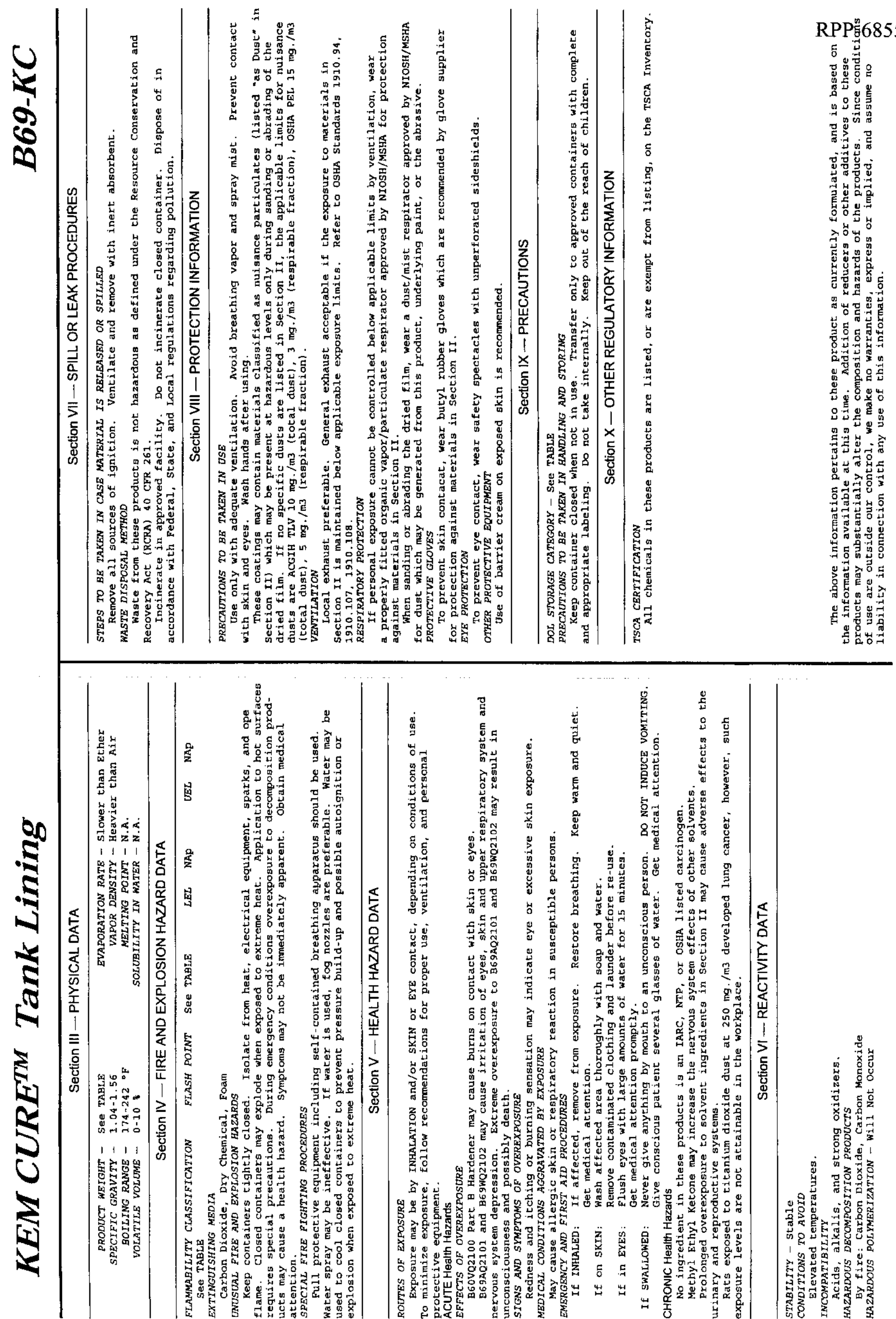
st

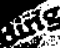

YHIELD SS-100 $\mathrm{m}$ is a

te-of-the-art. high pertormance, sprayed. plural component pure polyurea elastomer. This system is based on amine-terminated polyether resins, amine chair extenders and MDI prepolymers. It provides a fiexible, tough, resilient monolithic mernbrane with good water and chemical resistance.

\section{RECCMMENDEDUSES}

- Earthen containment lining used with or without geotextile fabric.

- Liner for concrete tanks. ponds, lagoons, reservoirs, cikes, irrigation ditches. iunnels, barges, etc.

- Membrane covering used with geotextile fabrics to

capsulate contaminates in ـndfill applications.

- Replace or repair failed existing sheet membrane liners.

- Steel tanks, silos and steel pipes.

- Protective elastomer for sprayed-in-place urethane foam.

- Encapsulant for styrofoam and other ypes of flotation.

- Encapsulant for asbestos \& lead paint.

- Truckbed and undercarriage liner.

- Protective coatings for decorative products such as props, waterialls, signage, statues. highway markings. elc.

\section{FEATURES}

- POLYSHIELO SS-100 $\mathrm{m}$ is a seamless membrane that can be handled and walked on within 1 minute or less from

- time it is sprayed.

Unlike polyurethanes and ewoxies. PCLYSHIELD SS$100^{\text {NA }}$ is Hycropinodic and thereicre arfec:ed ver! little oy camp or cold suriaces. It can be sorayed direcily on water or ice and has zeen sprayed at

\section{Technical Data \\ POLYSHIELD SS-100 $\mathrm{TM}$}

$40^{\circ} \mathrm{F}\left(40^{\circ} \mathrm{C}\right)$ with minimal effect on tack free time.

- Due to its almost instantaneous gel time. POLYSHIELD SS-100 10 can be built up to any thickness in one application including vertical and overtiead sur. faces. Eliminates need for multi-coat applications.

- POLYSHIELD SS-100 $\mathrm{nt}$ has high temperature stability with a working temperature of up to $250^{\circ} \mathrm{F}\left(121^{\circ} \mathrm{C}\right)$ with intermittent temperatures up to $300^{\circ} \mathrm{F}\left(149^{\circ} \mathrm{C}\right)$.
PCLYSHIELD SS. $100 \mathrm{~N}$ is $100 \%$ solids. No solvents, no V.O.C.'s.

\section{COLORS}

- It should be noted that POLYSHIELD SS-100 $\mathrm{m}$ is an aromatic polyurea, therefore. as with all aromatics over a period of time color change as well as superficial oxidation will occur.

- Aliohatic urethane and other suitable top coats can be used where long-term aesthetics are of critical importance.

\section{Typical Physical Properties}

\begin{tabular}{|c|c|c|}
\hline & WET & \\
\hline Solld & Buwoinht & $100 \%$ \\
\hline & By volume & $100 \%$ \\
\hline & V.O.C. & 0 \\
\hline & Coverege & 100 sq. ft./16 dry mils /gat. \\
\hline & Weight per gal & $\begin{array}{l}8.55 \mathrm{lbs}(3.87 \mathrm{~kg}) \text { Approx. } \\
\text { Combined weight }\end{array}$ \\
\hline sens & & \\
\hline & $\begin{array}{l}\text { A component cps } \\
\text { B component cps }\end{array}$ & $\begin{array}{l}500 \text { approx@ } 77^{\circ} \mathrm{F}\left(25^{\circ} \mathrm{C}\right) \\
550 \text { approx@ } 77^{\circ} \mathrm{F}\left(25^{\circ} \mathrm{C}\right)\end{array}$ \\
\hline
\end{tabular}

Curetimes

Gel Less than two seconds

Teckitee $8-12$ seconds

Post cure 12 hours

Recoat 0.12 hours

Clean up solvent DPM. NMP, Polyclean

Tninner Notused

'DRY

Stress/Tensile strength Elongation

Permeatlity MVT as $30 \mathrm{mils}(0.8 \mathrm{~mm})$ Harciness

Harciness

$100 \%$ Modulus $300 \%$ Modulus

Tear resistance

Service :emcerature

Abrasion resistance

$i \mathrm{~kg}, 1000$ rev, $\mathrm{H}-18$ wheels

Flame Spread at 20 mils

Smoke Density at 20 mils

Weatherability

2500 psi $\perp 100$ (172 bar)

$265 \% \pm 50$

0.024 US Perms $11 .+$ ngifas $\mathrm{m}^{*}$

$50 \pm 5$ shore $D$

$90 \pm 5$ shore $\lambda$

$1600 \pm 100$ psi ( 110 bar)

$1925 \div 100$ psi(132 bar)

$430 \pm 50 \mathrm{PLI}$

$60^{\circ} \approx: 0300^{\circ}=1-50^{\circ} 0: 0150 \circ$

\section{$110 \mathrm{mg}$ lost}

$10^{\circ}$

5

no evidence of fallure after 3000 hrs (GLiV)

Samoles for tests serayed wiGusmer H.ll $\bigcirc$ :0CO psi l69 bar:

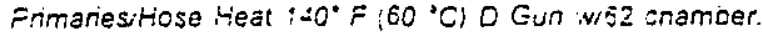

-Prcessing aaramerers as :ve!l as pigment hyes and quantiby wil
RPP-68'55, Rev. 0

GENERALAPPLICATCN INSTRUCTIONS

- Apply POLYSHIELD SS$100^{* N}$ to only clean, dry sound surfaces free of lcose par. ilcles or other foreign matter. A primer may be required. sucject to type and/or conditicn of the substrate. Consult technical servica personnel for specific primer reccmmendations and substrate preparation procedures.

- PCLYSHIELO SS-1CONA can be sprayed over a broad range of ambient and substrate temceratures. The irritations are in the ability of the acolication ecuipment to provide adequate material pressure and heat. Contac: lechnical service personnel for specific recommencations. pricing and availacility of spray and auxiliary equipment.

- It is recommended that POLYSTIEID SS- $100^{\text {*n }}$ be sprayed in multiodirectional (ncrih-south/east-west) passes to insure uniform thickness.

- The polvol "B" somifcrent must be thoroughily power mixed eacin day. pror to use. Contact an SPi tecinnician regarding proper mixing equipment.

\section{RECCMMENOED EQUIPMENT} ANO SETINGS

- Standard i:1 ratio, heated, plural somponent equipment developing minimum of 1000 csi (Eg bar) dynamic pressure 'wiil acequateiy scray OCLYSCHE:D SS-100'x.

- Pre-nester iemperatura should be at $160.170^{\circ} \approx(71$. $\left.76^{\prime} \mathrm{C}\right)$.

- Hose temcerature sncuid be at : $00-170^{\circ} \mathrm{F}\left(71-76^{\circ} \mathrm{C}\right)$. A hose hermometer inseried uncer the insulation near the gun snould reac a minimum oi : $A=: 55^{\prime}=\left(50.200^{\circ} \mathrm{C}\right)$. 
RPP-6855, Rev. 0

May 22, 2000

2506-001MAB

Ms. Shere Bush

Specialty Products, Inc.

$2410104^{\text {th }}$ St. Ct.S.

Ste. D

Lakewood, WA 98499

Subject: Decontaminability Testing - Specialty Products coating

Dear Ms. Bush:

\section{Project Introduction}

This letter is a fulfillment of the request of Specialty Products (Purchase Order 2531).

\section{Technical Introduction}

The selected test option calls for drying a contamination solution unto a prepared (coated) sample. The sample is then washed with a sequential series of washes with 1) water, 2) ambient temperature decontamination solution and finally 3 ) hot decontamination solution.

\section{Method}

The Test was conducted in accordance with ASTM D4256-89 with minor changes noted below in

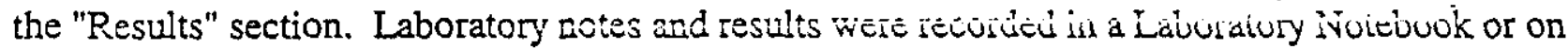
GammaVision TM data printouts.

\section{$\underline{\text { Results }}$}

The total decontamination factor (DF) is the ratio of the original activity to the activity after treatment. Note that these values include contamination removal by the previous steps. The decontamination factors are given for each of ${ }^{137} \mathrm{Cs},{ }^{60} \mathrm{Co}$ and Total Count. ${ }^{60} \mathrm{Co}$ is typical of a transition metal ion in that it tends to be less soluble in water than an alkali metal like ${ }^{137} \mathrm{Cs}$. The Total Count is essentially the average of the two, since the initial activity of the two radionuclides was essentially the same and the only activities on the sample are ${ }^{137} \mathrm{Cs}$ and ${ }^{60} \mathrm{Co}$.

1 ASTM 4256-89 "Standard Test Method for Determination of the Decontaminability of Coatings Used in LightWater Nuclear Power Plants

PN Services - 2939 Richardson Road - Richlard, Washington 99352 - Telephone: (509) 375-3535 - Fax: (509) 375-5230 


\begin{tabular}{|l|r|r|r|r|r|r|r|r|r|}
\cline { 2 - 9 } \multicolumn{1}{c|}{} & \multicolumn{8}{c|}{ Total Decontamination Factors } \\
\hline Sample & \multicolumn{3}{|c|}{ Water } & \multicolumn{2}{|c|}{ Ambient Decon solution } & \multicolumn{3}{|c|}{ Hot Decon solution } \\
\hline & ${ }^{137} \mathrm{Cs}$ & ${ }^{60} \mathrm{Co}$ & $\begin{array}{l}\text { Total } \\
\text { Count }\end{array}$ & ${ }^{137} \mathrm{Cs}$ & ${ }^{60} \mathrm{Co}$ & $\begin{array}{l}\text { Total } \\
\text { Count }\end{array}$ & ${ }^{137} \mathrm{Cs}$ & ${ }^{60} \mathrm{Co}$ & $\begin{array}{l}\text { Total } \\
\text { Count }\end{array}$ \\
\hline $\begin{array}{l}\text { Concrete } \\
\text { Block }\end{array}$ & 26 & 68 & 40 & 28 & 70 & 35 & 29.4 & 74 & 43 \\
\hline $\begin{array}{l}\text { Steel } \\
\text { Plate }\end{array}$ & 15 & 31 & 22 & 16 & 30 & 22 & 16 & 31 & 22 \\
\hline
\end{tabular}

\begin{tabular}{|c|c|c|c|c|c|c|c|c|c|}
\hline & \multicolumn{9}{|c|}{ Total Percent Removal } \\
\hline Sample & & Water & & Ambie & at Decon & olution & Hot & Decon so & ution \\
\hline & ${ }^{137} \mathrm{Cs}$ & ${ }^{60} \mathrm{Co}$ & $\begin{array}{l}\text { Total } \\
\text { Count }\end{array}$ & ${ }^{137} \mathrm{Cs}$ & ${ }^{60} \mathrm{Co}$ & \begin{tabular}{ll|} 
Total \\
Count \\
\end{tabular} & ${ }^{137} \mathrm{Cs}$ & ${ }^{60} \mathrm{Co}$ & $\begin{array}{l}\text { Total } \\
\text { Count }\end{array}$ \\
\hline $\begin{array}{l}\text { Concrete } \\
\text { Block }\end{array}$ & 96.2 & 98.5 & 97.5 & 96.5 & 98.6 & 97.2 & 96.6 & 98.6 & 97.7 \\
\hline $\begin{array}{l}\text { Steel } \\
\text { Plate }\end{array}$ & 93.4 & 96.8 & 95.4 & 93.7 & 96.7 & 95.4 & 93.8 & 96.8 & 95.6 \\
\hline
\end{tabular}

The stepwise decontamination factor is the ratio of the activity remaining after the previous step to the activity after treatment. The stepwise decontamination factors may not reflect the complete ability of a decontamination method, due to the activity reduction of previous steps.

\begin{tabular}{|l|r|r|r|r|r|r|r|r|r|}
\cline { 2 - 9 } \multicolumn{1}{c|}{} & \multicolumn{8}{|c|}{ Stepwise Decontamination Factors } \\
\hline Sample & \multicolumn{3}{|c|}{ Water } & \multicolumn{2}{|c|}{ Ambient Decon solution } & \multicolumn{2}{c|}{ Hot Decon solution } \\
\hline & ${ }^{137} \mathrm{Cs}$ & ${ }^{60} \mathrm{Co}$ & $\begin{array}{l}\text { Total } \\
\text { Count }\end{array}$ & ${ }^{137} \mathrm{Cs}$ & ${ }^{60} \mathrm{Co}$ & $\begin{array}{l}\text { Total } \\
\text { Count }\end{array}$ & ${ }^{137} \mathrm{Cs}$ & ${ }^{60} \mathrm{Co}$ & $\begin{array}{l}\text { Total } \\
\text { Count }\end{array}$ \\
\hline $\begin{array}{l}\text { Concrete } \\
\text { Block }\end{array}$ & 26 & 67 & 40 & 1.1 & 1.0 & 0.9 & 1.0 & 1.1 & 1.2 \\
\hline $\begin{array}{l}\text { Steel } \\
\text { Plate }\end{array}$ & 15 & 31 & 22 & 1.0 & 1.0 & 1.0 & 1.0 & 1.0 & 1.0 \\
\hline
\end{tabular}

\begin{tabular}{|l|r|r|r|r|r|r|r|r|r|}
\hline \multicolumn{1}{c|}{} & \multicolumn{9}{c|}{ Stepwise Percent Removal } \\
\hline & \multicolumn{3}{|c|}{ Water } & \multicolumn{2}{|c|}{ Ambient Decon solution } & \multicolumn{3}{|c|}{ Hot Decon solution } \\
\hline & ${ }^{137} \mathrm{Cs}$ & ${ }^{60} \mathrm{Co}$ & $\begin{array}{l}\text { Total } \\
\text { Count }\end{array}$ & ${ }^{137} \mathrm{Cs}$ & ${ }^{60} \mathrm{Co}$ & $\begin{array}{l}\text { Total } \\
\text { Count }\end{array}$ & ${ }^{137} \mathrm{Cs}$ & ${ }^{60} \mathrm{Co}$ & $\begin{array}{l}\text { Total } \\
\text { Count }\end{array}$ \\
\hline $\begin{array}{l}\text { Concrete } \\
\text { Block }\end{array}$ & 96.2 & 98.5 & 97.5 & 7.0 & 2.6 & -13 & 3.2 & 5.6 & 17.3 \\
\hline $\begin{array}{l}\text { Steel } \\
\text { Plate }\end{array}$ & 93.4 & 96.8 & 95.8 & 4.3 & -3.3 & 1.4 & 2.6 & 2.0 & 2.3 \\
\hline
\end{tabular}


The used water wash was tested to help confirm the loss of radioactivity from the samples and did confirm the loss of both ${ }^{137} \mathrm{Cs}$ and ${ }^{60} \mathrm{Co}$. Due to the dilution factor in the wash water and the decreasing amount of activity on the samples, only the water wash was tested.

The samples are "decontaminated" by dipping them in stirring water or decon solution. After the water wash the samples were lightly tissue-wiped on the uncontaminated side after rinsing the uncontaminated side (per the ASTM method). No major contamination was detected.

It was noted in the preparation of the ambient decon solution that the makeup water was closer to $15^{\circ} \mathrm{C}$ than the method-required $24 \pm 3^{\circ} \mathrm{C}$. The water solution (for the water wash) had not been checked for temperature, as the ambient air temperature was close to $24^{\circ} \mathrm{C}$. This may have caused the slightly low values for ${ }^{137} \mathrm{Cs}$ removal for the water wash.

Although the ASTM method calls for this report to include "Procedures and conditions relating to the test specimen preparation", since PN Services did not prepare the samples, this information is not included.

The specimens were stained brown on the areas where the last of the contaminating solution had dried. The stains were in a doughnut shaped pattern. The brown color could indicate attack by unneutralized nitric acid, but the samples clearly had white crystalline solids on them after the contamination solution had dried (before the water wash), which would indicate that neutralization by sodium hydroxide had occurred.

The immersed portions of the samples were slightly darker than the un-immersed part, after the ambient decontamination solution immersion.

Changes from the letter of the ASTM procedure were made for a number of reasons. Due to the size of the steel plate sample, the decontanination was done in a 2L glass crystallizing dish (vs the 600 $\mathrm{mL}$ polyethylene beaker of step 10.2.1). Both samples were decontaminated in the same bath. Section 9.2 states that "...immediately adjust to $\mathrm{pH} 4$ with $8 \mathrm{M}$ ammonium hydroxide $(\mathrm{NaOH}) . "$ The correct chemical formula for ammonium hydroxide is $\mathrm{NH}_{4} \mathrm{OH}$. We were left to make a decisian shout whether tn nee $\mathrm{NanH} n \mathrm{nr} \mathrm{NH} . \mathrm{OH}$. Since Hanford solutinns are likely to contain $\mathrm{NaOH}$ - sodium hydroxide, this was used as the neutralizing agent. Also, measuring the $\mathrm{pH}$ of a 0.2 $\mathrm{mL}$ solution was not possible so the solution was neutralized with an equivalent amount of $8 \mathrm{M}$ $\mathrm{NaOH}$ solution.

\section{Discussion and Hypotheses}

The differences between the plate and block samples could be accounted for by: 1) the higher ratio of front (unrinsed/unwiped) area to wipe-able area for the plate, 2) the block was more easily positioned in the gamma detector than the plate, which was just slightly wider than the shelf jig. The higher ratio of front area to wiped area for the plate may have had the effect of making the front surface available for recontamination. Positioning the plate in the gamma counter shelf jig was difficult. If the initial (freshly contaminated) count were done with the plate tilted slightly further away from the detector than the other counts, the decontamination ratio would be lowered due to the lowered initial count. 
A possible reason for the differences between ${ }^{137} \mathrm{Cs}$ and ${ }^{60} \mathrm{Co}$ is that since the solution was neutralized, the ${ }^{60} \mathrm{Co}$ may have been in an insoluble hydroxide compound, and therefore not as subject to binding with the coating. A pH neutral solution of $\mathrm{Cs}$ still has ionic $\mathrm{Cs}$ in it, which would be attracted to ion exchange sites.

\section{Conclusions}

The coating material was decontaminated to a minimum decontamination factor (DF) of 21.6 (95.4 $\%$ removal) with ambient water. Further washes with ambient and hot decontamination solution increased the minimum DF to 22.4 (95.5\% removal).

The coating material was decontaminated to a maximum decontamination factor of $40 \quad(97.5 \%$ removal) with ambient water. Further washes with ambient and hot decontamination solution increased the maximum DF to 43 (97.7 \% removal).

I can be reached by phone at (509) 372-7814, or via E-mail at beck.ma@wcsmail.com.

Kindest regards,

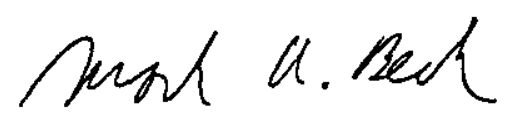

Mark A. Beck

Chemist II

cc: File

Peter Newton, PN Services

Alan Jordan, PN Services 


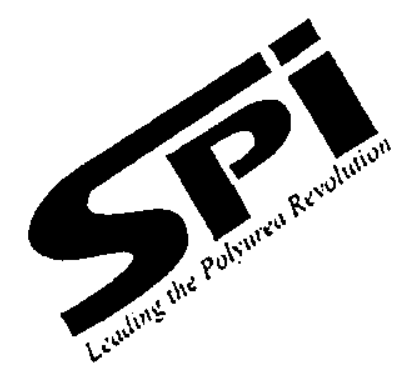

2410104 th St. Ct. S., SuiteD

Lakewood, WA 98499

(253) 588-7101(800) 627-0773

Fax (253) 588.7196

E-mail info@specialty-products.com

www.specialty-products.com

\section{Adhesion Study with POLYUREA HT \\ Comparing A.E.-4 to P.E.P. (Penetrating Epoxy Primer) \\ on Same Surfaces}

\begin{tabular}{|l|l|l|}
\hline \multicolumn{1}{|c|}{ SURFACE } & \multicolumn{1}{|c|}{$\begin{array}{c}\text { WITH A.E.-4 } \\
\text { FAILURE MODE }\end{array}$} & \multicolumn{1}{|c|}{$\begin{array}{c}\text { PRIMED WITH P.E.P. } \\
\text { FAILURE MODE }\end{array}$} \\
\hline Stainless Steel & & \multicolumn{1}{|c|}{} \\
& $\begin{array}{l}\text { 1000 PSI } \\
\text { Dolly Glue \& } \\
\text { Coating Adhesion Failure }\end{array}$ & $\begin{array}{l}700 \text { PSI } \\
\text { Coating Adhesion Failure }\end{array}$ \\
\hline Glass & $\begin{array}{l}\text { 1050 PSI } \\
\text { Glass Failure }\end{array}$ & $\begin{array}{l}750 \text { PSI } \\
\text { Glass Failure }\end{array}$ \\
\hline Concrete Block & $\begin{array}{l}350 \text { PSI } \\
\text { Concrete Cohesion Failure }\end{array}$ & $\begin{array}{l}\text { 450 PSI } \\
\text { Concrete Cohesion Failure }\end{array}$ \\
\hline Mild Steel With Severe Rust & $\begin{array}{l}\text { 700 PSI } \\
\text { Rust Cohesion Failure }\end{array}$ & $\begin{array}{l}\text { 1050 PSI } \\
\text { Glue Failure }\end{array}$ \\
\hline Red Brick & $\begin{array}{l}\text { Co PSI } \\
\text { Coating Adhesion Failure }\end{array}$ & $\begin{array}{l}\text { 1050 PSI } \\
\text { Coating Adhesion Failure }\end{array}$ \\
\hline Ceramic Tile & $\begin{array}{l}\text { 900 PSI } \\
\text { Tile Cohesion Failure }\end{array}$ & $\begin{array}{l}\text { 850 PSI } \\
\text { Tile Cohesion Failure }\end{array}$ \\
\hline
\end{tabular}
performed.

Surfaces were washed with soap and water. No further surface preparation was

This study indicates adhesion enhancement using P.E.P. on substrates that are porous. Due to its deep penetrating characteristics, P.E.P. may also be beneficial on certain porous and semi-porous substrates to displace oxygen; thereby, reducing the potential of corrosion and cathodic disbondment.
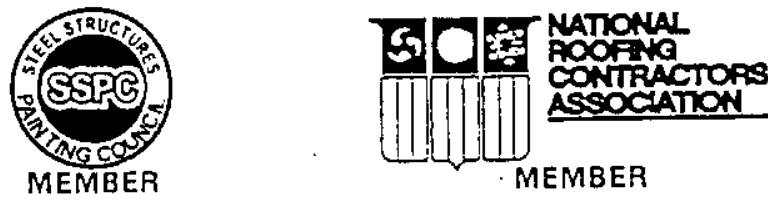


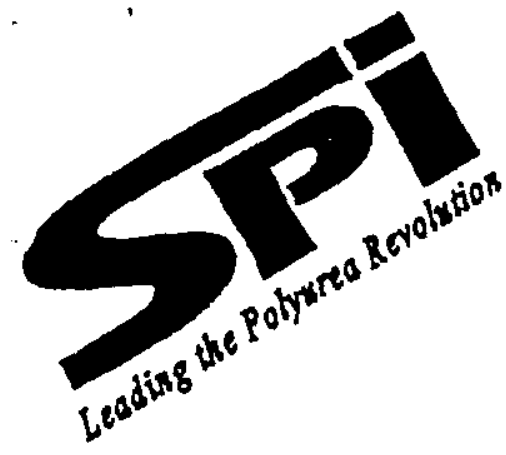

SPECIALTY PRODUCTS, ING

RPP-6855, Rev. 0

2410 104th St. Ct. S., Suite D

Lakewood, WA 98499

(253) 588-7101 (800) 627-0773

Fax (253) 588-7196

E-mail info@specialty-products.com

www.specialty-products.com

\section{ADHESION TESTS \\ POLYSHIELD SS-100TM \\ ON CONCRETE (VARIOUS)}

Tech Bulletin 0294-4

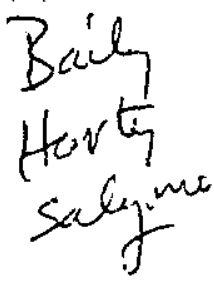

Adhesion testing was performed according to ASTM D-4541 using an Elcometer 106 tester.

\begin{tabular}{ll} 
Samole Number & $\begin{array}{l}\text { Pull-off Force } \\
\text { Pounds/square inch } \quad \text { Failure } \\
\text { Mode }\end{array}$ \\
\hline
\end{tabular}

1. Concrete block

2. Concrete paver with SPI Urethane (2 component) primer

3. Concrete paver after 60 days cure

4. Concrete paver POLYSHIELD SS-100 $\mathrm{TM}$ sprayed over wet concrete
125 average

300

150

225
Substrate removal

Test glue failure

Substrate removal

From substrate

\section{POLYSHIELD SS-100 TM TEST RESULTS}

The above data is per our ASTM TECH BULLETIN 1294

Referenced item is: 17.

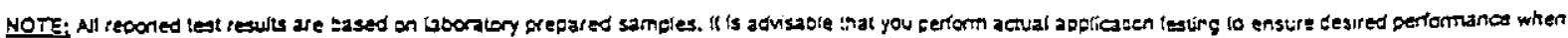
censidenng a POL YSHIEL SS-100" produc:

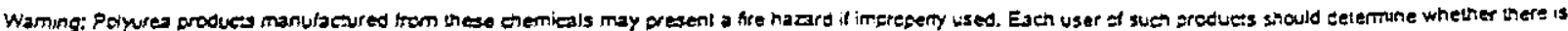
cotential nazart in a spectic acplicaion and ake the necesiary precoutions.

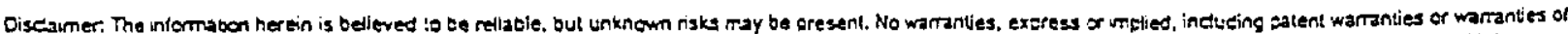

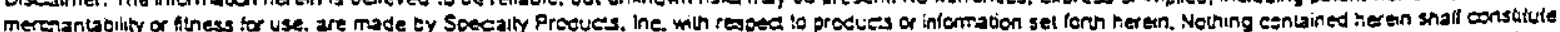

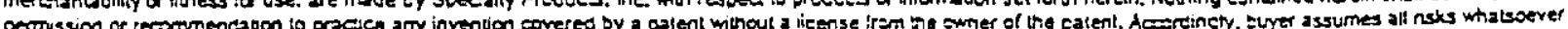

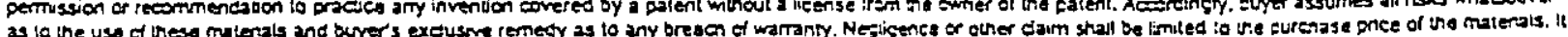

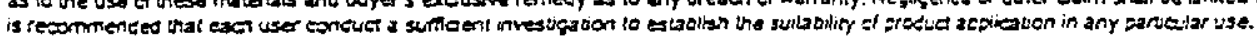




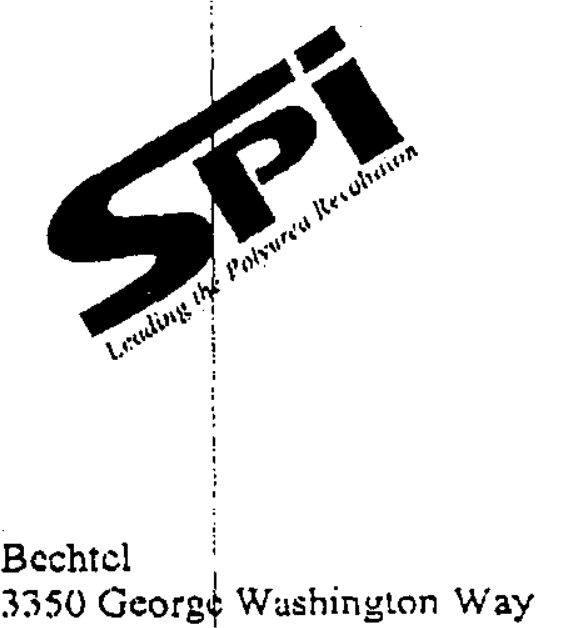

Richland. WA $\circlearrowleft 352$

Attn: Michacl $\wedge$ Hughes

Duar Michael,
SPECIALTY PRODUCTS, INC. 2410104 th St. Ct. S., Suite D =

Lakewood, WA 98499

(253) $588.7101(800) 627-0773$

Fax (253) 588-7196

E-mail info@specialty-products.com whw.specialty-products.com

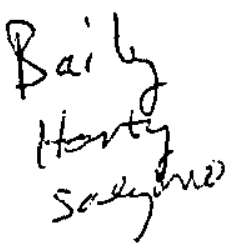

This leller provides assurance that the Polyshield SS-100tM formulation which is going to be used for the encapsulation of the various valves and langes per subcontract $0200 \mathrm{~W}-\mathrm{SC}$ - $($ j0053 will meet the following requirements (as staled in the Scope of Work, 0200 W-SW-G0053, section 4.0):

1. The physical and chemical characloristics of the Polyshicld SS-100\%M fomulation provldes an encapsulation life of 25 ycars when exposed to a solution containing any of the following:

75 years

- Approximatcly $2-4 \%$ HNO, as residual valve leakage. Tests conducted on Polyshield SS-100TM, according to $\Lambda$ STM D3912 with $11.5 \% \mathrm{HNO}_{3}$, anter 40 days indicatcs yirtually no cflect, slight color change on white test speciman.

- Residual solution with trace amounts of Pu nitrate ( $\left.\mathrm{Pu}(\mathrm{N} \cap 7)_{4}\right)$, Aluminum Nitratc $\left(\mathrm{Al}\left(\mathrm{NO}_{3}\right)_{3}\right)$, Ferrous Sulfamale $\left(\mathrm{Fe}\left(\mathrm{NH}_{2} \mathrm{SO}_{3}\right)_{2}\right)$, Sodiun Dichromale $\left(\mathrm{Na}_{2} \mathrm{Cr}_{2} \mathrm{O}_{7}\right), \mathrm{HCI}$, Fexone, and UNII.

2. The Pu(NO3) $)_{4}$ will not be able to permate through the Polyshicld $\mathrm{SS}-100^{\text {im }}$ formulation.

3. The polyshield SS-100'M formulation is nol porous and does not dissolve in, or ahsorh the $\mathrm{Pu}\left(\mathrm{NO}_{3}\right)_{4}$

4. The Polyshicld SS-100 10 formulation is UI $/ F M$ rated par ASTM E-84 with a NFPA classificalion of $\mathrm{A}$.

IC 7 wn be of further assistance, or if you requirc additional informalion, please do not hesitate to contact mo at.
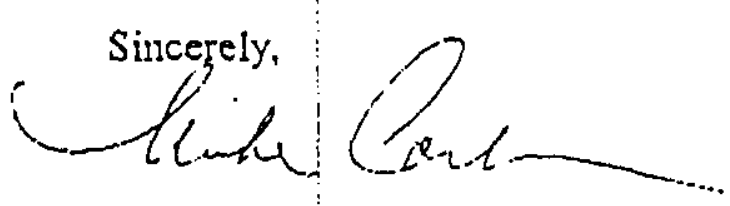

Mikc Cork

Research Director

MC:pl
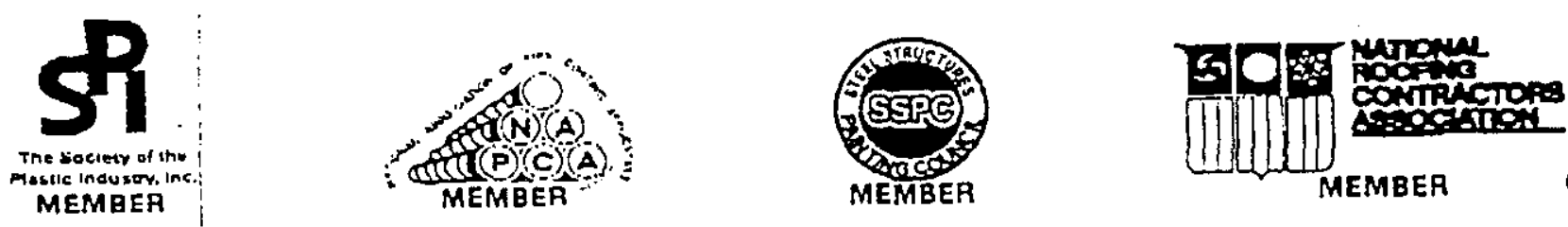


\section{HUNTSMAN}

\section{Technical Bulletin}

\section{Chemical Resistance Testing for Polyurea Spray Elastomers Chemical Resistance ASTM D 3912}

\section{Chemical}

Methanol

Gasoline

Diesel fuel

Toluene

MTBE

$5 \% \mathrm{MTBE} /$ Gasoline

Motor Oil

Hydraulic Fluid

2-ikethylbutace

Water

Room temperature

$82^{\circ} \mathrm{C}, 14$ days

$10 \% \mathrm{NaCl} / \mathrm{Water}$

Room temperature

$50^{\circ} \mathrm{C}, 14$ days

$10 \%$ Sugar/Water

Sulfuric Acid

$5 \%$

$10 \%$

$3 \%, 50^{\circ} \mathrm{C}, 14$ days

Hydrochloric Acid

$5 \%$

$10 \%$

Phosphoric Acid

$10 \%$

Ammonium Hydroxide

$10 \%$

$20 \%$

Sodium Hydroxide

$10 \%$

$20 \%$

$50 \%$

$1 \%, 50^{\circ} \mathrm{C}, 14$ days

Potassium Hydroxide

$10 \%$

$20 \%$

Acetic Acid

$10 \%$

\section{Month Exposure}

S. swelling, $<48$ bours

Slight surface change, no hardness loss

No visible damage

S. swelling, $<24$ hours

Slight surface change

Slight surface change

Slight surface change, no hardness loss Slight surface change, no hardness loss

No visible damage

No visible damage

No visible damage

No visible damage

No visible damage

No visible darnage

No visible damage

No visible damage

No visible damage

No visible damage

No visible damage

No vișible damage

No visible damage

No visible damage

No visible damage

No visible damage

Slight surface discolor, no hardness loss

Slight surface discolor, no hardness loss

No visible damage

No visible damage

No visible damage

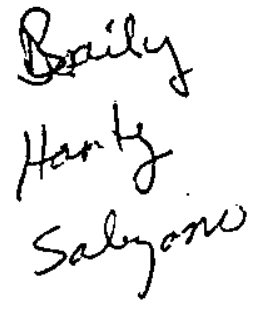




\section{VersaFlex FSS 45DC Spray Polyurea, Concrete}

Manufacturer

VersaFlex Incorporated

22 North $6^{\text {th }}$ Street

Kansas City, KS 66101

Phone: (800) 321-0906

FAX: (913) 321-9007

\section{Product Description}

VersaFlex FSS 45DC is a fast set, rapid curing, $100 \%$ solids, flexible, two component polyurea elastomer spray coating material. FSS 45DC is used by itself or in combination with other materials to produce coatings, liners, wearing courses, and resilient surfaces on concrete substrates. Its extremely fast gel time makes it suitable for applications down to $-20^{\circ} \mathrm{F}$ without special conditioning of the component resins and isocyanates. FSS 45DC produces an extremely tough film at all thicknesses. Single or multiple pass applications produce films from 10 mils to 1000 mils without appreciable sag or runs. FSS 45DC may be applied in all positions and to any suitably prepared substrate.

FSS 45DC is inert, it will not hydrolyze, leach, or contaminate other materials, and is bondable and paintable.

FSS 45DC is relatively moisture and temperature insensitive, allowing application in the most problematic ambient conditions.

\section{Uses}

Versaflex FSS 45DC is a superior coating material designed specifically for industrial applications receiving constant or intermittent attack from contained materials, subsurface hydrostatic pressure, most corrosive substances, and abrasive action. FSS $45 D C$ is flexible, accommodating movement of the substrate, yet strong enough to remain intact under all conditions except major structural dislocations. With or without reinforcements FSS 45DC may be used in transitional areas with confidence. FSS 45DC may be used in interior or exterior applications.

FSS 45DC is recommended for repair of other films, damaged concrete, or new construction and in cold weather conditions, cold storage facilities, freezers, and food processing plants where time and temperature are serious concerns. FSS 45DC is ideal for applications in:

- Industrial Facilities

- Parking Garage Decks

- Warehouse Floors

- Below Grade Waterproofing

- Above Grade Dampproofing

- Manufacturing Facilities

- Water and Waste Water Treatment

- Cold Storage Facilities

- Food Processing Facilities

- Pulp and Paper Mills

- Bottling and Canning Facilities

- Walkways and Balconies

- Secondary Containment

- Refineries

- Fertilizer and other Process Plants

- Mining Operations

- Landfill Containment

- Freezers

- Airports

\section{Advantages}

- $100 \%$ Solids, Meets VOC Regulations

- Flexible, $520 \%$ Elongation

- Excellent Thermal Stability

- Heat of Deflection $250^{\circ} \mathrm{F}$, no load

- Glass Transition Temperatures $-40^{\circ} \mathrm{F}$ and $250^{\circ} \mathrm{F}$

- Generally Suitable for Use when pH ranges from $4-11$

- Good Resistance to a Wide Range of Chemical Attack

- Non-catalysed, Non-reactive

- Low Permeance Rate

- Seamless Elastomer

- Remains Flexible in Cold Temperatures

- Return Project to Service in 60 Minutes

- Cures From $-20^{\circ} \mathrm{F}$ to $225^{\circ} \mathrm{F}$

- Odorless, No Toxic Vapors

- USDA Approved

\section{Limitations}

FSS 45DC should not be used for direct contact with extremely high or low pH attack. Composite systems are available. Consult VersaFlex. 


\section{Typical Physical Properties}

Cured Film Properties

Solids Content

Shore A Hardness

Elongation

Tensile Strength, psi

$100 \%$ Modulus, psi

$300 \%$ Modulus, psi

Tear Strength, pli, Die C

Taber abrasion, mg wt loss

(1000 gms, 1000 revs, $\mathrm{H}-18$ wheels)

Moisture Vapor Transmission, perms

Gel Time

Tack Free

Open to Traffic

\section{Coverage Rates}

Theoretical Square Feet Per Gallon

\begin{tabular}{|l|lllllll|}
\hline Mils & 10 & 15 & 50 & 60 & 80 & 100 & 125 \\
\hline & 160 & 107 & 32 & 27 & 20 & 16 & 13 \\
\hline
\end{tabular}

Note: 1604 mil inches per gallon. Totally dependent on substrate texture and condition.

\section{Packaging}

- One Hundred Ten Gallon Kit: 55 gallons of 'A' side and 55 gallons of ' $B$ ' side.

- Ten Gallon Kit: 5 gallons of 'A' side and 5 gallons of 'B' side.

\section{Mixing}

FSS 45DC must be spray applied using approved equipment. Use 1:1 ratio pump, with appropriate material heaters, as required for individual application. For information contact

\section{VersaFlex.}

\section{Colors}

Standard color is charcoal gray, light gray, or black. Other colors available upon request.

\section{Consult VersaFlex.}

\section{Shelf Life}

One year, in original, unopened factory containers, under normal storage conditions of $55^{\circ} \mathrm{F}$ to $95^{\circ} \mathrm{F}$.
Test Method

ASTM D2240

ASTM D638

ASTM D638

ASTM D638

ASTM D638

ASTM D624

ASTM D4060

ASTM E96
Typical Value

$$
\begin{gathered}
100 \% \\
450 \\
520 \% \\
2145 \\
960 \\
1450 \\
430
\end{gathered}
$$

180

0.025

8 Seconds 25 Seconds 60 Minutes

\section{Clean-up}

Cured product may be disposed of without restriction. Excess liquid ' $A$ ' and ' $B$ ' material should be mixed together and allowed to cure, then disposed of in the normal manner. Product containers that are "drip free" may be disposed of according to local, state and federal laws.

\section{Safety}

Read Material Safety Data Sheets provided with all shipments. Additional copies are available upon request from Versaflex or your local dealer.

Basic safety for personal protection is:

- Long-sleeve overalls or disposable Tyvex overalls.

- Rubber gloves.

- Splash shield or safety glasses with splash guards.

- Rubber or leather boots.

- Do not use near high heat or open flame.

- Do not take internally.

- Keep out of the reach of children.

\section{Surface Preparation and Installation}

Regard VersaFlex specifications for FSS 45DC Spray Polyurea, for detailed preparation and installation procedures. Substrate priming is not required on all substrates, consult Versaflex for recommendations. 
Chemical Resistance

\begin{tabular}{|c|c|c|c|}
\hline $\begin{array}{l}\text { Recommended } \\
\text { - Recommended Conditionally }\end{array}$ & $\begin{array}{l}\mathrm{R} \\
\mathrm{C}\end{array}$ & $\begin{array}{l}\text { Test Procedure: ASTM D130 } \\
\text { Year }\end{array}$ & Exceeds 1 \\
\hline (washdown within 1 hour of & & Test Media & Result \\
\hline spillage) & & Acetone & C \\
\hline * Not Recommended & $\mathrm{N}$ & Antifreeze & $\mathbf{R}$ \\
\hline $\begin{array}{l}\text { Suitable for immersion and/or } \\
\text { splash and spillage conditions }\end{array}$ & 1 & Benzene & $\mathrm{R}$ \\
\hline $\begin{array}{l}\text { - Suitable for occasional/intermittent } \\
\text { contact for up to } 72 \text { hours }\end{array}$ & 2 & Butyl Alcohol & $\begin{array}{l}\mathrm{R} \\
\mathrm{R}\end{array}$ \\
\hline $\begin{array}{l}\text { Test Procedure: ASTM D3912 } 25^{\circ} \mathrm{C} \\
\text { Year }\end{array}$ & xceeds 1 & $\begin{array}{l}\text { Carbon Dioxide } \\
\text { Calcium Hypochlorite }\end{array}$ & $\begin{array}{l}\mathrm{R} \\
\mathrm{R} \\
\mathrm{N}\end{array}$ \\
\hline$\overline{\text { Test Media }}$ & Result & Chlorine (5000 ppm in water) & 2 \\
\hline Acetic Acid $10 \%$ & $\mathrm{C}$ & Citric Acid & $R$ \\
\hline Ammonium Hydroxide $10 \% / 20 \%$ & $R$ & Cylloexanol & $R$ \\
\hline Diesel Fuel & $\mathrm{R}$ & Dichloacetic Acid & C \\
\hline Gasoline & $\mathrm{R}$ & Dimethyl Formamide & N \\
\hline Hydraulic Fluid & $\mathbf{R}$ & Ethanol & 2 \\
\hline Hydrochloric Acid 5\%/10\% & $\mathrm{R}$ & Ethylene Glycol & 1 \\
\hline Methanol & $R$ & Gasoline & $R$ \\
\hline Motor Oil & $R$ & Hexane & R \\
\hline MTBE & 1 & Hydraulic Oil & $\mathrm{R}$ \\
\hline MTBE/Gasoline $5 \%$ & $\mathbf{R}$ & Hydrochloric Acid $<35 \%$ & $\mathbf{R}$ \\
\hline $\mathrm{NaCl}$ Water $10 \%$ & $R$ & Lactic Acid 10\% & 1 \\
\hline Phosphoric Acid $10 \%$ & $R$ & Methylene Chloride & C \\
\hline Potassium Hydroxide $10 \% / 20 \%$ & $\mathrm{R}$ & Methyl Ethyl Ketone & C \\
\hline Sodium Hydroxide $10 \% / 20 \% / 50 \%$ & $\mathrm{R}$ & Methanol & $R$ \\
\hline SugarNater $10 \%$ & $\mathbf{R}$ & Mineral Spirits & $\mathrm{R}$ \\
\hline Sulfuric Acid $5 \% / 10 \%$ & $\mathrm{R}$ & Monobutyl Ether & $\mathrm{R}$ \\
\hline Skydrol & 2 & Nitric Acid $20 \%$ & C \\
\hline Toluene & $\mathrm{C}$ & Phenol & 2 \\
\hline Water & $\mathbf{R}$ & Skydrol & 2 \\
\hline 2-Methylbutane & $R$ & Sodium Bicarbonate & $\mathrm{R}$ \\
\hline & & Sodium Chloride & $\mathrm{R}$ \\
\hline & & Sodium Hydroxide $50 \%$ & $\mathrm{R}$ \\
\hline Exposure to UV will cause disc & tion, no & Sodium Hypochlorite $10 \%$ & $2^{\circ}$ \\
\hline change in physical properties & & Stearic Acid & $\mathrm{R}$ \\
\hline & & Sulfuric Acid $70 \%$ & $N$ \\
\hline & & Trichloroethylene & C \\
\hline & & Trisodium Phosphate & $\mathrm{R}$ \\
\hline & & Toluene & C \\
\hline & & Vinegar & $\mathrm{R}$ \\
\hline & & Xylene & C \\
\hline
\end{tabular}

Warranty - VersaFlex Incorporated will refund the price of or replace, at its election, product it finds to be defective provided the product has been used properly. Except as expressly stated above, the Company makes no warranty of merchantability and no warranty of fitness for any particular purpose, nor does it make any warranty, expressed or implied, of any nature whatsoever with respect to the product or its use.
In no event shall the company be liable for delay caused by defects, for loss of use, for indirect, special or consequential damages, or for any charges or expenses of any nature incurred without its written consent. 


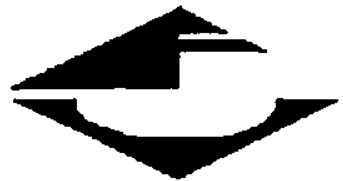

VersaFlex

INCORPORATED
Corporate Office: 3145 Broadway, Kansas City, MO 64111

(800)561-6191 Fax: (816)960-0400

\section{Use of Polyurea as Primary Containment Liner in High pH Environment}

Regarding: VersaFlex FSS 45DC spray polyurea to contain high $\mathrm{pH}(7$ - 14) liquids and slurry materials.

Reference \#1: Contained material: Sodium Chlorate - ph 13

Container:

Tile Lined Steel Tank and Mild Steel Tank Interior

Roof

The initial installation was undertaken at Weyerhaeuser (then: Avenor) Dryden, Ontario pulp plant in June 1998. The completed installation has been in constant service since that time. The tank is inspected on a semi-annual basis. Four such inspections have taken place to date. The system is performing without flaw or repair. The owner has subsequently released several more tile line steel tanks and stainless steel tanks for lining.

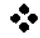

Reference \#2: Contained material: White Liquor (Sodium Chlorate) - pH 12

Container:

This installation occurred at Kimberly Clark Winslow, ME in August 1998.

$$
\text { * }
$$

Reference \#3: Contained material: Bleaching Chemicals - pH 12

Container: 
Sarety

Read and understand we provided Material Safety Dala Sbeets. Use adequalc venilation and all required personal protective equipinent. For confined space anly use fresb air supply and Tyvek suit. For open oir use an organic vapor respirator with dual cartridges. A full fece respir ator is recommended for added eye protection.

\section{Mixing}

Slowly premix the pext B will drill and filly blede. taking cere to not entrap air inlo the produch Contimuc mixing wod you no longer see any striations. Pxt a does not require promixing.

\section{Substrate Preparation}

Ground: For ground cover it is recommended tbat all suriaces be tovered with geotexulle cloth and sccured with stokes every 24 incbes an center before spraying.

Concrete: Shorbiast substrate to 2 profile ingt resenbles 80 - 100 mesh sandpaper. Always perform - Calciun Cbloride Test as per ASTM E-1907. Do not proceed if moiscure vepor content is $>3 \mathrm{lbs}$. per 1000 squt and call General Polymers for technical assistance. Honor all expansion joints. Rouse all crocks, spalls und boles. Fill all cracks, spalls and boles with FX 375 or FX 121. Prime using FX 311.

Metai: Sand/grind or sandblast to whitc metal with a 3 mil profile. Prime using FX 311 .

\section{Application}

Use only phral component equipment capable of producing 3000 psi at $160^{4} \mathrm{~F}$. Gosmer GX7 or equivilest type impirgement gun is biubly recommonded. 3.5 gallon to 22 gallon per minute spray tips ure upproved depending on desired thickness.

\section{Limitations}

Product will discolar wben exposed to UV ligbh thls is most pronounced in litbl colors. Product mast be applied witb beaced. olural componeor spray equipencne.

\section{Shelf Life}

Product can be stored for up to 1 year in sealed un. opened cooluners. Store material betweed 40-140\%.

\section{Warranty}

The anle of Cederal Polyzners Corporation's (General Polymers) produces are governed by the Cincral Polymers Sicundard Terns and Conditions of Sale. General Palymers bas no bnowledge or control conceming boyer's use of the producl nor over tbc quality of the concrete or substate to which they are applicd. General Polymers ussumes no responsibility for any loss or damaze resulting from the bandling or use of the products by the buyer. Goneral Polymirs makes the following LIMDIED WARRANTY that its products have been supplied tree fiom unanuacturing defects, and will couform to Generd Poiymers manufacuring scandards. Technical data fumished by General Polymers is true and accurats to the Dest or our knowledge: bowever wo guarantec of accuracy is given or implied. 'Tbis Limited Warmely shall not upply in the case of improp instaliation, improper subsuale consuruction, damagc bcy and the scopo wod protection of the products. exposure of we products to solvens andor higher concentrations of arids then bel for which the procluets are designed and loss of bend tae lo bydrostadic pressure. vapor pressure. capillary action or moisnure forn wibin, ender or adjucent to the concrete surface.

GENERAL POLYMENS LABILTTY SHALL NOT EXCEEDREPLACEMENT OF OR RETURN OF THE PURCHASE PRICE FOR THE PRODUCTS WHICH IT MAY SELL WHICH MAY PROVE TO BE DEFECTIVE UNDER NORMAL USE AND SERVICE WITHIN ONE YEAR FROM DATE OF SALE AND WHICH UPON EXAMLNATION BY GENERAL POLYMERS SHALL DISCLOSE. TO GENERAL POLYMERS SATISFACTION. TO BE DEFECTIVE. IN NO EVENT SHALL GENERAL POLYMERS BE LAABLE FOR INCIDENTAL OR CONSEQUENTIAL DAMAGES, INCLUDING, BUT NOT UUITED TO. BUYERS LOSS OF MATERIAL OR PROFITS, INCREASED EXPENSE OF OPERATTON, BODILY INJURY, LOSS OF USE OF PROPERTY. OR DORN TIME. CENERAL POLYMERSMAXESNO MMPLED WARRANTIES OFNER CHANTABUTTY OR FITNESS FOR A PARTICULAR PURPOSE. THE BUYER HEREDY EXPRESSLY WATES ANY CLAMM TO ADDTTIONAL DNMAGES.

This Limited Warrapty supersedes any otber warranty or obber represcatiorion. whether writen or oral. heretufore made belwein the paries.

GPosP pX3R7/ 


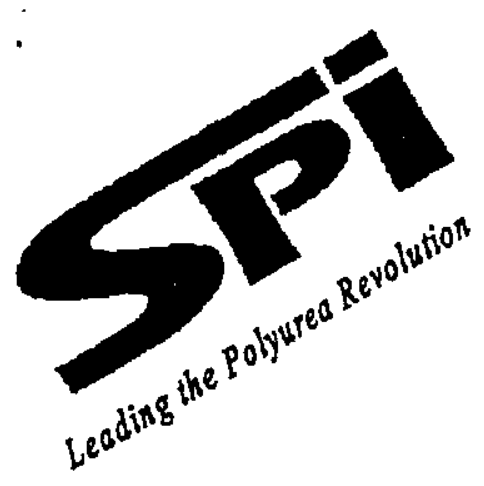

\title{
MATERIAL SAFETY DATA SHEET
}

\author{
E:MERGENCY CONTACT:
}

Spills, Leaks, Fire or Exposure Call Chemtrec: (800) $424-9300$

\section{SECTION 1 - CHEMICAL PRODUCT AND COMPANY DENTIFICATION}

Product Name: POL,YSHELD/POLYUREA Group including SS-100"s , FRP

Company: Specialty Products, Inc. $2410104^{\text {th }}$ St. Ct. S., Suite D

Lakewood. WA 98499

(253) 588-7101

\section{SECTION 2 - COMPOSITION / INFORMATION ON INGREDIENTS}

$\begin{array}{llll}\text { HAZARDOUS NGREDIENT(S) } & \%(w / w) & \text { ACGIH TLV } & \text { CAS NO. } \\ \text { 4,4' - Diphenylmethane Diisocyanate (4.4' MDI) } & -32 & 0.005 \mathrm{ppm} & 101-68-8 \\ \text { Modified MDI } & -58 & \text { Not Listed } & \text { Not Listed } \\ \text { Proprictary Chemicai } & -5-12 & \text { Not Listed } & \end{array}$

\section{SECTION 3 - HAZARDS IDENTIFICATION}

\section{EMIERGENCY OVERVIEW}

Health Hazards: Irritating to eycs. respiratory system and skin. Risk of serious damage to respiratory system. May cause sensitization by inhalation and skin contact. Repeated inhalation of acrosol at levels above the occupational exposure limit could cause respiratory sensitization. The onser of the respiratory symptoms may be delayed for several hours after exposure. A hyper-reactive response to even minimal concentrations of MDI may develop in sensitized persons.

Physical Hazards: Reacts slowly with water to produce carbon dioxide that may rupture closed containers. This reaction accelerates at higher temperanures.

Appearance: Clear liquid.

Odor: None.

Read the entire MSDS for a more thorough cvaluation of the hazards.

\section{SECTION 4 - FIRST AID MEASURES}

General: In case of accident or if you feel unwell. seek medical advice IMMEDLATELY (show the MSDS where possible).

Inhalation: Remove patient from exposure, keep warm and at rest. Obtain medical attention. Treatment is symptomatic for primary irritation or bronchospasm. If breathing is labored, qualified personnel should administer oxygen. Apply artificial respiration if brearhing has ceased or shows signs of tailing. 
Skin Contact: Remove contaminated clothing. Wash affected arcas thoroughly with soap and water. If irritation, redness, or " a buming sensation develops and persists, obtain medical advice. Contaminated clothing should be thoroughly cleaned before reuse.

Eye Contact: Immediately flush eyes with running water for a minimum of 15 minutes. Hoid eyelids open during flushing. If irritation persists, repeat flushing. Obtain medical attention IMMEDLATELY.

Ingestion: DO NOT induce vomiting. Provided the patient is conscious, wash out mouth with water then give 1 or 2 glasses of water to drink. Reter person to medical personnel for immediate attention.

Note to Physicians: Symptomatic and supportive therapy as needed. Following severe exposure medical follow-up should be monitored tor at least 48 hours.

\section{SECTION 5 - FIRE-FIGHTING MEASURES}

Fire and Explosion Hazards: Containers may burst under intense heat. Due to reaction with water, a hazardous buildup of pressure could result if contaminated containers are resealed.

Extinguishing Media: Carbon dioxide. dry chemical, or appropriate foam. If water is used. very large quantities are required. Reaction benveen water and hor isocyanate may be vigorous. Contain runoff water with temporary barriers.

Fire Fighting Procedures: As appropriate for surrounding materials/equipment.

Fire Fighting Protective Equipment: Use self-contained breathing apparatus and full protective clothing (Bunker gear).

Flash Point: $>230^{\circ} \mathrm{F}\left(110^{\circ} \mathrm{C}\right)$

Flammable Limits (Lower): Not available.

Flammable Limits (Upper): Not available.

Auto Ignition Temperature: $240^{\circ} \mathrm{C}\left(464^{\circ} \mathrm{F}\right)\left(4,4^{\prime}\right.$ - Diphenylmethane Diisocyanate)

Decomposition Temperature: Not available.

Rate of Burving: Nor available.

Explosive Power: None.

Sensitivity to Mechanical Impact: None.

Sensitivity to Static Discharge: None.

Combustion Products: Carbon monoxide, carbon dioxide, nitrogen oxides and some HCN.

\section{SECTION 6 - ACCIDENTAL RELEASE MEASLRES}

For major spills. call Chemtrec $(800-42+9300)$

Spills, Leaks, or Releases: Cleanup should only be performed by mained personnel. People dealing with major spillages should wear full protective clothing including respiratory protection. Evacuate the area. Prevent further leakage, spillage or entry into drains. Contain and absorb large spillages onto an inert, nonflammable absorbent cartier (such as earth or sand). Shovel into open-top drums or plastic bags for further deconiamination, if necessary. Wash the spillage area clean with liquid decontaminant. Test amosphere for MDI vapor. Neutralize small spillages with decontaminant. Remove and dispose of residues. Notify applicable government authorities if release is reportable. The CERCLA RQ for MDI is 5,000 lbs. (see CERCLA in Section 15).

Preparation of Decontamination Solution: Prepare a decontamination solution of $0.2-0.5 \%$ liquid detergent and 3-8\% concentrated ammonium hydroxide in water $(5-10 \%$ sodium carbonate may be substituted for the ammonium hydroxide). Follow the precautions on the supplier's material safety data sheets when preparing and using solution.

Use of Decontamination Solution: Allow deactivated material to stand for at least 30 minutes before shoveling into drums. Do not tighten the bungs. Mixing with wet earth is also effective, but slower. 


\section{SECTION 7 - HANDLNG AND STORAGE}

Handling: Avoid personal contact with the product or reaction mixrure. Use only with adequate ventilation to ensure that the defined occupational exposure limit is not exceeded. The efficiency of the ventilation must be monitored regularly because of the possibility of blocknge. Avoid breathing acrosols, mists and vapors. When the product is sprayed or heated. an approved MSHANIOSH positive-pressure, supplied-ait respirator may be required.

Storage Requir ements: Keep containers properly sealed and when stored indoors, in a well ventilated area. Keep contents away trom moisture. Due to reaction with water, producing $\mathrm{CO}_{2}$ gas, a hazardous buildup of pressure could result if contaminated containers are resealed. Do not rescal contaminated containers! Uncontaminated containets. free of moisturc. may be resealed only after placing under a nitrogen blanket. Do not store in containers made of copper, copper alloys or galvanized surtaces.

Storage Temperature: Ideal storage temperarure is $16-38^{\circ} \mathrm{C}\left(60-100^{\circ} \mathrm{F}\right)$.

Kecp stocks of decontaminant (See Section 6) readily available.

\section{SECTION 8 - EXPOSURE CONTROLS/PERSONAL PROTECTION}

\section{PREVENTIVE MEASURES:}

Conditions of use, adequacy of engineeting or other control measures. and actual exposures will dictate the need for spetific protective devices at your workplace.

Engineering Controls: Use local exhaust ventilation to mathitain airborne concentrations below the TLV. Suitable respiratory equipment should be used in cases of insufficient ventilation or where operational procedures demand it. For general guidance on engineering control measures refer to the ACGIH publication "Industrial Ventilation".

Personal Protective Equipment:

Eye Protection: Chemical safery goggles. If there is a potential for splashing, use a full face shield.

Skin Protection: The following protective materials are recommended:

Gloves - neoprene, nitrile-butadiene rubber, buryl nubber. Thin disposable gloves should be avoided for repeated or long term use. Protective clothing should be selected and used in accordance with "Guidelines for the Selection of Chemical Protective Clothing" published by ACGIH.

Respiratory Protection: Use a NIOSHMSSHA-approved positive pressure air-supplied respirator equipped with a full facepiece, or an air-supplied hood, if airbome concentrations exceed or are expected to exceed the TLV. Air purifying (cartridge type) respirators are not approved for protection against diisocyanates.

\section{EXPOSURE GUIDELINES:}

Medical supervision of all employces who handle or come in contact with respiratory sensitizers is recommended. Persons with asthmatic-type conditions, chronic bronchitis. other chronic respiratory diseases or recurrent skin eczema or sensitization should be excluded from working with this product. Once a person is diagnosed as sensitized. no further exposure to the material that caused the sensitization should be pernitred.

\section{HAZARDOUS INGREDLENT(S):}

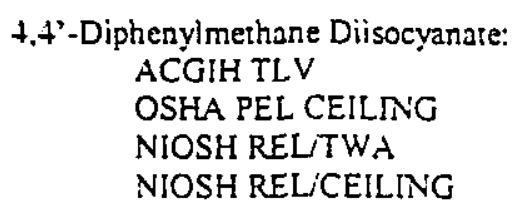

NOTE: The Occupational Exposure Limits listed for isocyanates do not apply to previously sensitized individuals. 


\title{
SECTION 9 - PHYSICAL AND CHEMICAL PROPERTIES
}

\author{
Aternate Name(s): Not applicable. \\ Chemical Name: Not applicable (mixnure). \\ Chemical Family: Diisocyanate \\ Molecular Formula: Not applicable (mixture). \\ Appearance: Clear liquid. \\ Odor: None. \\ Odor Threshold (ppm): 0.4 (4.4'-Diphenylmethane Diisocyanate) \\ pH: Nor applicable. \\ Flash Point: $>230^{\circ} \mathrm{F}\left(110^{\circ} \mathrm{C}\right)$ \\ Vapor Pressure (mm Hg at $\left.20^{\circ} \mathrm{C}\right)$ : Approx. $4 \times 10^{*}$ \\ Vapor Density (Air=1): 8.5 approx. \\ Boiling Point: Not applicable. \\ Melting Point: Not available. \\ Solubility (Water): (Reacts with water) \\ Specific Gravity: 1.1549 \\ Evaporation Rate: Not available.
}

\section{SECTION 10 - STABILITY AND REACTNITYY}

Hazardous Decomposition Products: Highly unlikely under normal industrial usc. See Section 5.

Chemical Stability: Stable at room temperarure.

Conditions to Avoid: Avoid high temperanres. Avoid freezing.

Incompatibility with other Substances: This product will react with any materials containing active hydrogens such as water. alcohol. amines, bases and acids. The reaction with water is very slow under $50^{\circ} \mathrm{C}\left(122^{\circ} \mathrm{F}\right)$ but is accelerated at higher temperatures.

Hazardous Polymerization: Polymetization may occur at elevated temperanres in the presence of alkalies. tertiary amines and meral compounds.

- Teratogenicity and Fetotoxicity: No birth defects were seen in nwo independent animal (rat) studies. Fetotoxicity was observed at coses that were extremely toxic (including lethal) to the mother. Fetotoxiciry was not observed at doses that were not maternally toxic. The doses used in these studies were maximal, respirable concentrations well in excess of the defined occuparional limits.

\section{SECTION 11 - TOXICOLOGICAL INFORMATION}

\section{TOXICOLOGICAL DATA:}

Polymeric MDI: $\quad$ Oral LD50 (rat) $>5.00 \mathrm{mg} / \mathrm{kg}$

Dermal LD50 (rabbit) $>5.00 \mathrm{mg} / \mathrm{kg}$

Inhalation LC50 (rat) $=490 \mathrm{mg} / \mathrm{m} 3 / 4 \mathrm{H}$ (respirable aerosol)

\section{POTENTIAL HEALTH EFFECTS:}

Inhalation: This product is a respiratory and potential respiratory sensitizer. Repeated inhalation of vapor or aerosol at levels above the occupational exposure limit could cause respiratory sensitization. Symptoms may include irritation to the cycs. nosc. throat and lungs. possibly combined with dryness of the throat, tightness of chest and difficulty in breathing. The onset of the respiratory symptoms may be delayed for several hours after exposure. A hyperreactive response to even minimal concentrations of MDI may develop in sensitized persons.

Skin Contact: Moderate irritant. Repeated andior prolonged contact may cause skin sensitization. Animal studies have shown that respiratory sensitization can be induced by skin contact with known respiratory sensitizers including diisocyanates. These resuits emphasize the need for protective clothing including gloves to be worn at all times when handling these chemicals or in maintenance work.

Eye Contact: The aerosol, vapor or liquid will irrtate human eyes following contact. 
Ingestion: Ingestion may cause irrization of the gastrointestinal tract. Based on the oral LD50, this product is considered practically nontoxic by ingestion.

Chronic Effects: A sudy was conducted where groups of rats were exposed for 6 hours/day, 5 days/week for a lifetime to amospheres of respirable polymeric MDI aerosol. Overall, the tumor incidence, both benign ( $6 \mathrm{mg} / \mathrm{m} 3)$, there was a significant incidence of a benign tumor of the lung (adenoma) and one malignant tumor (adenocarcinoma). There were no lung rumors at $1 \mathrm{mg} / \mathrm{m}^{3}$ and no effects at $0.2 \mathrm{mg} / \mathrm{m} 3$. The increased incidence of lung rumors is associated with prolonged respiratory irritation and the concurtent accumulation of yellow material in the lung, which occurted throughout the study. In the absence of prolonged exposure to high concentrations leading to cbronic irritation and lung damage, it is highly unlikely that tumor formation will occur.

There are repors that chronic exposure may result in permanent decrease in lung function.

Carcinogenicity: The ingredients of this product are not classified as carcinogenic by ACGIH or IARC, not regulated as carcinogens by OSHA. and not listed as carcinogens by NTP.

Mutagenicity: There is no substantial evidence of mutagenic potential.

Reproductive Effects: No adverse reproductive effeces are anticipated.

\section{SECTION 12 - ECOLOGICAL INFORMATION}

Environmental Fate and Distribution: It is unlikely that significant environmental exposure in the air or water will arise, based on consideration of the production and use of the substance.

Persistence and Degradation: Immiscible with water, but will react with water to produce iner and non-biodegradable solids.

Toxicity: Polymeric MDI.

LCO (Zebra Fish) $>1000$ mgil

EC50 (Daphnia magna) (24 hours) $>1000 \mathrm{mg} / \mathrm{l}$

EC50 (E. Coli) $>100 \mathrm{mg} /$

\section{SECTION 13 - DISPOSAL CONSIDERATIONS}

The generation of waste should be avoided or minimized wherever possible.

Disposal should be in accordance with local, state, provincial or national regulations. This material is not a hazardous waste under RCRA 40 CFR 261. Small quantities should be treated with a decontaminant solution (See Section 6). The treated waste is not a hazardous material under RCRA 40 CFR 261. Chemical waste. even small quantities, should never be poured down drains, sewcrs, or waterways.

Empry containers should be decontaminated and either passed to an approved drum recycler or destroyed.

\section{SECTION 14 - TRANSPORT INFORMATION}

DOT: Single containers less than $5,000 \mathrm{lbs}$. are not regulated.

Single containers with 5,000 lbs. or more of $4,4^{\prime}-\mathrm{MDI}$ are regulated as: Other Regulated Substances, Liquid, N.O.S. (Methylene Diphenyl Diisocyanate), 9 NA3082. PGIII. RQ.

Transportation Emergency Telephone Number: 1-800-424-9300 (CHEMTREC)

TDG: Not Regulated.

IMO: Not Regulated.

IATA/ICAO Class: Not Regulated. 


\section{SECTION 15 - REGULATORY INEORMATION}

\section{USA CLASSIFICATION:}

OSHA Classification:

-Physical: Not regulated.

-Health: Highly toxic. Respiratory sensitizer. Skin sensitizer. Irritant

-Target Organ: Respiratory tract. Skin.

TSCA (Toxic Substances Control Act) Regulations: All ingredients are on the TSCA Chemical Substance Inventory.

EPCRA Section 313 (40 CFR 372): This product contains the following chcmical(s) subject to reporting requirements: approx. 32\% 4,4-MDI.

CERCLA (Comprehensive Environmental Response, Compensation and Liability Act): 4,4-Methylene Diphenyl Diisocyanate (CAS 101-68-8) has a 5,000 lb. RQ (reportable quantiry). Any spill or release above the RQ must be reported to the National Response Center $(800-4248802)$. The \% of 4,4-MDI in this product is listed in Section 2 of this MSDS.

This product does not contain nor is it manufactured with ozone depleting substances,

Other Regulations/Legislation which apply to this product:

Massachusetts Right-to-Know. Pennsylvania Right-to-Know, New Jersey Right-to-Know, CERCLA.

\section{CANADIAN CLASSIFICATION:}

This product has been classified in accordance with the hazard criteria of the CPR (Controlled Products Regulations) and this MSDS (Material Safery Data sheet) contains all the information required by the CPR.

Controlled Products Regulations (WHMIS) classification: D-1A: Very toxic (acute effects). D-2A: Very Toxic. D-2B: Toxic.

CEPA / Canadian Domestic Substances List (DSL): This product contains substance(s) not on the Canadian Domestic Substances List (CEPA DSL), environmental notification may be required.

\section{SECTION 16-OTHER INFORMATION}

$\begin{array}{lll}\text { Glossary: } & \text { ACGIH - } & \text { American Conference of Governmental Industrial Hygienists } \\ & \text { IARC - } & \text { International Agency for Research on Cancer } \\ \text { NTP - } & \text { National Toxicology Program } \\ & \text { OSHA - } & \text { Occupational Safery and health Administration }\end{array}$

FOR YOUR PROTECTION: The information and recommendations in this publication are, to the best of our knowledge, reliable. The toxicity and risk characteristics of products made by Specialty Products, Inc. will necessarily differ from the toxiciry and risk characteristics that occur when such products are used with other materials during a manufacturing process. The resulting risk characteristics should be determined and made known to ultimate end-users and processors. Specialty Products, Inc., MAKES NO WARRANTIES OF ANY KIND, EXPRESS OR IMPLIED, INCLUDING THOSE OF MERCHANTABILITY AND FITNESS FOR A PARTICULAR PURPOSE. 


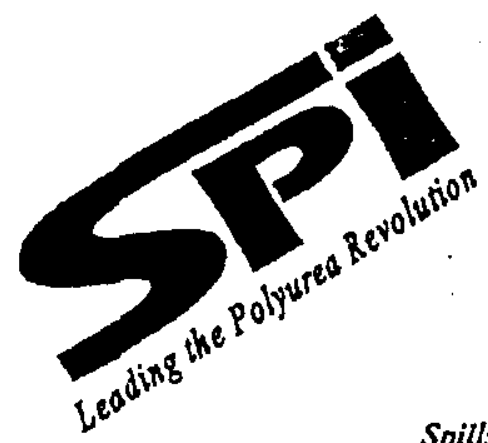

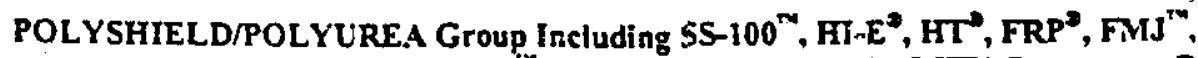

F.B.E. $4^{\text {ix }}$, Glass Shield-100 A.E.TM, J-IIM Componeot B

MSDS Number: 1008-599

Revision Date: 09-SEP-98

\section{MATERIAL SAFETY DATA SHEET}

EMERGENCY CONTACT:

Spills, Leaks, Fire or Exposure Call Chemtrec: (800) \$24-9300

HMIS Information:

Health $3^{*}$

Flammability 1

Reactivity

\section{SECTION 1 - CHEMICAL PRODUCT AND COMPANY IDENTIFICATION}

Product Name:

Chemical Name:

Chemical Formula:

Maaufactured By:

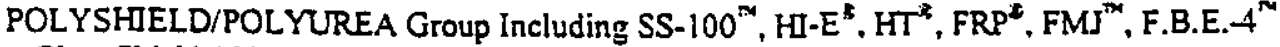
Glass Shield-100 A.E. ${ }^{\text {TM }}$, J-IITM Component B

Mixture of amine compounds

N/A Product is a Mixture

Specialty Products, Inc. $2410104^{\text {th }}$ St. Ct. S., Suite D

Lakewood. WA 98499

(253) 588-7101

\section{SECTION 2 - HAZARDOUS INGREDIENTS}

Chemical \& Common Name (Chemical Identity is Proprietary)

*(Chemical Identiry is Proprietary)

(Chemical Identity is Proprietary)
C.AS \# Wt\% OSHA PEL 60-90 None established

10-40 None established

2-20 None established
ACGIH TLV

None established

None established

None established

*Designates a hazardous chemical as defined by SARA Title III, Section 311,312

\section{SECTION 3 - PHYSICAL CHARACTERISTICS}

Boiling Range:

Vapor Pressure (mm Hg):

Specific Gravity:

Vapor Deasity (Air $=1$ ):

$\%$ Volatile (Volume):

Volatile Organic Content (VOC):

Solubility (Specific solvents):

Appearance and Odor: $586^{\circ} \mathrm{F}$

$0.9 \mathrm{~mm}$ @ $68^{\circ} \mathrm{F}$

$0.98-1.02$

6.2

0

0 gramsiliter

Moderate

Viscous liquid in various colors; characteristic amine odor

\section{SECTION 4 - FIRE \& EXPLOSION DATA}

Flash Point: Above $275^{\circ} \mathrm{F}\left(135^{\circ} \mathrm{C}\right)$

Extinguishing Media: Dry chemical, toam. carbon dioxide. halogenated agents. Watcr or foam can cause trothing.

Special Firefighting Procedures: Use water to cool fire-exposed containers. Self-contained breathing apparatus. with full tacepiece and protcctive clothing should be wom. 
Unusual Fire and Explosion Hazards: None known.

Reactivity: Product is stable under normal conditions.

Hazardous Polymerization: Will not occur.

Incompatibilities (materials to avoid): Will react with acids.

Conditions to avoid: AVOID MOISTURE CONTAMINATION IN CONTAINERS. CONTAINERS SHOULD NOT BE RESEALED IF CONTAMINATION IS SUSPECTED. $\mathrm{CO}_{2}$ CREATED PRESSURE CAN DEVELOP. DO NOT ATTEMPT TO USE CONTAMINATED MATERIAL.

Hazardous Decomposition Products: Combustion products: Toxic levels of ammonia. Oxides of nitrogen. carbon, and some aldehydes and ketones may also be produced.

\section{SECTION 5 - HEALTH HAZARDS}

PRIMARY ROLTES OF E.YTRY: Eye contact, inhalation, ingestion, skin contact.

\section{ACL'TE HEALTH EFFECTS:}

EYE CONTACT: Will cause irritation, buming or chemical burns.

LHALATIO.N: Vapors or mist are irritating and may cause nasal discharge, coughing, and discomfort in nose, throat and chest. Severe overexposure may result in difficulty breathing, headache, nausea, vomiting, and drowsiness.

LVESTION: Ingestion of this product is expected to be hamful or fatal. Otal LD50 $=485 \mathrm{mg} / \mathrm{kg}$.

SKIN CONTACT: This product can be toxic by dermal absorption. Dermal LD50 $=700 \mathrm{mg} / \mathrm{kg}$.

\section{ENIERGE.YCY FIRST AID PROCEDLRES:}

EYE CONTACT: Wash with clean water for at least fifeen minutes: get medical attention.

I.HALATION: Move individual to fresh air. If breathing has stopped, apply artificial respiration; get medieal attention immediately.

I.YGESTION: If person is conscious and can swallow, immediately give two glasses of water (15 oz) but do not induce vomiting. This material is cortosive. If vomiting oecurs, give fluids again. Have a physician deternine if condition of patient will permit induction of vomiting or evacuation of stomach. Do not give anything by mouth to an unconscious or convulsing person.

SKIN CONTACT: Immediately tlush skin with plenty of water for at least 15 minutes. Remove contaminated clothing and shoes. Get medical attention. Wash clothing and decontaminate shoes betore reuse.

CHRONIC HEALTH EFFECTS: Prolonged or repeated over exposure may result in lung damage.

MEDICAL CONDITIONS AGGRAVATED BY EXPOSLRE: Pre-existing lung or skin conditions could be aggtavated by repeated exposure.

\section{SECTION 6 - SPILL OR LEAK PROCEDURES}

Steps to be taken in case material is spilled or released: Ventilate arca. Avoid brealhing vapor. Use of self-contained breathing apparalus may be required in confined or enclosed areas. Contain any spills with dikes or absorbents to prevent migration and entry into sewers or streams. Take up small spills with dry chemical absorption. Large spills may be taken up with pump or vacuum and finished off with dry chervical absorbent.

Waste Disposal Method: Dispose of material in accordance with all federal. state, and local regulations. 


\section{SECTION 7-SPECLAL PROTECTION DATA}

Respiratory Protection: Wear MSHANIOSH-approved respirator for organic vapors. Ensure workers are trained in their proper use.

Ventilation: Mechanical ventilation, adequate to keep exposure below TLV, is recommended.

Protective Gloves: Neoprenc or nitrile rubber.

Eye Protection: Goggles or face shield.

Otber Protective Clothing or Equipment: Eyewash fountain and safery shower should be accessible: impervious protective clothing.

\section{SECTION 8 - HANDLING \& STORAGE DATA}

Precautions to be Taken in Handling and Storage: Store in well-ventilated, cool, dry area. Purge with nitrogen and close containet when not in use.

Other Precautions: Store in original container: keep tightly closed. Do not reuse conthiner for other purposes. KEEP OLT OF REACH OF CHLLREN.

\section{SECTION 9 - OTHER INFORMATION}

TSCA Information: All ingredients are on the TSCA Chemical Substance Inventory.

WHYUS Information: Not all ingredients are confirmed on the Canadian DSL (Domestic Substances List).

The information contained herein is based on data considered to be aceurate. However, no warranty is expressed or implied regarding the accuracy of these datt or the results to be obtaiped fur the use thereof. Recipients are advised to contirm in advance of need that the information is current applicable, and suitsble regarding all curtent regulations. 


\section{Amercoat 3}
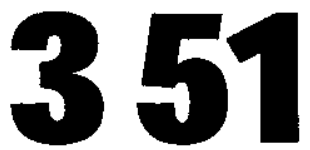

\section{0\% solids multi-purpose epoxy}

\section{Product Datal}

\section{Application Instructions}

- Solventless

- High-build

- Hot water resistant

- Chemical resistant

- Abrasion resistant

- Excellent barrier properties

- Standard airless application

- Easily cleaned

\section{Typical Uses}

- Chemical tank lining

- Water tank lining

- Pipe lining and coating

- Abrasion resistant coating

- Concrete protection

Amercoat 351 is a solventless, high performance coating that can be applied with standard airless equipment. It is suitable for use as a tank lining for a variety of fuel and clean products for non-reactive chemicals, caustic, potable water, salt water, ballast and dry bulk materials.

The abrasion resistance of Amercoat 351 allows it to be used as a lining for slurries, or as a coating for concrete in high wear services.

Amercoat 880 glass flake additive may be added to Amercoat 351 to increase film build, further reinforce mechanical properties and lower moisture permeability. For increased film build in one coat, Amercoat 884 can be added.

Amercoat 351 is an excellent barrier coat, providing long-term resistance to corrosion even under aggressive conditions. It is suitable for immersion in both salt and deionized waters up to $120^{\circ} \mathrm{F}\left(49^{\circ} \mathrm{C}\right)$.

\section{Typical Properties}

\section{Abrasion (ASTM D4060)}

$1 \mathrm{~kg} / 1000$ cycles $/ \mathrm{cs}-17$ wheel

Adhesion, elcometer (ASTM D4541)

Salt spray - 12 mils $/ 5000$ hrs.

face corrosion (ASTM B117)

face blistering (ASTM B117)

Humidity condensation (ASTM D4585)

face corrosion

blistering

Moisture Vapor Transmission

(ASTM F1249)

Steam cleanable

\section{1 mg wt. loss 1200 psi}

None

None

$2000+$ hrs

None

$6.07 \mathrm{~g} / \mathrm{m}^{2}$

Yes
None

\section{Physical Data}

\begin{tabular}{|c|c|c|}
\hline Finish & \multicolumn{2}{|l|}{ Semigloss } \\
\hline $\begin{array}{l}\text { Color* } \\
\text { "Note: When exposed to sunlight, }\end{array}$ & \multicolumn{2}{|c|}{$\begin{array}{l}\text { Gray } \\
\text { olor change will occur: }\end{array}$} \\
\hline Components & \multicolumn{2}{|l|}{2} \\
\hline Curing mechanism & \multicolumn{2}{|c|}{$\begin{array}{l}\text { Chemical reaction between } \\
\text { components }\end{array}$} \\
\hline Volume solids (caiculated) & \multicolumn{2}{|l|}{$100 \%$} \\
\hline $\begin{array}{l}\text { Dry film thickness per coat } \\
\text { with } 880 \\
\text { with } 8844^{1 / 2} \text { gal } \\
\text { with } 8841 \mathrm{gal}\end{array}$ & \multicolumn{2}{|c|}{$\begin{array}{l}8-12 \text { mils }(200-300 \text { microns } \\
12-25 \text { mils } \\
20-30 \text { mils } \\
45-55 \text { mils }\end{array}$} \\
\hline $\begin{array}{l}\text { Theoretical coverage } \\
1 \text { mil ( } 25 \text { microns) } \\
8 \text { mils ( } 200 \text { microns) }\end{array}$ & $\begin{array}{l}\mathrm{ft}^{2} / \mathrm{gal} \\
1604 \\
201\end{array}$ & $\begin{array}{r}\mathrm{m}^{2} / \mathrm{L} \\
39.4 \\
4.9\end{array}$ \\
\hline VOC mixed & $\begin{array}{l}\text { lb/gal } \\
0.0\end{array}$ & $\mathrm{~g} / \mathrm{L}$ \\
\hline Temperature resistance & \begin{tabular}{ll}
\multicolumn{2}{c}{ Wet } \\
${ }^{\circ} \mathrm{F}$ & ${ }^{\circ} \mathrm{C}$ \\
120 & 49 \\
140 & 60
\end{tabular} & \begin{tabular}{ll}
\multicolumn{2}{c}{ Dry } \\
${ }^{\circ} \mathrm{F}$ & ${ }^{\circ} \mathrm{C}$ \\
200 & 93 \\
250 & 121
\end{tabular} \\
\hline $\begin{array}{l}\text { Flash point (SETA) } \\
351 \text { cure } \\
351 \text { resin } \\
\text { Amercoat } 928\end{array}$ & $\begin{array}{r}{ }^{\circ} \mathrm{F} \\
>212 \\
>212 \\
175\end{array}$ & $\begin{array}{r}{ }^{\circ} \mathrm{C} \\
>100 \\
>100 \\
47\end{array}$ \\
\hline
\end{tabular}

\section{Qualifications}

USDA - Incidental Food Contact

\section{Application Data}

Applied over

Surface preparation steel concrete

Primer

Method

Mixing ratio (by volume) 351

351 - 4 gal mixed

351 - 4 gal mixed

351 - 4 gal mixed

Pot life (hours)

Environmental conditions

Temperature air and surface material

Surface temperatures must be at least $5^{\circ} \mathrm{F}\left(3^{\circ} \mathrm{C}\right)$ above dew point to prevent condensation.
Primed or prepared steel, concrete

SSPC-SP10

ASTMD 4259 or 4260

Amercoat 370

3 parts resin to 1 part cure

$2 \times 1$-gal can 880

$1 \times{ }^{1}{ }_{2}-$ gal can 884

$1 \times 1$-gal can 884

$\begin{array}{ccc} & { }^{\circ} \mathrm{F} /{ }^{\circ} \mathrm{C} & \\ 90 / 32 & 70 / 21 & 50 / 10 \\ 1 / 2 & 1 & 1 \frac{1 / 2}{2}\end{array}$

$\begin{array}{ll}{ }^{\circ} \mathrm{F} & { }^{\circ} \mathrm{C} \\ 40 \text { to } 90 & 4 \text { to } 32 \\ 50 \text { to } 90 & 10 \text { to } 32\end{array}$

Airless spray 
RPP-6855, Rev. 0

\section{Chemical Resistance}

The following is a representative list of chemicals to which Amercoat 351 may be exposed as a lining. Contact your Ameron representative for recommendations concerning specific requirements.

$\begin{array}{ll}\text { Alum } & \text { Gasoline, unleaded } \\ 10 \% \text { Ammonium hydroxide } & \text { Kerosene } \\ \text { Aromatic } 100 & \text { Methanol (to } 120^{\circ} \mathrm{F}, 49^{\circ} \mathrm{C} \text { ) } \\ \text { n-Butyl acetate } & \text { Mineral oil } \\ \text { Carbon Tetrachloride } & \text { Nonyl phenol } \\ \text { Castor oil } & \text { Oxygenated salt water } \\ 50 \% \text { Caustic (to } 160^{\circ} \mathrm{F}, 71^{\circ} \mathrm{C} \text { ) } & \text { Palm oil (to } 160^{\circ} \mathrm{F}, 71^{\circ} \mathrm{C} \text { ) } \\ \text { Crude oil (to } 120^{\circ} \mathrm{F}, 49^{\circ} \mathrm{C} \text { ) } & \text { Salt water (to } 120^{\circ} \mathrm{F}, 49^{\circ} \mathrm{C} \text { ) } \\ \text { Diesel fuel } & 20 \% \text { Sodium carbonate } \\ \text { Diethylene glycol } & \text { Triton X-100 } \\ \text { Ethanol (to } 120^{\circ} \mathrm{F}, 49^{\circ} \mathrm{C} \text { ) } & \text { Water (to } 120^{\circ} \mathrm{F}, 49^{\circ} \mathrm{C} \text { ) } \\ \text { Formaldehyde } & \text { Xylene }\end{array}$

\section{Systems Using Amercoat 351}

1st Coat
Amercoat 351
Amercoat 351

2nd Coat

Amercoat 351

Amercoat $450 \mathrm{HS}$

\section{Surface Preparation}

Coating performance is, in general, proportional to the degree of surface preparation. Prior to coating, the surface must be clean, dry, undamaged and free of all contaminants, including salt deposits. Round off all rough welds and remove all weld spatter.

Steel - Abrasive blast SSPC-SP10. Blast to achieve an anchor profile of 1 to 2 mils (25-50. microns) anchor profile as indicated by a Keane-Tator Surface Profile Comparator. Testex Tape or similar device. Remove abrasive residue or dust from surface. Apply Amercoat 351 as soon as possible to keep steel from rusting. If a holding primer is required, Amercoat $83 \mathrm{HS}$ may be used.

Note: Apply Amercoat 351 as soon as possible after surface preparation to prevent recontamination. Do not leave blasted steel uncoated overnight. In case of contamination, remove contaminants Spot blast if needed.

Concrete--Clean concrete surface. Abrasive blast (ASTM D4259) or acid etch (ASTM D4260) to remove all previous coatings, chalk and surface glaze or laitance. Full small holes or voids in cast concrete wall or overhead surfaces with $\mathrm{Nu}-\mathrm{Klad}$ 114A filler compound before applying Amercoat 351. Apply Amercoat 351 within 7 days after application of Nu-Klad 114A.

Adhere to all application instructions, precautions, conditions and limitations to obtain the maximum performance. For conditions outside the requirements or limitations described, contact your Ameron representative.

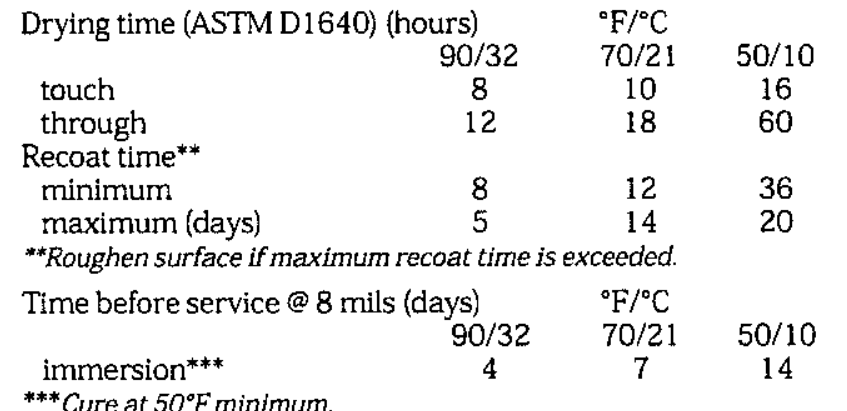

Cure at $50^{\circ} \mathrm{F}$ minimum.

Equipment cleaner

Amercoat 928

\section{Shipping Data}

\begin{tabular}{|c|c|c|}
\hline $\begin{array}{l}\text { Packaging } \\
\text { cure } \\
\text { resin }\end{array}$ & \multicolumn{2}{|c|}{$\begin{array}{l}1-\text { and } 4-\mathrm{gal} \text { can } \\
0.25 \text { gal in } 1 \text {-gal can } \\
1.0 \text { gal in } 1-\mathrm{gal} \text { can } \\
0.75 \mathrm{gal} \text { in } 1 \text {-gal can } \\
3.0 \text { gal in } 5 \text {-gal can }\end{array}$} \\
\hline $\begin{array}{l}\text { Shipping weight (approx) } \\
\text { 1-gal unit }\end{array}$ & lb & $\mathrm{kg}$ \\
\hline $\begin{array}{l}\text { cure } \\
\text { resin }\end{array}$ & $\begin{array}{l}2.5 \\
9.3\end{array}$ & $\begin{array}{l}1.1 \\
4.2\end{array}$ \\
\hline $\begin{array}{l}\text { 4-gal unit } \\
\text { cure } \\
\text { resin }\end{array}$ & $\begin{array}{r}9.0 \\
40.0\end{array}$ & $\begin{array}{r}4.1 \\
18.1\end{array}$ \\
\hline
\end{tabular}

Shelf life when stored indoors at 40 to $100^{\circ} \mathrm{F}\left(4\right.$ to $\left.38^{\circ} \mathrm{C}\right)$ cure and resin

1 year from shipment date

Numerical values are subject to normal manufacturing tolerances, color and testing variances. Allow for application losses and surface irregularities.

The mixed product is nonphotochemically reactive as defined by South Coast Alr Quality Management District's Rule 102 or equivalent regulations.

\section{Low Temperature Limitations}

After application the substrate and coating temperature must be at $40^{\circ} \mathrm{F}$ or above to avoid creating film defects from exposure to temperatures below $40^{\circ} \mathrm{F}$.

Cure time required before exposure to temperatures below $40^{\circ} \mathrm{F}$ are as follows:

$$
\begin{array}{llll}
70^{\circ} \mathrm{F} & 60^{\circ} \mathrm{F} & 50^{\circ} \mathrm{F} & 40^{\circ} \mathrm{F} \\
3 \mathrm{hrs} & 7 \mathrm{hrs} & 16 \mathrm{hrs} & 48 \mathrm{hrs}
\end{array}
$$

\section{High Temperature Limitation}

After application at surface temperatures of $40^{\circ} \mathrm{F}$ to $90^{\circ} \mathrm{F}$ the Amercoat 351 must cure as follows before being exposed to temperatures above $90^{\circ} \mathrm{F}$ to avoid sagging:

$$
\begin{array}{lllll}
90^{\circ} \mathrm{F} & 70^{\circ} \mathrm{F} & 60^{\circ} \mathrm{F} & 50^{\circ} \mathrm{F} & 40^{\circ} \mathrm{F} \\
4 \mathrm{hrs} & 6 \mathrm{hrs} & 8 \mathrm{hrs} & 10 \mathrm{hrs} & 24 \mathrm{hrs}
\end{array}
$$

When surface temperatures are above $90^{\circ} \mathrm{F}$ use Amercoat 884 additive to maintain film build. Without the Amercoat 884 additive sagging may occur above 4 mils DFT at a substrate temperature of $140^{\circ} \mathrm{F}$. 


\section{Application Equipment}

The following is a guide; suitable equipment from other manufacturers may be used. Changes in pressure and tip size may be needed to achieve the proper spray characteristics.

Airless spray-Standard equipment with a ratio of $45: 1$, such as Graco King. Pump should be equipped with ${ }^{3}{ }_{8}$ inch internal diameter high pressure spray hose for lengths of less than 50 feet. For length greater than 50 feet, spray hose should be $1 / 2$ inch internal diameter.

When Amercoat 880 is added, the tip size should be 0.035 -inch or larger. Tip size when Amercoat 884 is added should be 0.027 to 0.035 .

Power mixer-Jiffy Mixer

Brush or Roller-Additional coats may be required to attain proper thickness.

\section{Application Procedure}

Amercoat 351 is packaged in the correct proportions of resin and cure which must be mixed together before use.

1. Flush equipment with Amercoat 928 cleaner.

2. Stir both resin and cure to an even consistency. Add cure to resin mixing until a uniform consistency is achieved. Do not use thinners. Never mix more than can be sprayed within pot life time.

Pot life (hours)

$$
\begin{array}{ccc} 
& { }^{\circ} \mathrm{F} /{ }^{\circ} \mathrm{C} & \\
90 / 32 & 70 / 21 & 50 / 10 \\
1 / 2 & 1 & 1 / 2
\end{array}
$$

3. Apply a wet coat in even, parallel passes. Overlap each pass 50 percent to avoid bare areas, pinholes or holidays. Cross spray at right angles if necessary.

4. Material temperature must be between 50 and $90^{\circ} \mathrm{F}$. Higher temperatures shorten the pot life. Lower temperatures affect sprayability.

5. Ventilate with clean air during application. Maintain air temperature to prevent condensation on coating surface.

6. Check film thickness using a wet film thickness gauge. If films less than 8 mils ( 200 microns) apply additional material. Maximum dry film thickness when using Amercoat 880 is 25 mils per coat.

Note: To increase film bulld with one application Amercoat 884 can be added - $1 / 2$ gal can for a 4-gal unit of Amercoat 351 will increase dry film thickness to between 20-30 mils. See Amercoat 884 Product Data Sheet for specific information.

7. For immersion service, check for bare areas, pinholes and holidays with a non-destructive wet sponge holiday detector such as Tinker-Rasor Model M1 or Model AP/W. Apply additional Amercoat 351 to areas requiring touch-up within maximum recoat time.

Time before service@ 8 mils (days)

immersion**

$90 / 32$

${ }^{\circ} \mathrm{F} /{ }^{\circ} \mathrm{C}$

$70 / 21$

7

$50 / 10$

${ }^{* *}$ Cure at $50^{\circ} \mathrm{F}$ minimum.

8. Clean equipment with Amercoat 928 immediately after use.

\section{Repair}

Spot abrasive blast to remove all rust, loose paint and other contaminants from damaged areas abraded to bare steel.

Clean and roughen coating surface if recoat time is exceeded. Apply Amercoat 351 as soon as possible after surface is cleaned to prevent contaminants on the surface.

\section{Warranty}

Ameron warrants its products to be free from defects in material and workmanship. Ameron's sole obligation and Buyer's exclusive remedy in connection with the products shall be limited, at Ameron's option, to either replacement of products not conforming to this Warranty or credit to Buyer's account in the invoiced amount of the nonconforming products. Any claim under this Warranty must be made by Buyer to Ameron in writing within five (5) days of Buyer's discovery of the claimed defect, but in no event later than the expiration of the applicable shelf life, or one year from the delivery date, whichever is earlier. Buyer's failure to notify Ameron of such nonconformance as required herein shall bar Buyer from recovery under this Warranty.

Ameron makes no other warranties concerning the product. No other warranties, whether express, implied, or statutory, such as warranties of merchantability or fitness for a particular purpose, shall apply. In no event shall Ameron be liable for consequential or incidental damages.

Any recommendation or suggestion relating to the use of the products made by Ameron, whether in its technical literature, or in response to specific inquiry, or otherwise, is based on data believed to be reliable; however, the products and information are intended for use by Buyers having requisite skill and knowhow in the industry, and therefore it is for Buyer to satisfy itself of the suitability of the products for its own particular use and it shall be deemed that Buyer has done so, at its sole discretion and risk. Variation in environment, changes in procedures of use, or extrapolation of data may cause unsatisfactory results.

\section{Limitation of Liability}

Ameron's liability on any claim of any kind, including claims based upon Ameron's negligence or strict liability, for any loss or damage arising oul of, connecled with, or resulting from the use of the products, shall in no case exceed the purchase price allocable to the products or part thereof which give rise to the claim. In no event shall Ameron be liable for consequential or incidental damages. 


\section{Safety Precautions}

Read each component's material safety data sheet before use. Mixed material has hazards of each component. Safety precautions must be strictly followed during storage, handling and use.

CAUTION - Improper use and handling of this product can be hazardous to health.

Do not use this product without first taking all appropriate safety measures to prevent property damage and injuries. These measures may include, without limitation: implementation of proper ventilation, use of proper lamps, wearing of proper protective clothing and masks, tenting and proper separation of application areas. Consult your supervisor. Proper ventilation and protective measures must be provided during application and drying to keep vapor concentrations within safe limits and to protect against toxic hazards. Necessary safety equipment must be used and ventilation requirements carefully observed, especially in confined or enclosed spaces, such as tank interiors and buildings.

This product is to be used by those knowledgeable about proper application methods. Ameron makes no recommendation about the types of safety measures that may need to be adopted because these depend on application environment and space, of which Ameron is unaware and over which it has no control.

If you do not fully understand these warnings and instructions or if you cannot strictly comply with them, do not use the product.

Note: Consult Code of Federal Regulations Title 29, Labor, parts 1910 and 1915 concerning occupational safety and health standards and regulations, as well as any other applicable federal, state and local regulations on safe practices in coating operations.

This product is for industrial use only. Not for residential use.

\section{A AMERON $_{\text {Coatings }}^{\mathrm{AMEON}}$}

Ameron Coatings - 201 North Berry Street, Brea, California 92821 - (714) 529-1951

Ameron PCG/Europe • J. F. Kennedylaan 7, 4191 MZ Geldermalsen, The Netherlands • (3I) 345-587-587 


\section{Appendix D \\ Cost Estimates}




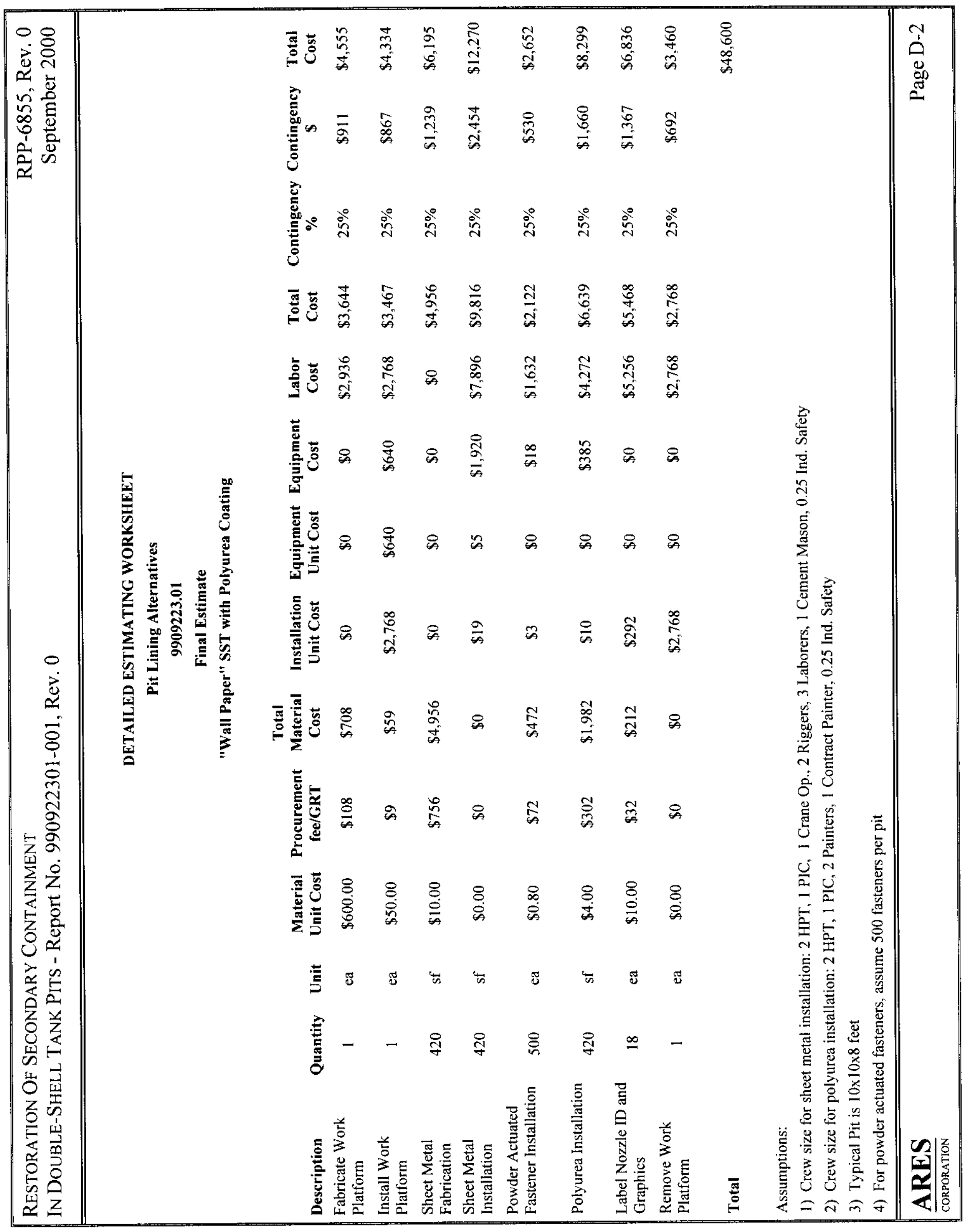




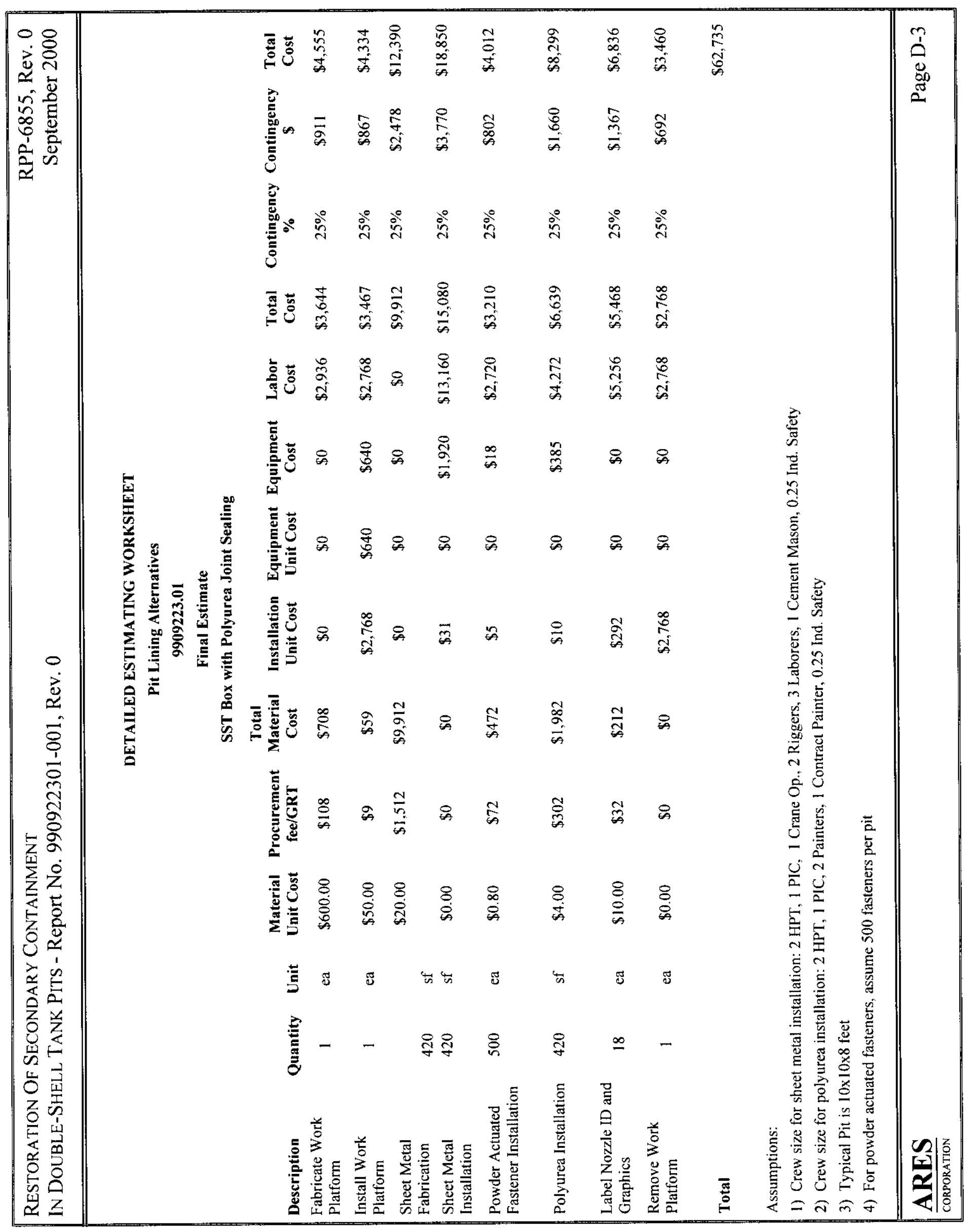




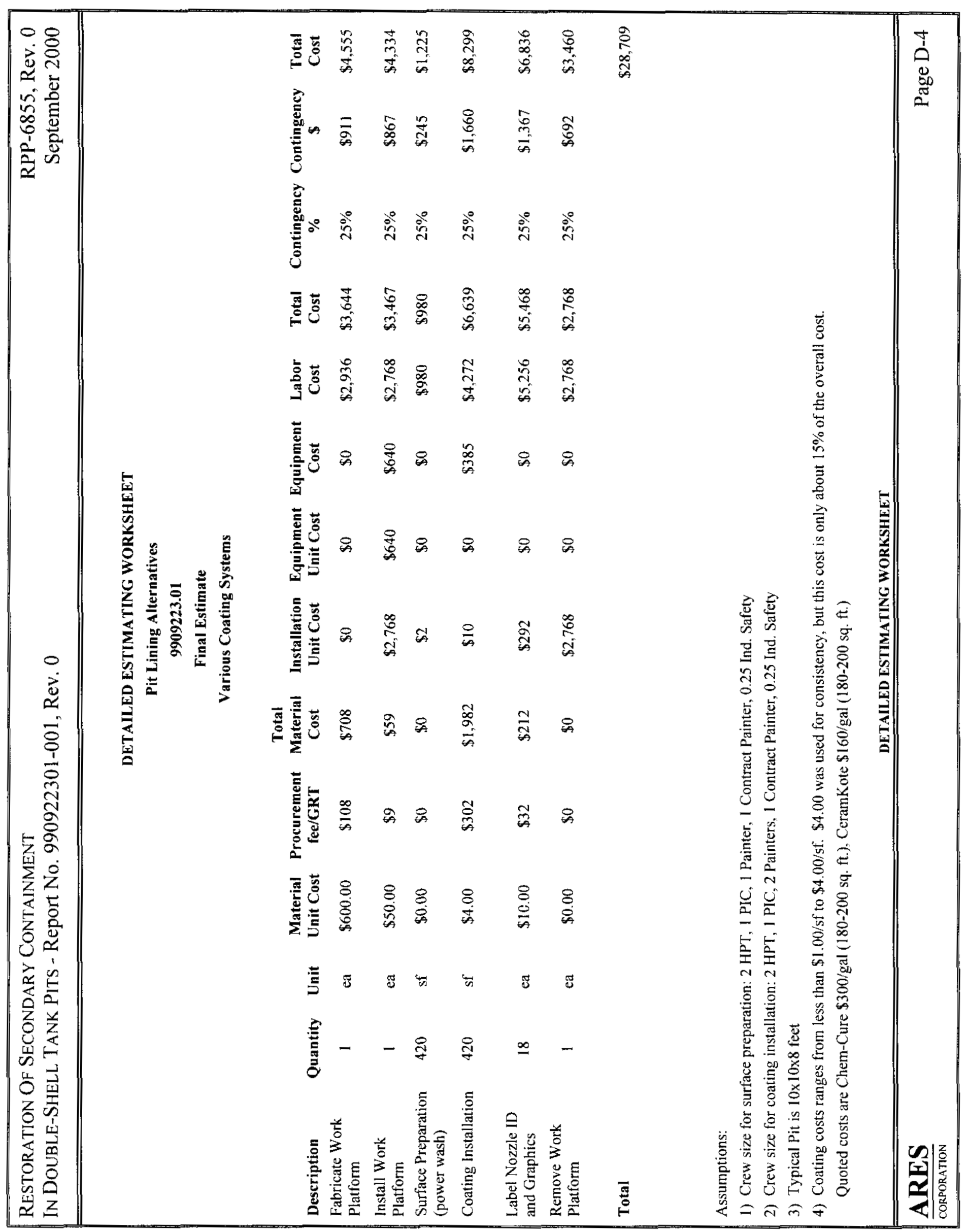




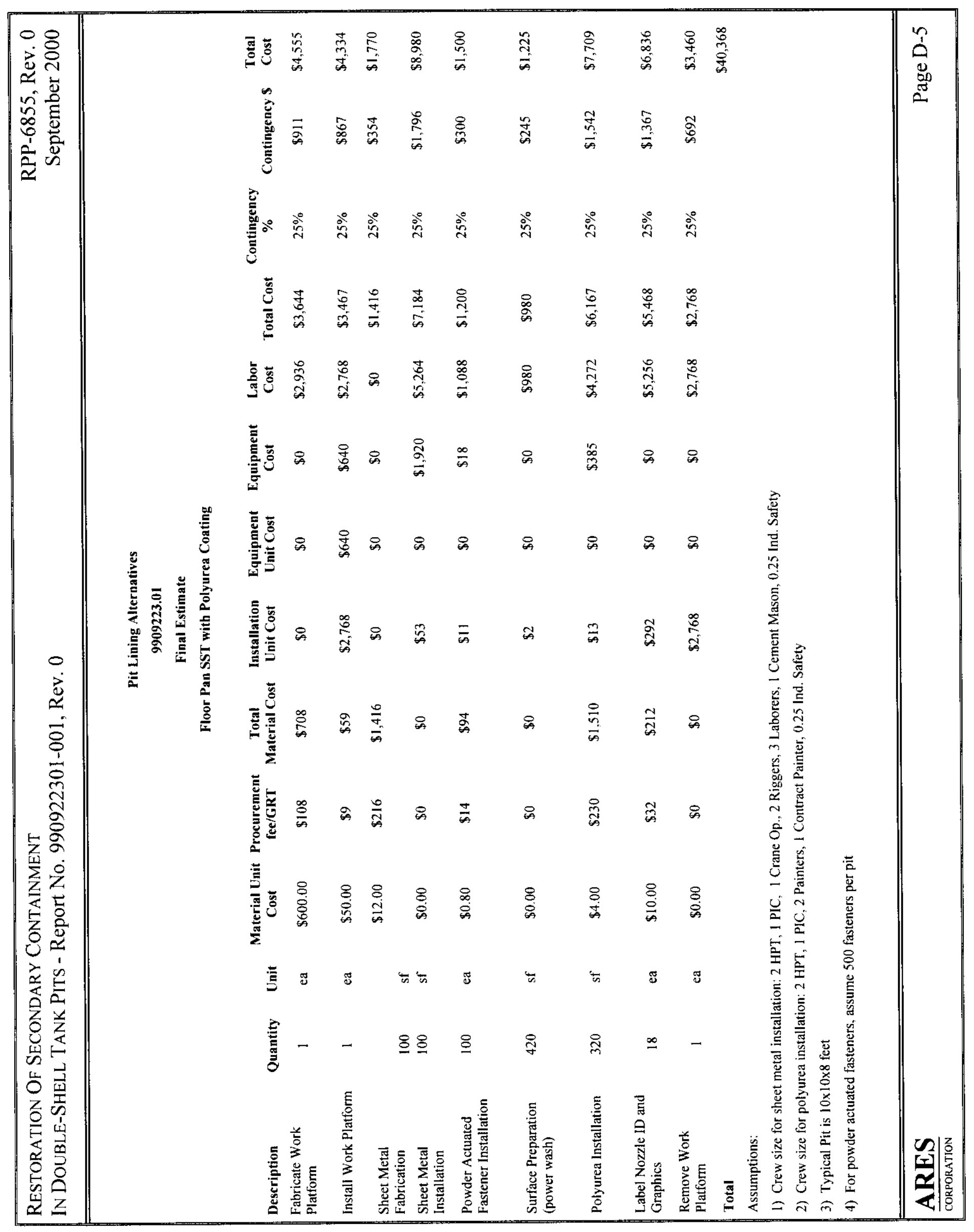


RESTORATION OF SECONDARY CONTAINMENT

IN Double-SHell TANK PITS - Report No. 990922301-001, Rev. 0

3
4
4
4
4

Backup Data for "Wall Paper Crew"

Description
Sheet Metal Installation

HPT (2)

PIC

Rate Hours Total

Crane Operator

Riggers (2)

Laborers (2)

Ind. Hygienist

Operator

Total

$\begin{array}{lrr}\$ 36.00 & 48 & \$ 1,728.00 \\ \$ 40.00 & 24 & \$ 960.00 \\ \$ 36.00 & 24 & \$ 864.00 \\ \$ 36.00 & 48 & \$ 1,728.00 \\ \$ 32.00 & 48 & \$ 1,536.00 \\ \$ 36.00 & 6 & \$ 216.00 \\ \$ 36.00 & 24 & \$ 864.00 \\ & & \$ 7,896.00\end{array}$

Powder Actuated Fasteners

Cement Mason

Laborer

$\$ 36.00$

24

$\$ 864.00$

Total

$\$ 32.00$

$24 \$ 768.00$

$\$ 1,632.00$

Polyurea Installation

HPT (2)

PIC

$\$ 36.00$

$\$ 40.00$

32

$\$ 1,152.00$

Painters (2)

$\$ 31.00$

$\$ 640.00$

Ind. Hygienist

$\$ 36.00$

$\$ 992.00$

Operator

$\$ 36.00$

$\$ 144.00$

Contract Painter

$\$ 48.00$

$\$ 576.00$

Total

$\$ 768.00$

$\$ 4,272.00$ 


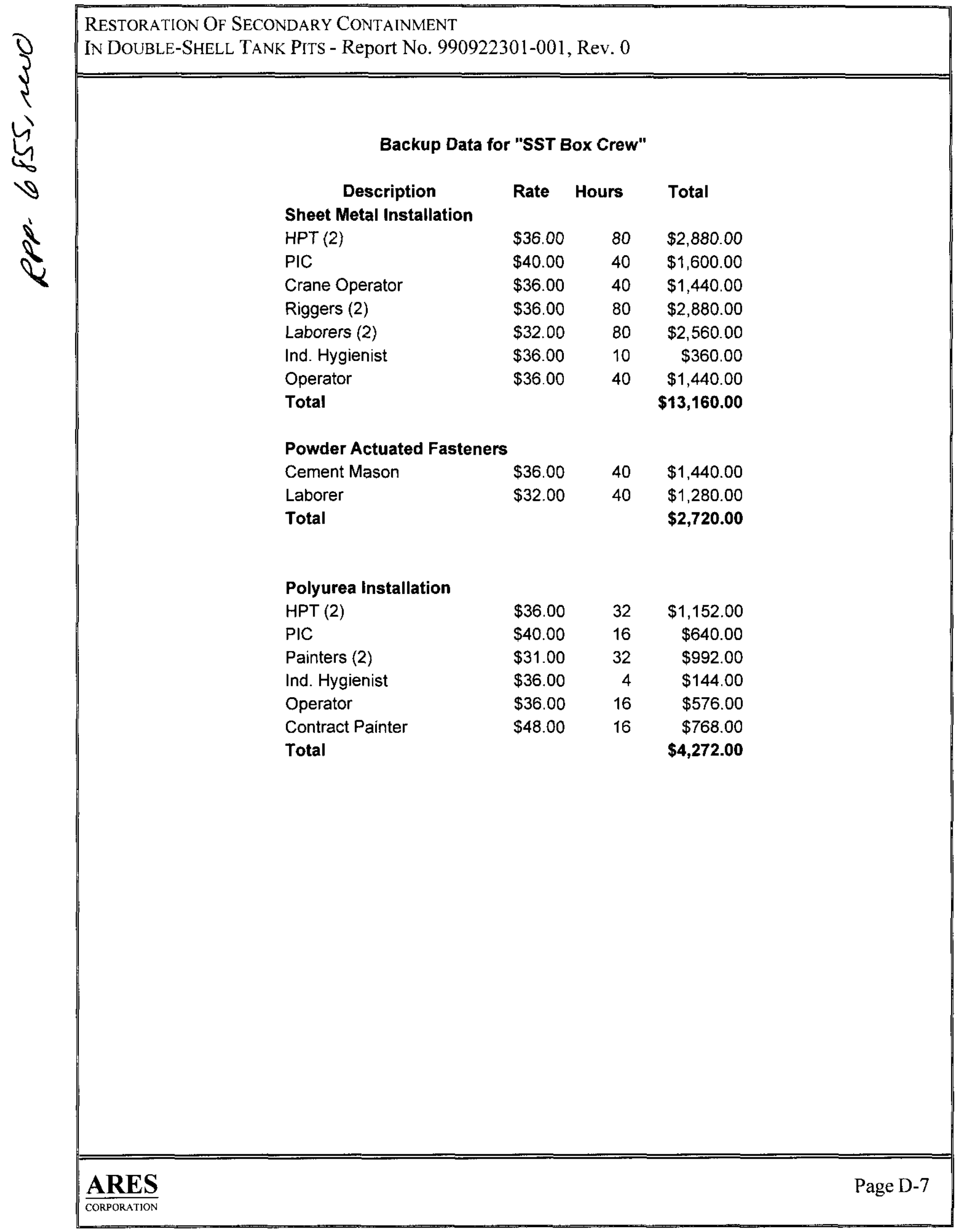


RESTORATION Of SECONDARY CONTAINMENT

In Double-Shell Tank PITS - Report No. 990922301-001, Rev. 0

\section{Backup Data for Coatings}

Description

Rate Hours

Total

Surface Preparation

HPT (2)

PIC

Painter

$\$ 36.00 \quad 8$

$\$ 288.00$

$\$ 31.00 \quad 4$

$\$ 160.00$

Ind. Hygienist

$\$ 36.00 \quad 2$

$\$ 124.00$

Operator

$\$ 36.00$

$\$ 72.00$

Contract Painter

$\$ 48.00$

$\$ 144.00$

Total

$\$ 192.00$

$\$ 980.00$

Coating Installation

HPT (2)

PIC

Painters (2)

Ind. Hygienist

Operator

Contract Painter

$\$ 36.00 \quad 32$

$\$ 40.00 \quad 16$

$\$ 1,152.00$

$\$ 31.00 \quad 32$

$\$ 640.00$

$\$ 992.00$

$\$ 36.00 \quad 4$

$\$ 144.00$

$\$ 36.00 \quad 16$

$\$ 576.00$

$\$ 48.00$

$\$ 768.00$

Total

$\$ 4,272.00$ 
RESTORATION OF SECONDARY CONTAINMENT

In Double-Shell TanK PITS - Report No. 990922301-001, Rev. 0

Backup Data for Floor Pan

\begin{tabular}{|c|c|c|c|}
\hline Description & Rate & Hours & Total \\
\hline \multicolumn{4}{|l|}{ Surface Preparation } \\
\hline HPT (2) & $\$ 36.00$ & 8 & $\$ 288.00$ \\
\hline $\mathrm{PIC}$ & $\$ 40.00$ & 4 & $\$ 160.00$ \\
\hline Painter & $\$ 31.00$ & 4 & $\$ 124.00$ \\
\hline Ind. Hygienist & $\$ 36.00$ & 2 & $\$ 72.00$ \\
\hline Operator & $\$ 36.00$ & 4 & $\$ 144.00$ \\
\hline Contract Painter & $\$ 48.00$ & 4 & $\$ 192.00$ \\
\hline Total & & & $\$ 980.00$ \\
\hline \multicolumn{4}{|l|}{ Sheet Metal Installation } \\
\hline HPT (2) & $\$ 36.00$ & 32 & $\$ 1,152.00$ \\
\hline PIC & $\$ 40.00$ & 16 & $\$ 640.00$ \\
\hline Crane Operator & $\$ 36.00$ & 16 & $\$ 576.00$ \\
\hline Riggers (2) & $\$ 36.00$ & 32 & $\$ 1,152.00$ \\
\hline Laborers (2) & $\$ 32.00$ & 32 & $\$ 1,024.00$ \\
\hline Ind. Hygienist & $\$ 36.00$ & 4 & $\$ 144.00$ \\
\hline Operator & $\$ 36.00$ & 16 & $\$ 576.00$ \\
\hline Total & & & $\$ 5,264.00$ \\
\hline \multicolumn{4}{|c|}{ Powder Actuated Fasteners } \\
\hline Cement Mason & $\$ 36.00$ & 16 & $\$ 576.00$ \\
\hline Laborer & $\$ 32.00$ & 16 & $\$ 512.00$ \\
\hline Total & & & $\$ 1,088.00$ \\
\hline \multicolumn{4}{|l|}{ Coating Installation } \\
\hline HPT (2) & $\$ 36.00$ & 32 & $\$ 1,152.00$ \\
\hline PIC & $\$ 40.00$ & 16 & $\$ 640.00$ \\
\hline Painters (2) & $\$ 31.00$ & 32 & $\$ 992.00$ \\
\hline Ind. Hygienist & $\$ 36.00$ & 4 & $\$ 144.00$ \\
\hline Operator & $\$ 36.00$ & 16 & $\$ 576.00$ \\
\hline Contract Painter & $\$ 48.00$ & 16 & $\$ 768.00$ \\
\hline Total & & & $\$ 4,272.00$ \\
\hline
\end{tabular}

Assume 3 days for "Wall Paper Installation"

Assume 5 days for "SST Box Installation"

Assume 2 days for floor pan installation

Assume 2 days for all coating (including polyurea) installation (one day for setup and takedown, one day for work)

Stainless Steel Fabrication of $\$ 20 / \mathrm{sf}$ is based on information from Anne Griggs. $\$ 10 / \mathrm{sf}$ is for much simpler fabrication.

Powder actuated nailer costs are from R.S. Means. Equipment cost of $\$ 700$ is divided by 39 pits.

Polyurea equipment costs are based on $\$ 15 \mathrm{~K}$ for all equipment divided by 39 pits. 
RESTORATION OF SECONDARY CONTAINMENT

In Double-Shell TANK PITs - Report No. 990922301-001, Rev. 0

\section{General Requirements for All Tasks}

Fabricate Work Platform

PIC

\section{Rate}

Hours

Total

Carpenter (2)

$\$ 40.00 \quad 16$

$\$ 640.00$

Painter

$\$ 36.00 \quad 48$

$\$ 1,728.00$

$\$ 31.00$

$\$ 248.00$

Foreman

$\$ 40.00$

$\$ 320.00$

Total

$\$ 2,936.00$

\section{Install Work Platform}

HPT (2)

PIC

Carpenters (2)

Ind. Hygienist

Operator

Crane Operator

Riggers (2)

Total

$\begin{array}{lc}\$ 36.00 & 16 \\ \$ 40.00 & 8 \\ \$ 36.00 & 16 \\ \$ 36.00 & 4 \\ \$ 36.00 & 8 \\ \$ 36.00 & 8 \\ \$ 36.00 & 16\end{array}$

$\$ 576.00$

$\$ 320.00$

$\$ 576.00$

$\$ 144.00$

$\$ 288.00$

$\$ 288.00$

$\$ 576.00$

$\$ 2,768.00$

Assume 1 day to install work platform

\section{Remove Work Platform}

HPT (2)

PIC

Carpenters (2)

Ind. Hygienist

Operator

Crane Operator

Riggers (2)

Total

$\begin{array}{lc}\$ 36.00 & 16 \\ \$ 40.00 & 8 \\ \$ 36.00 & 16 \\ \$ 36.00 & 4 \\ \$ 36.00 & 8 \\ \$ 36.00 & 8 \\ \$ 36.00 & 16\end{array}$

$\$ 576.00$

$\$ 320.00$

$\$ 576.00$

$\$ 144.00$

$\$ 288.00$

$\$ 288.00$

$\$ 576.00$

$\$ 2,768.00$

Assume 1 day to remove work platform

\section{Label Nozzle ID and Graphics}

HPT (2)

PIC

Painters (2)

Ind. Hygienist

Operator

$\$ 36.00 \quad 48$

$\$ 40.00 \quad 24$

$\$ 1,728.00$

$\$ 31.00 \quad 48$

$\$ 960.00$

$\$ 36.00$

$\$ 1,488.00$

$\$ 216.00$

$\$ 36.00$

$\$ 864.00$

Total

$\$ 5,256,00$

Assume 3 days for nozzle ID and graphics 